\title{
IAEA CRP on HTGR Uncertainties in Modeling: Assessment of Phase I Lattice to Core Model Uncertainties
}

The INL is a

U.S. Department of Energy National Laboratory operated by

Battelle Energy Alliance

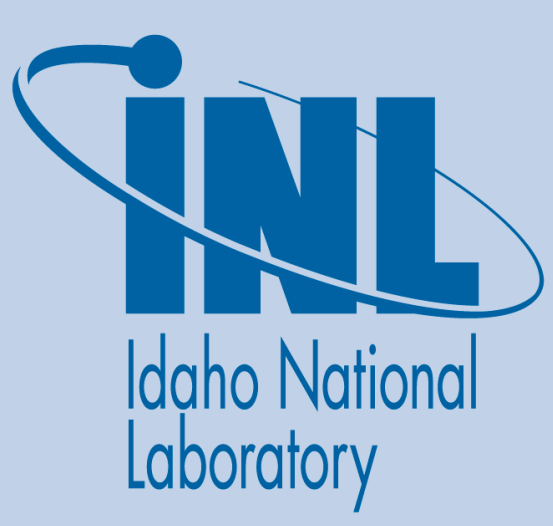

Pascal Rouxelin

Gerhard Strydom

September 2016

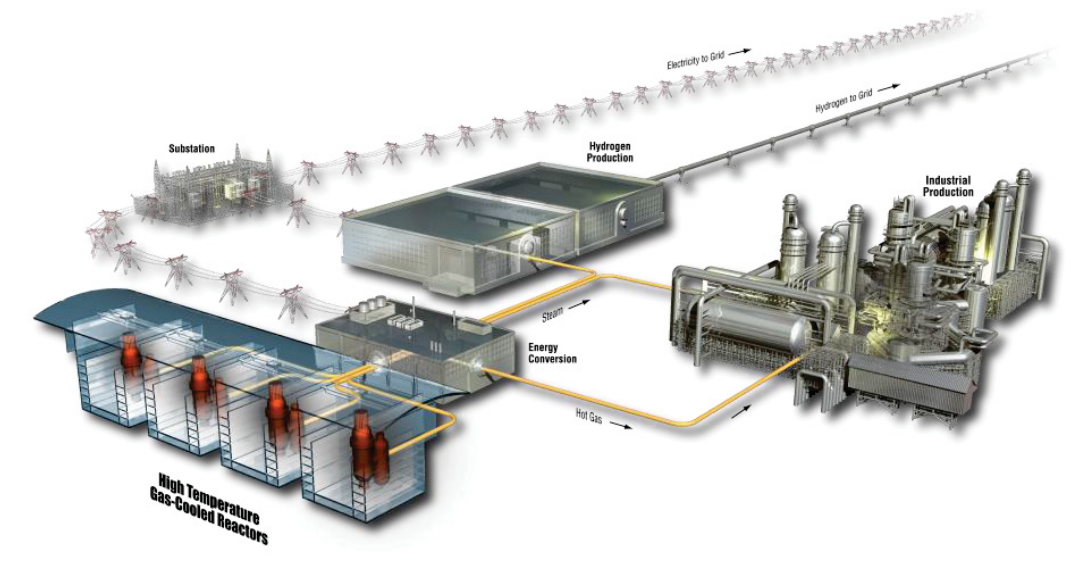




\section{DISCLAIMER}

This information was prepared as an account of work sponsored by an agency of the U.S. Government. Neither the U.S. Government nor any agency thereof, nor any of their employees, makes any warranty, expressed or implied, or assumes any legal liability or responsibility for the accuracy, completeness, or usefulness, of any information, apparatus, product, or process disclosed, or represents that its use would not infringe privately owned rights. References herein to any specific commercial product, process, or service by trade name, trade mark, manufacturer, or otherwise, does not necessarily constitute or imply its endorsement, recommendation, or favoring by the U.S. Government or any agency thereof. The views and opinions of authors expressed herein do not necessarily state or reflect those of the U.S. Government or any agency thereof. 
INL/EXT-15-36306

Revision 0

\title{
IAEA CRP on HTGR Uncertainties in Modeling: Assessment of Phase I Lattice to Core Model Uncertainties
}

\author{
Pascal Rouxelin \\ Gerhard Strydom
}

September 2016

Idaho National Laboratory

INL ART TDO Program

Idaho Falls, Idaho 83415

http://www.inl.gov

Prepared for the

U.S. Department of Energy

Office of Nuclear Energy

Under DOE Idaho Operations Office

Contract DE-AC07-05ID14517 

INL ART TDO Program

\section{IAEA CRP on HTGR Uncertainties in Modeling: Assessment of Phase I Lattice to Core Model Uncertainties}

INL/EXT-15-36306

Revision 0

September 2016

Author:

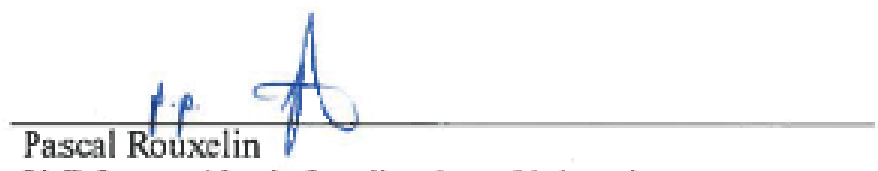

PhD Intern: North Carolina State University

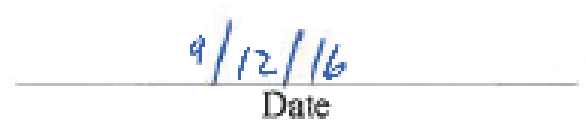

Technical Reviewer (confirmation of mathematical accuracy and correctness of data and ap propriateness of assumptions):

Gerhard Stridom

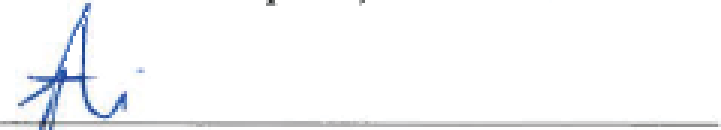

Technical Reviewer

Approved by:

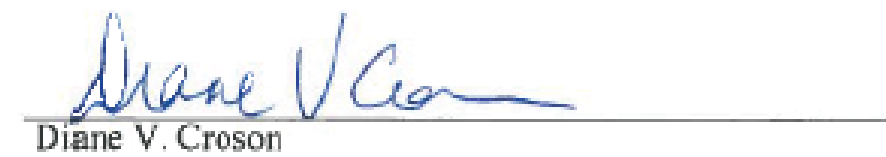

INL ART TDO Deputy Director
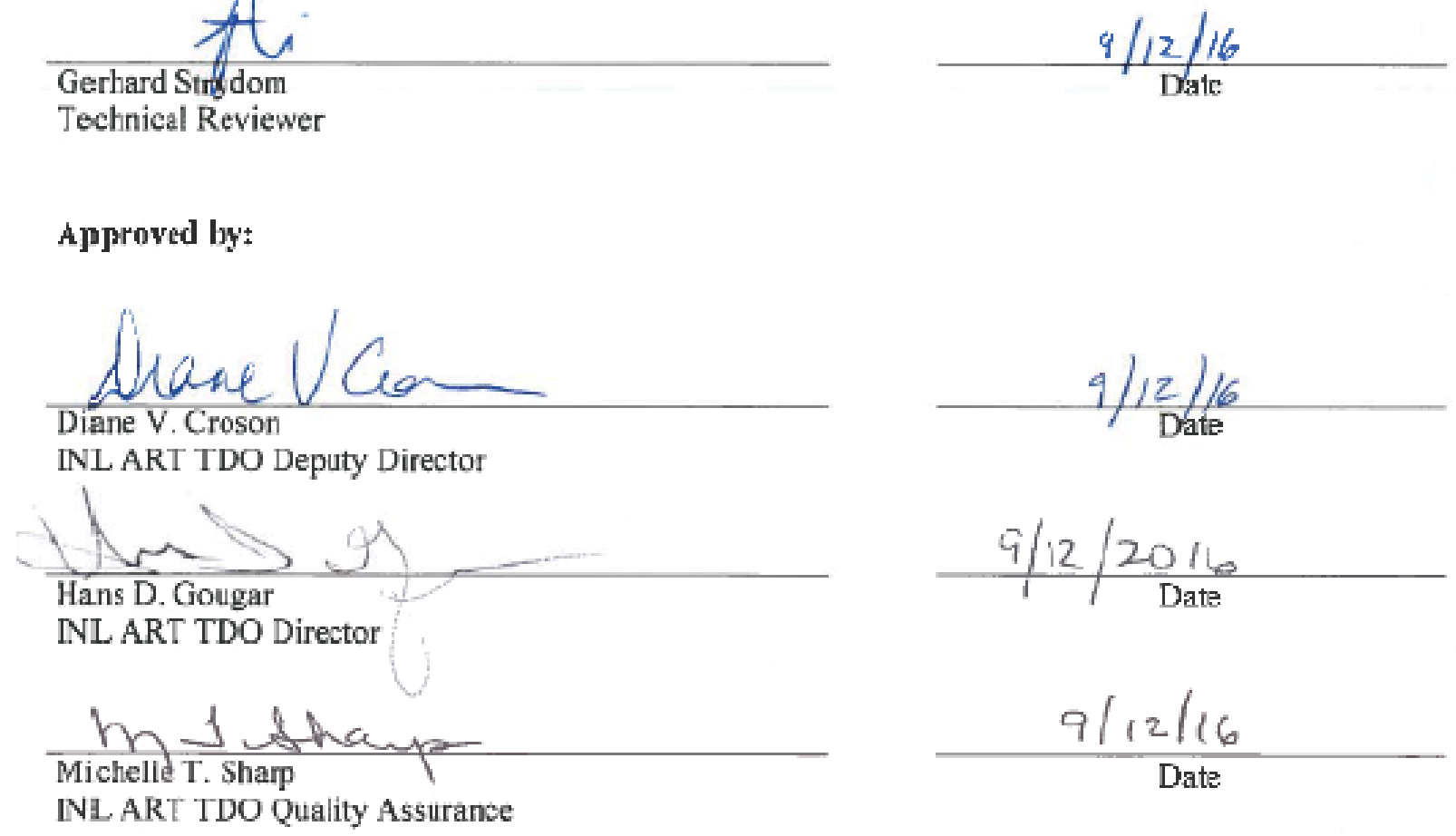



\section{SUMMARY}

Best-estimate combined with uncertainty analysis of reactors is replacing the traditional conservative (stacked uncertainty) method for safety and licensing analysis. To facilitate uncertainty analysis applications, a comprehensive approach and methodology must be developed and applied. High-temperature gas-cooled reactors (HTGRs) have several features that require techniques not used in light-water reactor analysis (e.g., coated-particle design and large graphite quantities at high temperatures). The International Atomic Energy Agency has therefore launched the Coordinated Research Project on HTGR Uncertainty Analysis in Modeling to study uncertainty propagation in the HTGR analysis chain. The benchmark problem defined for the prismatic design is represented by the General Atomics Modular HTGR-350.

This report focuses on discussing the best-estimate results obtained for Exercises I-2c and II-1a of the prismatic benchmark, which are defined as the last and first steps of the lattice and core simulation phases, respectively. The main purpose of the investigation is the assessment of the model uncertainties for this transition between the lattice (Phase I) and core (Phase II) stages, i.e. the impact that the choice of supercell model has on the core simulations. The uncertainty and sensitivity assessment of input uncertainties in the cross-sections, fission product yields and decay constants will be the topic of a forthcoming report that will be published early in 2017 .

The two-dimensional deterministic New ESC-based Weighting Transport (NEWT) code, included in the Standardized Computer Analyses for Licensing Evaluation (SCALE) package was used for the cross-section evaluation, and the results obtained were compared to the three-dimensional stochastic SCALE module KENO-VI. The NEWT cross-section libraries were generated for several permutations of the current benchmark Exercise I-2c super-cell geometry and were then provided as input to the Phase II core calculation of the stand-alone neutronics Exercise II-1a to assess the modeling uncertainties of using these various supercells. The steady-state core calculations were simulated with the INL code Parallel and Highly Innovative Simulation for INL Code System (PHISICS), and the system thermal-hydraulics code Reactor Excursion and Leak Analysis Program (RELAP) 5-3D.

It was observed that significant differences in terms of the multiplication factor and neutron flux exist between the various permutations of the Phase I super-cell lattice calculations, since the models vary significantly in graphite and depleted fuel contents. The cross section implemented in the one third core shows that the k-effective varies only minimally for each loading, with a maximum difference of $202 \mathrm{pcm}$ obtained between the most extreme cases. This "model" uncertainty is significantly lower than the cross-section uncertainties reported for the simple Phase I lattice problems (500 $\mathrm{pcm}$ ). One super-cell representing the softer neutron spectrum at the periphery of the core seems sufficient, while the use of the single block Exercise I-2a cross-sections is applicable to all center fuel regions. Only k-effective has been assessed in the full core analysis so far; in future studies, the flux and power profiles obtained with and without feedback effects will be investigated to confirm the conclusions drawn. 


\section{ACKNOWLEDGEMENTS}

The authors wish to acknowledge the significant contributions made to this project by Andrea Alfonsi. 


\section{CONTENTS}

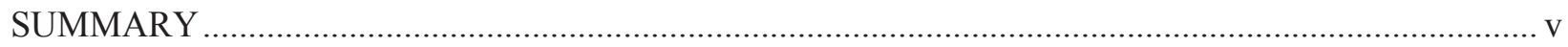

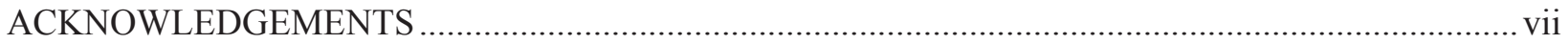

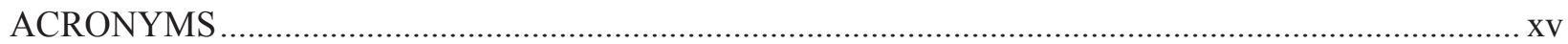

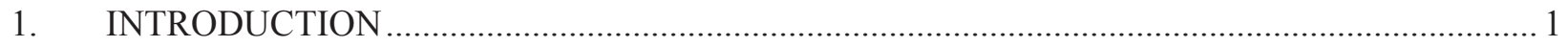

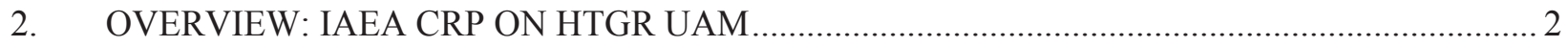

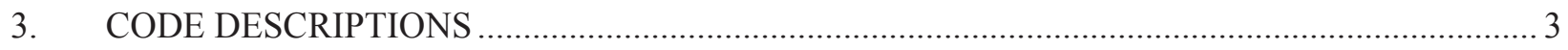

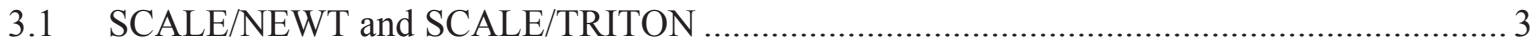

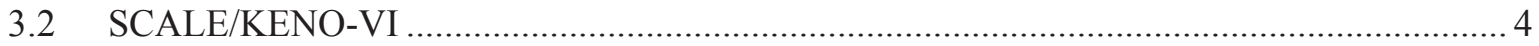

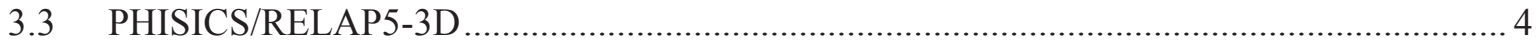

4. PHASE I LATTICE CALCULATIONS: EXERCISES I-2a, I-2b, AND I-2c ............................... 4

4.1 Super-cell Surrounded by Two Homogenized Regions ......................................................... 9

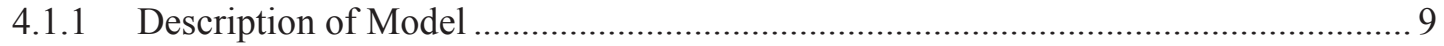

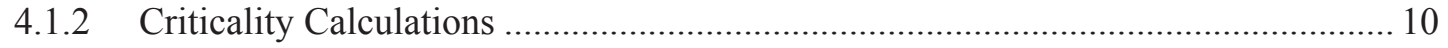

4.1.3 26-Group Neutron Flux Profiles of the HFP Super-Cells' Central Block ................ 20

4.1.4 Evaluation of the Neutron Group Importance in the Super-cells' Central Block in 26-Group Structure at HFP.................................................................. 27

4.1.5 Neutron Flux Profiles of Super-cells' Central Block in 26-Group Structure at

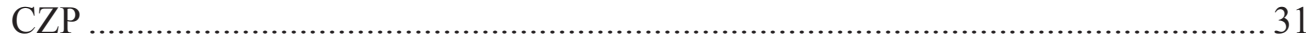

4.2 Super-cells Surrounded by Six Homogenized Regions ................................................... 39

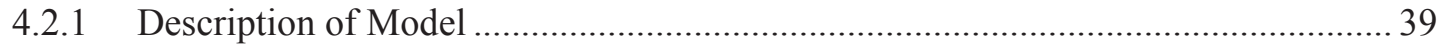

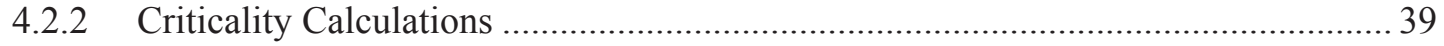

4.2.3 26-Group Neutron Flux Differences for the Super-cells' Central Block .................. 41

4.3 Heterogeneous Super-cell Surrounded by Heterogeneous Blocks...................................... 44

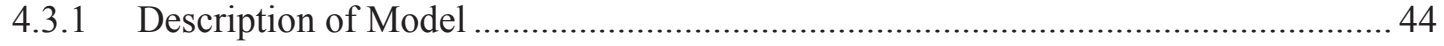

4.3.2 Neutron Flux Profile of Super-cells' Central Block in 26-Group Structure ............. 45

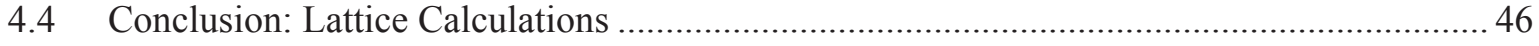

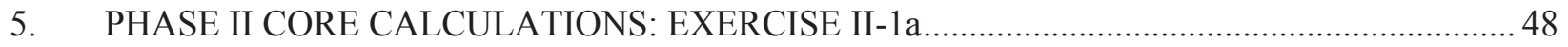

5.1 Description of PHISICS/RELAP5-3D Model …............................................................. 50

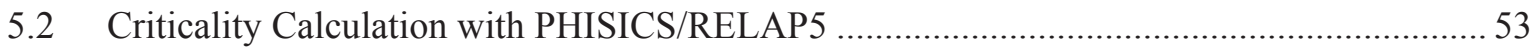

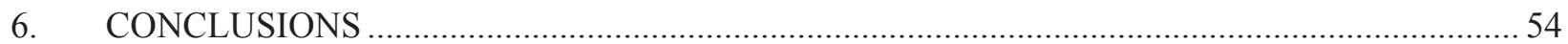

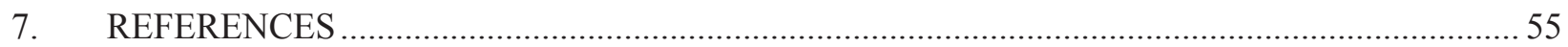




\section{FIGURES}

Figure 1. MHTGR-350 lattice cell for Exercise I-2 (single block) …................................................... 5

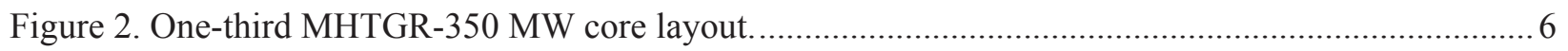

Figure 3. Fuel-loading pattern (A: fresh fuel, B: depleted fuel). ....................................................... 6

Figure 4. MHTGR-350 super-cell centered at Block 26 .................................................................... 7

Figure 5. Simplified representation of Exercise I-2c super-cell........................................................... 7

Figure 6. The 17 super-cell configurations for Exercise I-2c. ............................................................. 12

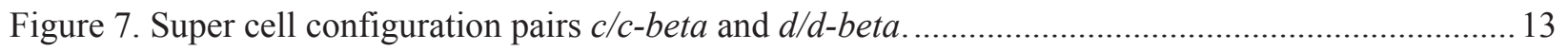

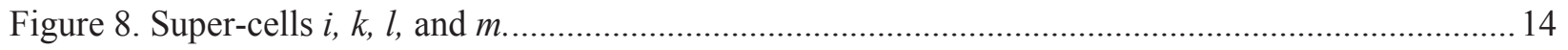

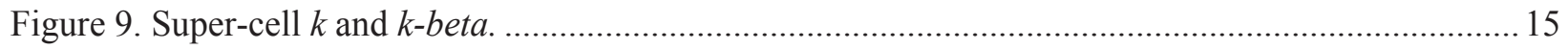

Figure 10. Exercise I-2c plots generated by NEWT (left) and KENO-VI (right) ................................... 17

Figure 11. Normalized neutron flux per unit lethargy in 26-group structure for Exercises 2a and $2 b$.

Figure 12. Neutron flux map of the Energy Group 3 at 1,200 $\mathrm{K}$ for a fresh-fuel block (Exercise I-2a: left) and a burned-fuel block (Exercise I-2b: right).

Figure 13. Neutron flux map of the Energy Group 18 at 1,200 K for a fresh-fuel block (Exercise I-2a: left) and a burned-fuel block (Exercise I-2b: right). 22

Figure 14. Normalized neutron flux per unit lethargy in 26-group structure for super-cells $c$ and $c$-beta. .22

Figure 15. Normalized neutron flux per unit lethargy in 26-group structure for super-cells $d$ and d-beta. .23

Figure 16. Normalized neutron flux per unit lethargy in 26-group structure for super-cells $r$ and $s \ldots \ldots \ldots . .23$

Figure 17. Normalized neutron flux per unit lethargy in 26-group structure for super-cells $i, k, l$, and $m$. Exercise $2 \mathrm{a}$ is plotted for reference.

Figure 18. Normalized neutron flux per unit lethargy in 26-group structure for super-cell $j$ and Exercise 2b.

Figure 19. Normalized neutron flux per unit lethargy in 26-group structure for super-cells $b, d, g$, $h$, and $j$.....

Figure 20. Normalized neutron flux per unit lethargy in 26-group structure for super-cells $a, c, e$, and $f$. Exercise $2 \mathrm{a}$ is plotted for reference.

Figure 21. Relative difference (\%) of normalized neutron per unit lethargy between fresh supercells and single blocks at HFP.

Figure 22. Relative difference (\%) of normalized neutron flux per unit lethargy between fresh super-cells $(i, m, l$, and $k)$ and single blocks at HFP.

Figure 23. Relative difference (\%) of normalized neutron per unit lethargy between burned supercells $(b, d, g, h$, and $j)$ and single blocks at HFP.

Figure 24. Normalized total reaction rate of Exercise I-2a, super-cells $i$ and $k$. .28 
Figure 25. Normalized absorption reaction rate of Exercise I-2a, super-cells $i$ and $k$...........................29

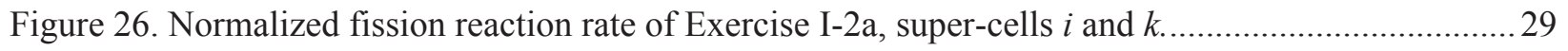

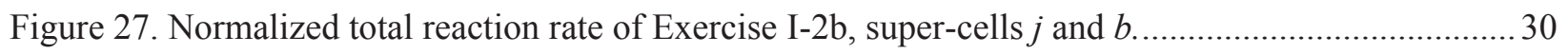

Figure 28. Normalized absorption reaction rate of Exercise I-2b, super-cells $j$ and $b$.......................... 30

Figure 29. Normalized fission reaction rate of Exercise I-2b, super-cells $j$ and $b$................................ 31

Figure 30. Comparison of normalized neutron flux per unit lethargy of Exercise 2a at HFP and

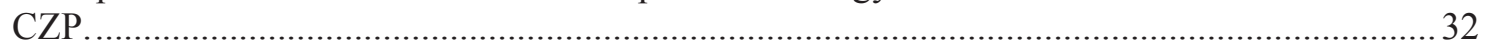

Figure 31. Comparison of normalized neutron flux per unit lethargy of super-cell $a$ at HFP and

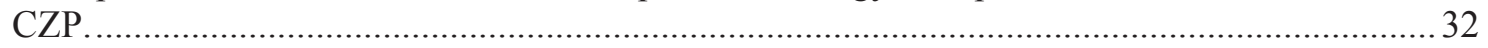

Figure 32. Comparison of normalized neutron flux per unit lethargy of super-cell $c$ at HFP and

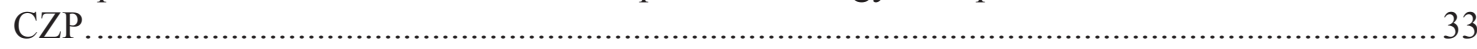

Figure 33. Comparison of normalized neutron flux per unit lethargy of super-cell $e$ at HFP and CZP.

Figure 34. Comparison of normalized neutron flux per unit lethargy of super-cell $f$ at HFP and CZP.

Figure 35. Comparison of normalized neutron flux per unit lethargy of super-cell $i$ at HFP and CZP

Figure 36. Comparison of normalized neutron flux per unit lethargy of super-cell $k$ at HFP and CZP .35

Figure 37. Comparison of normalized neutron flux per unit lethargy of super-cell $l$ at HFP and CZP .35

Figure 38. Comparison of normalized neutron flux per unit lethargy of super-cell $m$ at HFP and CZP. .36

Figure 39. Comparison of the normalized neutron flux per unit lethargy of Exercise $2 b$ at HFP and CZP. .36

Figure 40. Comparison of the normalized neutron flux per unit lethargy of super-cell $b$ at HFP and CZP.

Figure 41. Comparison of the normalized neutron flux per unit lethargy of super-cell $d$ at HFP and CZP.

Figure 42. Comparison of the normalized neutron flux per unit lethargy of super-cell $g$ at HFP and CZP

Figure 43. Comparison of the normalized neutron flux per unit lethargy of super-cell $h$ at HFP and CZP. .38

Figure 44. Comparison of the normalized neutron flux per unit lethargy of super-cell $j$ at HFP and CZP.

Figure 45. Plots of super-cell $c$ generated by NEWT (left) and KENO-VI (right) for the six homogenized regions.

Figure 46. Relative difference (in \%) of neutron flux profiles of two versus six homogenized regions in the fresh-fuel super-cells $c, e, f$, and $i$. 
Figure 47. Relative difference (in \%) of neutron flux profiles of two versus six homogenized regions in the fresh-fuel super-cells $i, k, l$, and $m$.

Figure 48. Relative difference (in \%) of neutron flux profiles of two versus six homogenized regions in the fresh-fuel super-cells $b, d, g, h$, and $j$.

Figure 49. Diagram of the heterogeneous version of super-cell $k$.

Figure 50. Geometrical layout of the heterogeneous super-cell $k$ generated by NEWT (left) and KENO-VI (right). .45

Figure 51. Normalized neutron flux per unit lethargy of super-cells $k$ and $k_{\text {het }}$ and Exercise 2a. .46

Figure 52. Lattice cells selected for fresh full core simulation 47

Figure 53. Lattice cells selected for mixed full core simulation. Fresh (A) and depleted (B) mixed core loading shown in bottom right. 48

Figure 54. Axial temperature profiles in MHTGR-350 core and reflector regions (K). 49

Figure 55. Cross-section numbering for Active Core Level 1. .50

Figure 56. PHISICS/RELAP5-3D core loading patterns with AMPX nuclear data libraries. .52

\section{TABLES}

Table 1. Energy group structure selected for collapse of NEWT-generated AMPX libraries. .8

Table 2. NEWT infinite multiplication factor for various permutations of Exercise I-2c (HFP)............. 12

Table 3. Comparison of NEWT results for super-cells $i, k, l$, and $m$. 14

Table 4. Comparison of NEWT and KENO results for various configurations of Exercises I-2a and $\mathrm{I}-2 \mathrm{~b}$ at HFP.

Table 5. Comparison of k-infinity in NEWT and KENO-VI (explicit BPs) for various permutations of Exercise I-2c at HFP.

Table 6. Comparison of k-infinity in NEWT and KENO-VI (homogenized BPs) for various permutations of Exercise I-2c at HFP.

Table 7. Effect of the homogenization of the BPs in KENO-VI.

Table 8. Comparison of k-infinity in NEWT for various permutations of Exercise I-2c at CZP and HFP.

Table 9. Features of the two groups selected for the flux maps of Exercises I-2a and I-2b. .20

Table 10. Infinite multiplication factors computed by NEWT and KENO-VI for the six-region model. Explicit BPs in KENO-VI.

Table 11. Infinite multiplication factors computed by NEWT and KENO-VI for the six-region model. Homogenized BPs in KENO-VI.

Table 12. Influence of the homogenization of the BPs obtained with KENO-VI.

Table 13. Infinite multiplication factor computed by NEWT and KENO for heterogeneous supercell $k$.

Table 14. PHISICS/RELAP5-3D effective multiplication factors for different core loading options with NEWT-generated nuclear data libraries.

Table A-1. SCALE 6.1.2/TRITON inventory of trace isotopes. 
Table A-2. Infinite multiplication factor at CZP and HFP of 10 super-cells characterized by two SCALE 6.1.2/TRITON inventories of trace isotopes.

Table B-1. Evaluation of effects the azimuthal angles on the multiplication factor in Exercises I-2a and I-2b.

Table B-2. Evaluation of effects the $\mathrm{P}_{\mathrm{n}}$ order on the multiplication factor in Exercises I-2a, I-2b, and I-2c. 


\section{ACRONYMS}

AMPX A Modular system for Producing coupled multi-group neutron gamma cross section sets

BP burnable poison

CRP Coordinated Research Project

CZP cold zero power

FZJ Forschungzentrum Juelich

HFP hot full power

HTGR high-temperature gas-cooled reactor

IAEA International Atomic Energy Agency

INL Idaho National Laboratory

INSTANT Intelligent Nodal and Semi-Structured Treatment for Advanced Neutron Transport

MHTGR modular high-temperature gas-cooled reactor

MRTAU Multi-Reactor Transmutation Analysis Utility

NEA Nuclear Energy Agency

NEWT New ESC-based Weighting Transport (Code)

OECD Organization for Economic Co-operation and Development

pcm per cent mille

PHISICS Parallel and Highly Innovative Simulation for INL Code System

RELAP Reactor Excursion and Leak Analysis Program

SA Sensitivity analysis

SCALE Standardized Computer Analyses for Licensing Evaluation (System)

TRISO tristructural isotropic

TRITON Transport Rigor Implemented with Time-dependent Operation for Neutronics depletion (control module)

UA uncertainty analysis

UAM uncertainty analysis in modeling

XS cross section 


\section{IAEA CRP on HTGR Uncertainties in Modeling: Assessment of Phase I Lattice to Core Model Uncertainties}

\section{INTRODUCTION}

The continued development of high-temperature gas-cooled reactors (HTGRs) requires verification of HTGR design and safety features with reliable high-fidelity physics models and robust, efficient, and accurate codes. The predictive capability of coupled neutronics/thermal-hydraulics and depletion simulations for reactor design and safety analysis can be assessed with sensitivity analysis (SA) and uncertainty analysis (UA) methods. Uncertainty originates from errors in physical data, manufacturing uncertainties, modeling, and computational algorithms. SA is helpful for ranking various sources of uncertainty and error in the results of core analyses. SA and UA can guide experimental, modeling, and algorithm research and development. Current SA and UA rely on derivative-based methods such as stochastic sampling methods or generalized perturbation theory to obtain sensitivity coefficients. Neither approach addresses all needs.

In order to benefit from recent advances in modeling and simulation and the availability of new cross-section co-variance data uncertainties, extensive sensitivity and uncertainty studies are needed for quantification of the impact of different sources of uncertainties on the design and safety parameters of HTGRs. In February 2009, the Technical Working Group on Gas-Cooled Reactors of the International Atomic Energy Agency (IAEA) recommended that the proposed Coordinated Research Project (CRP) on the HTGR Uncertainty Analysis in Modeling (UAM) be implemented. This CRP is a continuation of the previous IAEA and Organization for Economic Co-operation and Development (OECD)/Nuclear Energy Agency (NEA) international activities on verification and validation of available analytical capabilities for HTGR simulation for design and safety evaluations [1,2,3]. Within the framework of these activities, different numerical and experimental benchmark problems were established and analyzed, and insight was gained about specific physics phenomena and the adequacy of analysis methods.

The CRP benefits from interactions with the ongoing OECD/NEA light-water reactor UAM benchmark activity [4]. Because the prismatic design specification is based directly on the OECD/NEA modular HTGR (MHTGR)-350 MW benchmark [5], participants in both activities can leverage their core models developed for the OECD/NEA benchmark for this CRP benchmark with only minor changes.

This report focuses on discussing the best-estimate results obtained for Exercises I-2c and II- $1 \mathrm{a}$ of the prismatic benchmark, which are defined as the last and first steps of the lattice and core simulation phases, respectively. The main purpose of the investigation is the assessment of the model uncertainties for this transition between the lattice (Phase I) and core (Phase II) stages, i.e. the impact that the choice of supercell model has on the core simulations. The uncertainty and sensitivity assessment of input uncertainties in the cross-sections, fission product yields and decay constants will be the topic of a forthcoming report that will be published in December 2016.

Section 2 provides an overview of the HTGR UAM objectives and scope, based on the latest version of the Phase I specification document [6]. Section 3 describes the codes and models applied in this study. Section 4 summarizes Idaho National Laboratory (INL) best-estimate results obtained for Exercise I-2a (fresh single-fuel block), Exercise I-2b (depleted single fuel block), and Exercise I-2c (super-cell) and the first results of an investigation into the cross-section generation effects for the super-cell model. The two-dimensional deterministic code NEWT (New ESC-based Weighting Transport) included in the Standardized Computer Analyses for Licensing Evaluation (SCALE) 6.1.2 package was used for the cross-section evaluation, and the results obtained were compared to the three-dimensional stochastic SCALE6.1.2 module KENO-VI. The NEWT cross-section libraries were generated for several 
permutations of the current benchmark super-cell geometry and were then provided as input to the Phase II core calculation of the stand-alone neutronics Exercise II-1a. The steady-state core calculations reported in Section 5 were simulated with INL code PHISICS (Parallel and Highly Innovative Simulation for INL Code System) and the RELAP (Reactor Excursion and Leak Analysis Program) 5-3D system thermal-hydraulics code.

\section{OVERVIEW: IAEA CRP ON HTGR UAM}

SA and UA methods need to be considered as an integral part of the development of coupled-code methods. Of particular importance are innovative methods that address nonlinearity, can predict the probability distributions in output parameters, can treat discrete events, and handle simultaneously large input data and response fields in a computationally efficient manner.

In the IAEA CRP on HTGR UAM, different SA and UA methods will be compared and further developed, including the validation of the methodologies for uncertainty propagation in HTGR modeling. The uncertainty propagation will be estimated through the whole simulation process on a unified benchmark framework to provide credible coupled-code predictions with defensible uncertainty estimations of safety margins at the full core/system level. The proposed program will help to utilize the community of experts formed during the previous IAEA and OECD HTGR-related activities and expand it by combining expertise in physics (neutronics and thermal-hydraulics) and in SA and UA.

The objective is to determine the uncertainty in HTGR calculations at all stages of coupled reactor physics/thermal-hydraulics and depletion calculations. To accomplish this objective, a benchmark platform for uncertainty analysis in best-estimate, coupled-code calculations for design and safety analysis of HTGRs will be defined and utilized. The full chain of uncertainty propagation from basic data, engineering uncertainties, across different scales (multi-scale), and physics phenomena (multi-physics) will be tested on a number of benchmark exercises with maximum utilization of the available experimental data, published benchmark results, and released design details. Two main HTGR types (prismatic and pebblebed HTGRs) are selected based on previous benchmark experiences and available data. In principle, the sources of input uncertainties in computer code simulations can be identified as:

- Input data uncertainties

- Model assumptions and limitations

- Approximations in the numerical solution

- Nodalization

- Homogenization approaches

- Imperfect knowledge of boundary and initial conditions.

The focus of this report is on the second bullet Model assumptions and limitations indicated above. For each exercise, it is important to identify which new input uncertainties are taken into account and which input uncertainties are propagated from the previous exercise. Other important parameters to be defined are the output uncertainties and propagated uncertainty parameters for each exercise. This task is directly related to the objective of each exercise. The output uncertainties are defined for specified output parameters for each exercise to test the utilized uncertainty method. The propagated uncertainty parameters are output parameters selected to be propagated further through follow-up exercises in order to calculate the overall resulting uncertainty. The aim is to propagate as many uncertainties as feasible and as realistically to the subsequent coupled calculations as possible.

An overview of the benchmark exercises relevant to this report is provided here. Exercises I-1 and I-2 of the lattice Phase I are focused on the derivation of the multi-group and few-group microscopic cross-section libraries. The objective is to address the uncertainties due to the basic nuclear data as well as the impact of processing the nuclear and covariance data, selection of multi-group structure, and double 
heterogeneity or self-shielding treatment. The intention is to propagate the uncertainties in evaluated nuclear data libraries (microscopic point-wise cross sections) into multi-group microscopic cross-sections and to propagate the uncertainties from the multi-group microscopic cross-sections into the few-group cross-sections for use in the core simulation Phase II.

- Exercise I-1 (I-1a, b, c, d) - Cell Physics

Two basic unit cells are defined for Exercise 1 based on the MHTGR-350 design parameters. Two sub-cases are included: Exercise I-1a specifies a homogeneous fuel region tristructural isotropic (TRISO) fuel particles and matrix graphite, whereas Exercise I-1b requires the explicit modeling of the TRISO fuel particles to investigate their self-shielding effect on the multi-group microscopic cross-sections. Exercises I-1c and I-1d are equivalent to Exercises I-1and I-1b, respectively, but a triangular cell geometry is specified instead of a hexagonal unit cell geometry.

- Exercise I-2 (I-2a, b, c) - Lattice Physics

Exercise I-2a requires a lattice calculation to be performed on a single fuel block at hot full power (HFP) conditions, while Exercise I-2b specifies the same problem at $100 \mathrm{MWd} / \mathrm{kg}-\mathrm{U}$ burn-up. Exercise I-2c adds the spectral effects of the neighboring domain by performing a lattice calculation on a super-cell (or mini-core), which consists of a fresh fuel block surrounded by a mixture of depleted and fresh fuel on one side and graphite reflector blocks on the other side. This calculation is also performed at HFP conditions.

\section{- Exercise II-1a - Core Physics: Criticality (steady-state) stand-alone neutronics calculations}

A full core steady-state neutronics calculation is to be performed using the given fuel number densities and core temperature distributions. The coupling between this core exercise and the lattice Exercise I$2 \mathrm{c}$ is the main focus of this report.

\section{CODE DESCRIPTIONS}

This section provides an overview of the deterministic lattice code SCALE/NEWT used for Phase I, Exercises I-2a, I-2b, and I-2c, as well as the two Monte Carlo codes SERPENT and SCALE/KENO-VI utilized for comparison with NEWT and providing continuous energy (reference) eigenvalue solutions. The PHISICS/RELAP5-3D code utilized for the Phase II calculations is also described. The models developed for each of the exercises are discussed in the respective subsections of Sections 4 and 5.

\subsection{SCALE/NEWT and SCALE/TRITON}

The NEWT module of the SCALE 6.1 package, developed at the Oak Ridge National Laboratory, is a multi-group discrete-ordinates transport computer code characterized by flexible meshing features that allow complex geometric models. The NEWT computational approach is based on refined approximation of curves and irregular surfaces and therefore can represent models that would normally be highly impractical to design with $\mathrm{S}_{\mathrm{n}}$ ordinate methods. In this analysis, NEWT is first used to determine the reference (i.e., best-estimate) eigenvalues for Exercise I-2a-c and subseequently to generate the collapsed multi-group, flux-weighted microscopic AMPX cross-section libraries in format for use in the PHISICS/RELAP5-3D solution of Exercise II-1a.

Although NEWT can be used as a simple neutron transport solver, SCALE 6.1 provides the ability to include NEWT in a SCALE Transport Rigor Implemented with Time-dependent Operation for Neutronics depletion (TRITON) sequence to prepare the homogenized, flux-weighted nuclear data. In the 6.1 version of SCALE, the double heterogeneous configuration of prismatic lattices is still a limitation to the TRITON capabilities, especially in terms of SA and UA.

For the entire NEWT analysis, the infinite multiplication factor convergence criterion is set to 1 per cent mille (pcm). 


\subsection{SCALE/KENO-VI}

In the absence of experimental data, KENO-VI is used in parallel with the NEWT calculations to provide a Monte Carlo solution to these problems. The KENO-VI module of SCALE 6.1 is a high-fidelity, three-dimensional Monte Carlo criticality code, and both the ENDF-B-VII.0 continuous-energy and 238group cross-section data libraries can be applied [7]. All SCALE calculations were performed on a single processor. Although it has been shown in the INL report on the Phase I results [8] that the use of the ENDF-B-VII.1 library is important for HTGR applications, this library is currently only available for use in the SCALE 6.2 version. Only the 238-group results from Version 6.1.3 are reported here, using the older ENDF-B-VII.0 library. This approach is valid for a relative comparison study such as this.

All the calculations are carried out with 550 neutron generations and 50,000 neutrons per generation.

\subsection{PHISICS/RELAP5-3D}

A detailed description of the PHISICS/RELAP5-3D code can be found in Reference [9], and the MHTGR-350 model developed for this benchmark is described in Reference [10]. The most salient points of the code package are included here for completeness. It is important to note that the steady-state model used for the OECD/NEA MHTGR-350 benchmark is identical to the model applied here for Exercise II-1a of the IAEA CRP on HTGR uncertainties, as discussed in Section 5.

To be able to simulate MHTGR transients with the required neutronics fidelity, PHISICS has been coupled to the INL system thermal-hydraulics code RELAP5-3D. PHISICS is a neutronics code system in development at INL since 2011, and recent updates provided a very capable and flexible platform to cope with the challenges of coupled neutronics/thermal-hydraulic MHTGR core simulations. The different modules for PHISICS are a nodal and semi-structured, spherical-harmonics-based transport core solver (i.e., INSTANT) for steady-state and time-dependent problems, a depletion module (MRTAU), and a cross-section mixer-interpolator module. A detailed description of PHISICS's theory and structure is provided in Reference [9].

\section{PHASE I LATTICE CALCULATIONS: EXERCISES I-2a, I-2b, AND I-2c}

The main purpose of the lattice problems defined as Exercises I-2a and I-2b (fresh and depleted single blocks) and Exercise I-2c (super-cell) is the development of cross-section libraries for use in Phase II core calculations and the coupled propagation of cross-section and manufacturing uncertainties from Phase I to II. The single block geometry used for Exercises I-2a and I-2b is shown in Figure 1. In the PHISICS/RELAP5-3D one-third core model, the core region is represented by 91 hexagonal blocks on a radial level, as shown in Figure 2. The end of equilibrium cycle fuel-loading pattern is shown in Figure 3, with the red "A" blocks representing once-burned fuel and blue "B" blocks representing twice-burned fuel. No burnable poison (BP) was present at this stage of the core life. 


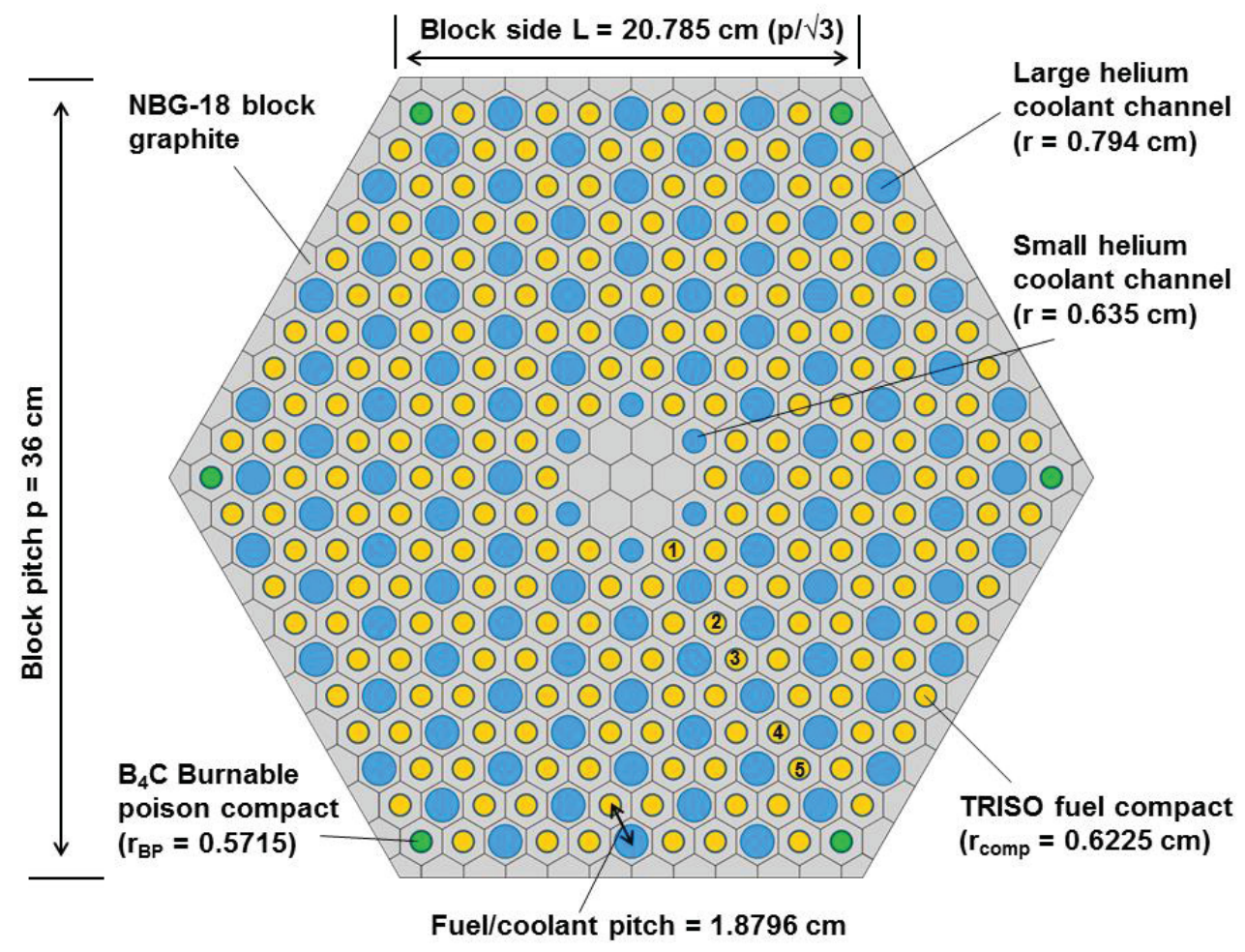

Figure 1. MHTGR-350 lattice cell for Exercise I-2 (single block).

The benchmark specifies the super-cell geometry, as shown in Figure 5, consisting of a purely reflecting region in the north and a mixture of fresh and burned homogenized fuel in the south to include the depletion and nuclide buildup effects. Referring to Figure 2, if each block in the core was surrounded with by six immediate neighbors, more than one super-cell may represent the local environment of the core. For example, Block 23 is surrounded by three reflector blocks at the north and three fuel blocks at the south, which makes the super-cell shown in Figure 5 an accurate sub-model. Block 16, however, is only surrounded by fuel blocks, and the neutron flux profile across this hexagonal block may be significantly different compared to the super-cell shown in Figure 5. 


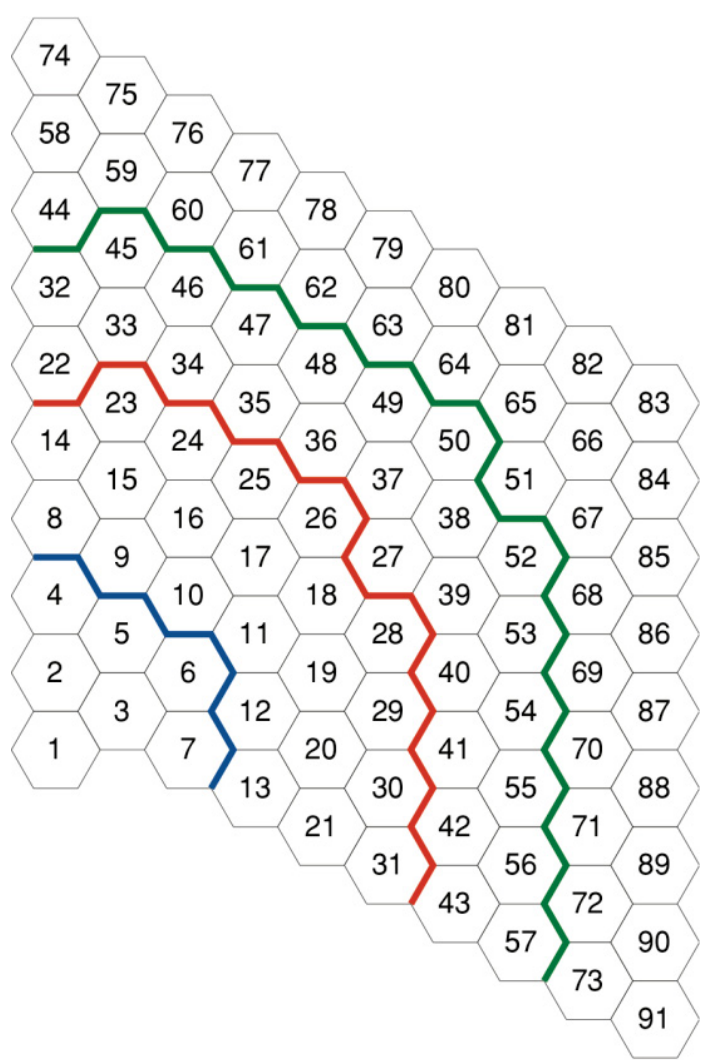

Figure 2. One-third MHTGR-350 MW core layout.

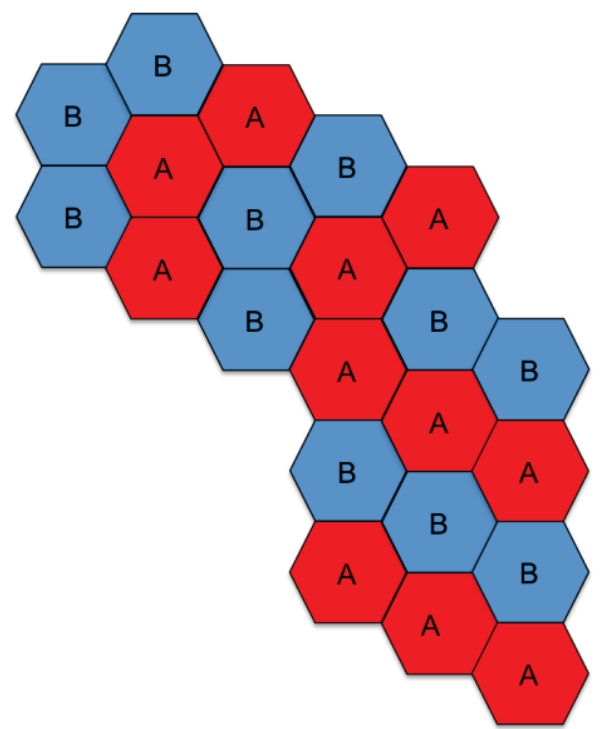

Figure 3. Fuel-loading pattern (A: fresh fuel, B: depleted fuel).

Thus, a part of the analysis is focused on the possible improvement brought by the super-cell model as compared to single-block lattices but also the refinement that could be achieved by modeling various permutations of these super-cells. For this study, 17 isotopically different super-cells are investigated, 
varying only in the way the six blocks surrounding the central block (fresh or burned) are homogenized. These super-cell variations are described in the subsequent subsections.

The calculations in NEWT and KENO-VI are performed in a 238-group structure with the ENDF/B-VII.0 nuclear data library. The cross-section libraries post-generated by NEWT are collapsed into a 26-group structure for further use in PHISICS/RELAP5-3D. This 26-group structure was originally specified by the research team at Forschungzentrum Juelich (FZJ) [11] and chosen by the OECD MHTGR-350 benchmark team to produce high-fidelity eigenvalue and reaction rates. However, good results have also been obtained with 6, 9, and 11 groups by other HTGR groups (see Reference [5] for more detail).

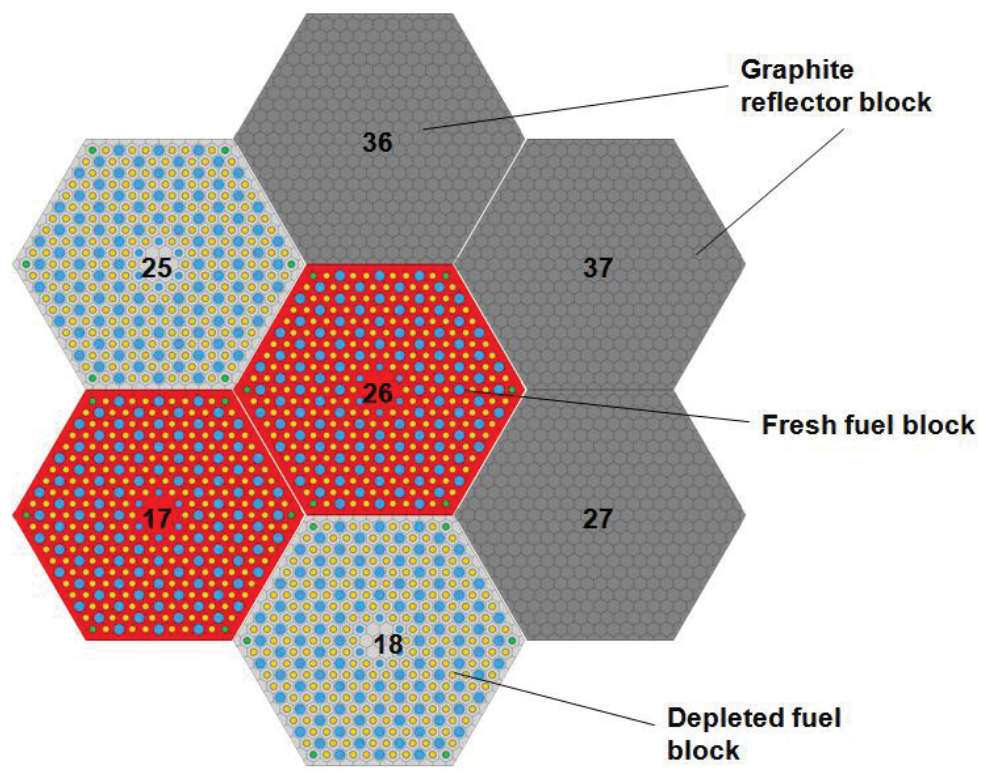

Figure 4. MHTGR-350 super-cell centered at Block 26.

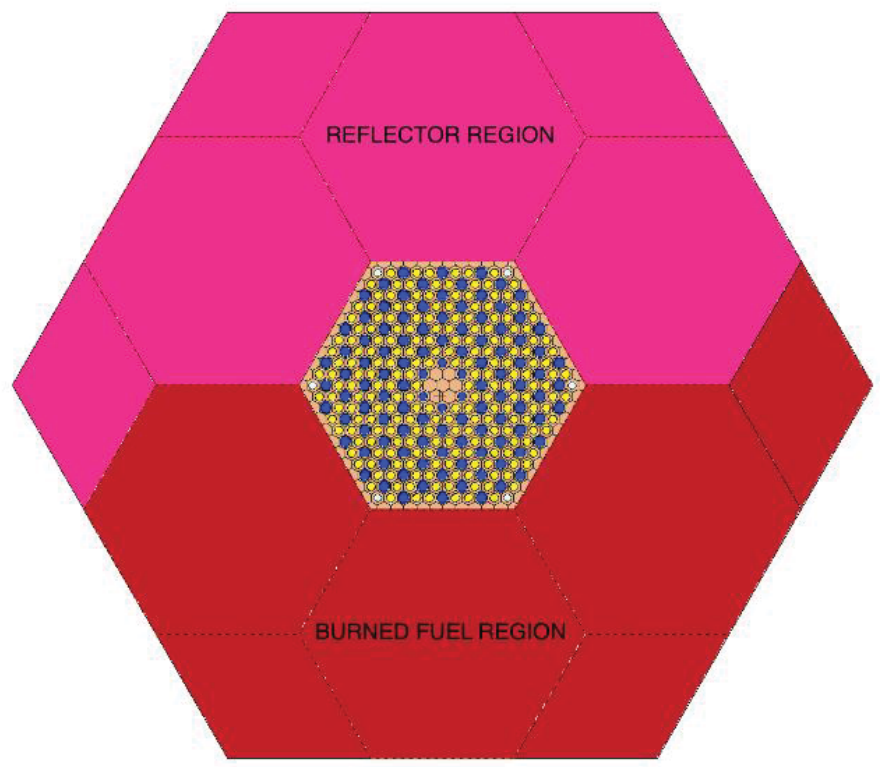

Figure 5. Simplified representation of Exercise I-2c super-cell. 
Because the group structure in NEWT can only be chosen as a subset of the SCALE 6.1.3 predefined 238-group structure, the 26-group arrangement in NEWT varies slightly compared to the reference FZJ structure. The differences between the two-group boundaries are indicated in Table 1. The neutron energies in Table 1 are the upper boundaries of the groups of interests; for instance, Energy Group 17 includes neutron energies between 2.38 and $1.29 \mathrm{eV}$. The energy range difference in the higher energy (fast) groups is significant, but this should not be a problem due to the relatively low amount of fission neutrons emitted at these high energies (about half a percent of the fission spectrum for each super-cell).

Table 1. Energy group structure selected for collapse of NEWT-generated AMPX libraries.

\begin{tabular}{|c|c|c|c|c|}
\hline $\begin{array}{l}\text { Group } \\
\text { No. } \\
(-)\end{array}$ & $\begin{array}{c}\text { FZJ/OECD } \\
\text { MHTGR-350 } \\
\text { Reference Group } \\
\text { Structure } \\
(\mathrm{eV})\end{array}$ & $\begin{array}{c}\text { SCALE/NEWT } \\
\text { Group Structure } \\
\text { Selected } \\
(\mathrm{eV})\end{array}$ & $\begin{array}{c}\text { Absolute Energy } \\
\text { Difference } \\
(\mathrm{eV})\end{array}$ & $\begin{array}{c}\text { Relative Energy } \\
\text { Difference } \\
(\%)\end{array}$ \\
\hline 1 & $1.490 \mathrm{E}+07$ & $2.000 \mathrm{E}+07$ & $-5.100 \mathrm{E}+06$ & -34.2 \\
\hline 2 & $7.410 \mathrm{E}+06$ & $8.187 \mathrm{E}+06$ & $-7.773 \mathrm{E}+05$ & -10.5 \\
\hline 3 & $3.680 \mathrm{E}+06$ & $3.000 \mathrm{E}+06$ & $6.800 \mathrm{E}+05$ & 18.5 \\
\hline 4 & $6.720 \mathrm{E}+05$ & $6.700 \mathrm{E}+05$ & $2.000 \mathrm{E}+03$ & 0.3 \\
\hline 5 & $1.110 \mathrm{E}+05$ & $1.000 \mathrm{E}+05$ & $1.100 \mathrm{E}+04$ & 9.9 \\
\hline 6 & $1.930 \mathrm{E}+04$ & $1.700 \mathrm{E}+04$ & $2.300 \mathrm{E}+03$ & 11.9 \\
\hline 7 & $3.355 \mathrm{E}+03$ & $3.000 \mathrm{E}+03$ & $3.550 \mathrm{E}+02$ & 10.6 \\
\hline 8 & $1.585 \mathrm{E}+03$ & $1.550 \mathrm{E}+03$ & $3.500 \mathrm{E}+01$ & 2.2 \\
\hline 9 & $7.485 E+02$ & $6.830 \mathrm{E}+02$ & $6.550 \mathrm{E}+01$ & 8.8 \\
\hline 10 & $2.754 \mathrm{E}+02$ & $2.850 \mathrm{E}+02$ & $-9.600 \mathrm{E}+00$ & -3.5 \\
\hline 11 & $1.301 \mathrm{E}+02$ & $1.220 \mathrm{E}+02$ & $8.100 \mathrm{E}+00$ & 6.2 \\
\hline 12 & $6.144 \mathrm{E}+01$ & $6.100 \mathrm{E}+01$ & $4.400 \mathrm{E}-01$ & 0.7 \\
\hline 13 & $2.900 \mathrm{E}+01$ & $2.750 \mathrm{E}+01$ & $1.500 \mathrm{E}+00$ & 5.2 \\
\hline 14 & $1.370 \mathrm{E}+01$ & $1.375 \mathrm{E}+01$ & $-5.000 \mathrm{E}-02$ & -0.4 \\
\hline 15 & $8.320 \mathrm{E}+00$ & $8.100 \mathrm{E}+00$ & $2.200 \mathrm{E}-01$ & 2.6 \\
\hline 16 & $5.040 \mathrm{E}+00$ & $5.000 \mathrm{E}+00$ & $4.000 \mathrm{E}-02$ & 0.8 \\
\hline 17 & $2.380 \mathrm{E}+00$ & $2.380 \mathrm{E}+00$ & $0.000 \mathrm{E}+00$ & 0.0 \\
\hline 18 & $1.290 \mathrm{E}+00$ & $1.300 \mathrm{E}+00$ & $-1.000 \mathrm{E}-02$ & -0.8 \\
\hline 19 & $6.500 \mathrm{E}-01$ & $6.500 \mathrm{E}-01$ & $0.000 \mathrm{E}+00$ & 0.0 \\
\hline 20 & $3.500 \mathrm{E}-01$ & $3.500 \mathrm{E}-01$ & $0.000 \mathrm{E}+00$ & 0.0 \\
\hline 21 & $2.000 \mathrm{E}-01$ & $2.000 \mathrm{E}-01$ & $0.000 \mathrm{E}+00$ & 0.0 \\
\hline
\end{tabular}


Table 1. (continued).

\begin{tabular}{|c|c|c|c|c|}
\hline $\begin{array}{c}\text { Group } \\
\text { No. } \\
\mathbf{( - )}\end{array}$ & $\begin{array}{c}\text { FZJ/OECD } \\
\text { MHTGR-350 } \\
\text { Rerence Group } \\
\text { Structure } \\
\mathbf{( e V )}\end{array}$ & $\begin{array}{c}\text { SCALE/NEWT } \\
\text { Group Structure } \\
\text { Selected } \\
\mathbf{( e V )}\end{array}$ & $\begin{array}{c}\text { Absolute Energy } \\
\text { Difference } \\
\mathbf{( e V )}\end{array}$ & $\begin{array}{c}\text { Relative Energy } \\
\text { Difference } \\
\mathbf{( \% )}\end{array}$ \\
\hline 22 & $1.200 \mathrm{E}-01$ & $1.250 \mathrm{E}-01$ & $-5.000 \mathrm{E}-03$ & -4.2 \\
\hline 23 & $8.000 \mathrm{E}-02$ & $8.000 \mathrm{E}-02$ & $0.000 \mathrm{E}+00$ & 0.0 \\
\hline 24 & $5.000 \mathrm{E}-02$ & $5.000 \mathrm{E}-02$ & $0.000 \mathrm{E}+00$ & 0.0 \\
\hline 25 & $2.000 \mathrm{E}-02$ & $2.530 \mathrm{E}-02$ & $-5.300 \mathrm{E}-03$ & -26.5 \\
\hline 26 & $1.000 \mathrm{E}-02$ & $1.000 \mathrm{E}-02$ & $0.000 \mathrm{E}+00$ & 0.0 \\
\hline & $0.000 \mathrm{E}+00$ & $1.000 \mathrm{E}-05$ & $-1.000 \mathrm{E}-05$ & \\
\hline
\end{tabular}

In the thermal range, only Groups 21, 22, and 24 present a difference with the FZJ group structure. These groups cover the energy range $0.2-0.08 \mathrm{eV}$ and $0.05-0.02 \mathrm{eV}$. In the isotope list selected for the analysis (reported in Appendix A), the only isotopes with one or more resonances below $1 \mathrm{eV}$ are ${ }^{149} \mathrm{Sm}$, ${ }^{151} \mathrm{Eu},{ }^{154} \mathrm{Eu},{ }^{235} \mathrm{U},{ }^{239} \mathrm{Pu},{ }^{241} \mathrm{Pu},{ }^{237} \mathrm{~Np},{ }^{241} \mathrm{Am}$, and ${ }^{243} \mathrm{Am}$. Among these resonances, only two fall into the range where the reference group structure and the NEWT group structure overlap: the ${ }^{149} \mathrm{Sm}$ resonance at $0.094 \mathrm{eV}$ and the ${ }^{154} \mathrm{Eu}$ resonance at $0.186 \mathrm{eV}$. With the thermal cutoff set at $2.38 \mathrm{eV}$, it seems reasonable to assume that the thermal neutrons in the 26-group structure adopted in NEWT should be treated very similarly to the original FZJ group structure.

The depleted fuel nuclide inventory (Ex. I-2b) was originally computed by a Monte Carlo simulation with SERPENT-2 [8]. The full detailed set of fission products produced by SERPENT-2 was reduced to a list of 94 isotopes for the NEWT and PHISICS/RELAP5-3D inputs in accordance with TRITON's inventory of trace isotopes [7]. A comparison is reported in Appendix A between this set of 94 isotopes and a smaller set of 64 isotopes (the comparison does not include the original SERPENT nuclide inventory). The tradeoff in the accuracy of the eigenvalue solutions produced by the set of 94 isotopes, versus increased computational speed and reduced memory requirements, was deemed acceptable.

\subsection{Super-cell Surrounded by Two Homogenized Regions}

In Subsections 4.1, 4.2, and 4.3, three approaches are compared to assess the effects of homogenization of the various super-cell regions. Here in Subsection 4.1, the central fresh-fuel block is surrounded by two homogenized regions constructed from various combinations of fresh, depleted, and reflector blocks. In Subsection 4.2, the six neighboring blocks are not homogenized into two regions but modeled as six distinct homogenized blocks. For the final comparison, all seven blocks are treated as heterogeneous regions, without any homogenization.

\subsubsection{Description of Model}

The flux spectra in the heterogeneous center block of the super-cell are influenced by the composition and locations of the neighboring blocks. A total of 17 super-cells (15 for fuel blocks and two for reflector blocks) have been developed, as shown in Figure 6. The legend is as follows:

- Pink (A): fresh homogeneous blocks

- $\quad$ Blue (B): burned homogeneous blocks 
- $\quad$ Black (R): graphite blocks (already homogenized according to the specification)

- Pink striped (A): fresh-fuel heterogeneous central blocks

- $\quad$ Blue striped (B): burned-fuel heterogeneous central blocks.

It should be noted that although Figure 6 shows single homogenized blocks, the super-cells are modeled as two homogenized regions (north and south). For example, super-cell $a$ is represented in NEWT with one graphite region (north) and a homogenized mixture of two burned-fuel blocks and one fresh-fuel block (south). The PHISICS/RELAP5-3D model also requires cross-section sets for the reflector located at the periphery of the core's fuel ring in Figure 2. Two reflector super-cells are investigated here, but the entire PHISICS/RELAP5-3D model will only use a single set of reflector cross sections. Super-cells $c, c$-beta, $d$, and $d$-beta contain exactly the same isotopic packing and therefore represent an identical location in the core-for example, Block 15 or 16. These super-cells only vary in the way that the regions are homogenized.

\subsubsection{Criticality Calculations}

Input files were prepared for two core states: a cold zero power (CZP) case at $293 \mathrm{~K}$ and a HFP case with all temperatures at $1,200 \mathrm{~K}$. The NEWT lattice results are evaluated using the standard nuclear data library ENDF/B-VII.0 for 238-group included in SCALE 6.1.2. The set of results includes criticality calculations and neutron flux profiles for the different lattices in order to estimate differences in the cross-section sets generated by NEWT. The infinite multiplication factor for the two-region super-cells at HFP is summarized in Table 2. The multiplication factor of the two reflector super-cells is not reported. The 17 super-cells' multiplication factor cannot be directly compared to the single-fuel block Exercises I-2a and I-2b, because super-cells (I-2c) $a, b, c, c$-beta, $d, d$-beta, $e, f, g$, and $h$ contain a mix of fresh and burned fuel. Super-cells $k, l$, and $m$ contain at least one reflector block that changes the fuel-to-moderation ratio in the homogenized region. Super-cells $r$ and $s$ are unrelated to Exercises I-2a and I-2b, and are only designed to generate a set of reflector cross sections using a super-cell model. Super cells $i$ and $j$ are the closest matches to the infinitely reflected lattice Exercises I-2a and I-2b, respectively, but the homogenization and resultant change in self-shielding causes significant differences compared to the single-block lattice results, in particular toward the global multiplication factor. 


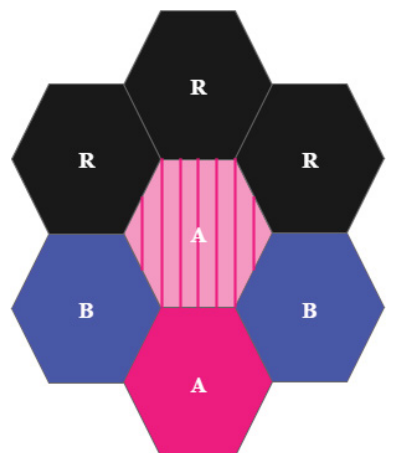

Super cell a

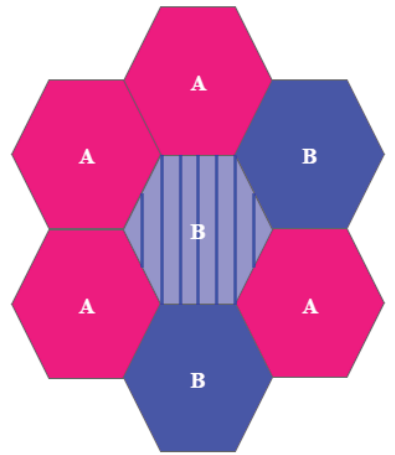

Super cell d

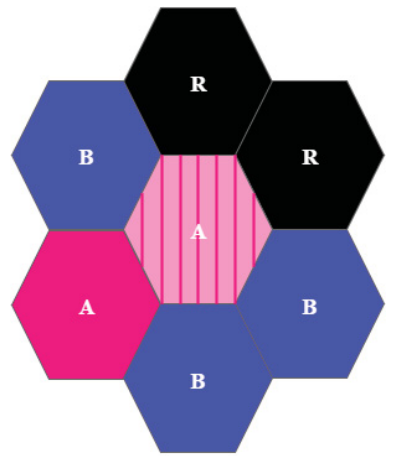

Super cell e

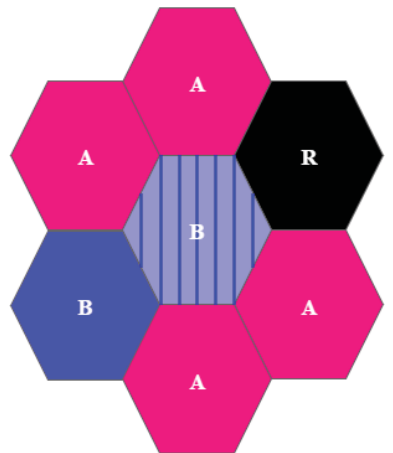

Super cell h

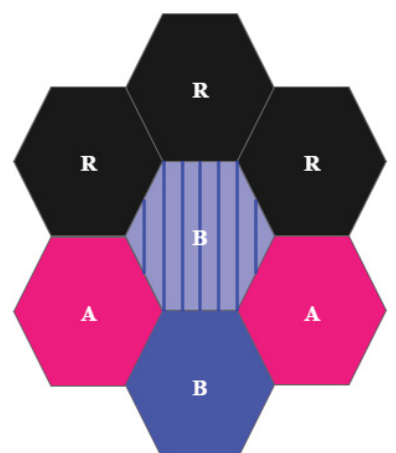

Super cell b

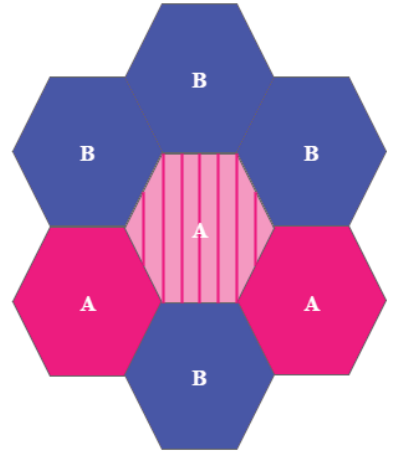

Super cell c-beta

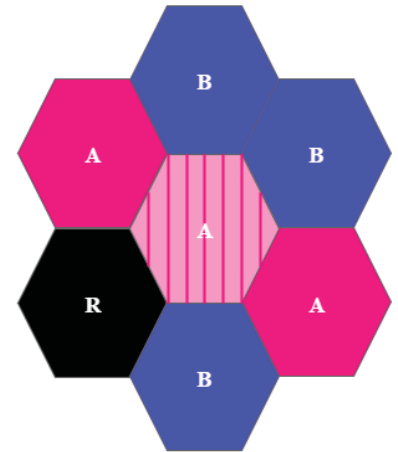

Super cell f

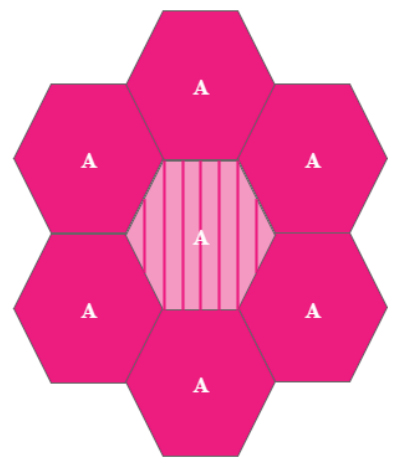

Super cell i

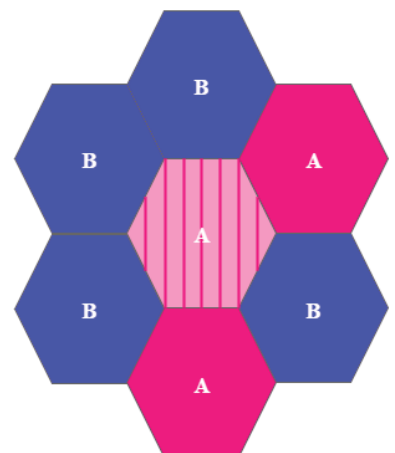

Super cell c

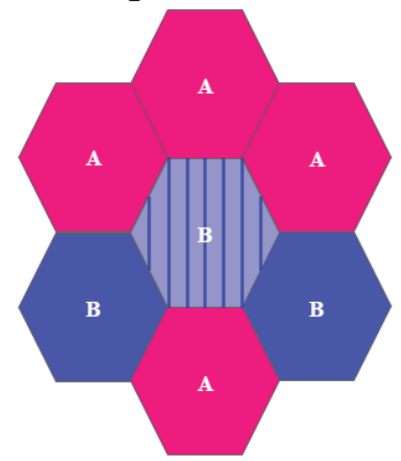

Super cell d-beta

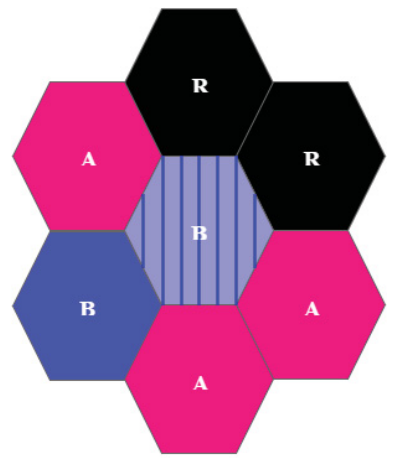

Super cell g

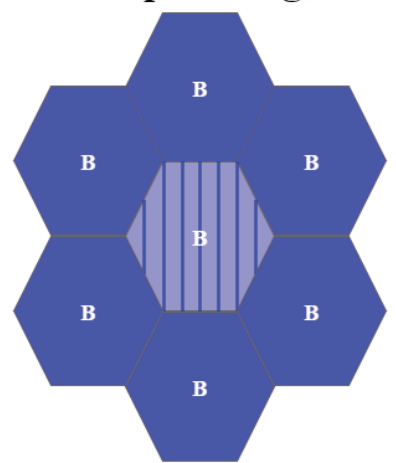

Super cell j 


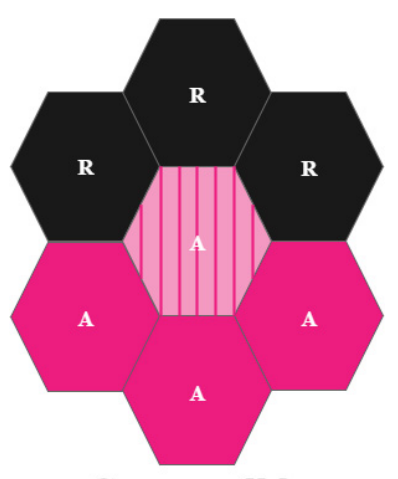

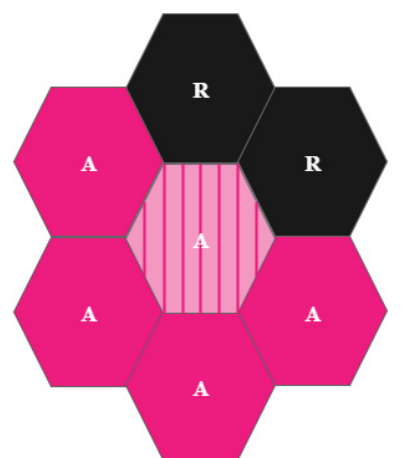

Super cell I

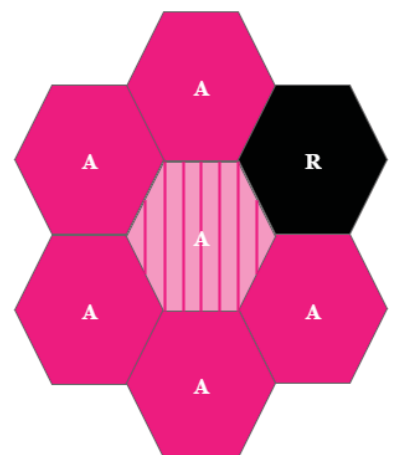

Super cell m

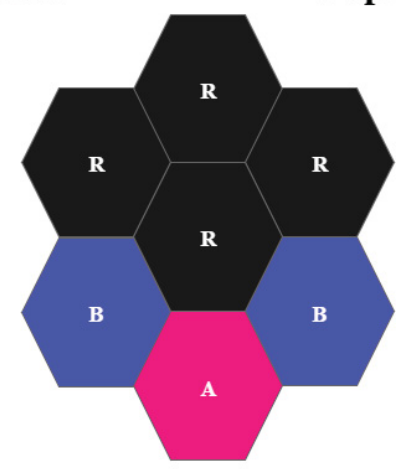

Super cell $\mathbf{r}$

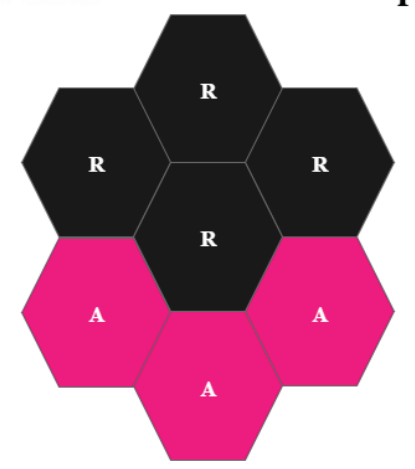

Super cell s

Figure 6. The 17 super-cell configurations for Exercise I-2c.

Table 2. NEWT infinite multiplication factor for various permutations of Exercise I-2c (HFP).

\begin{tabular}{|c|c|}
\hline Super-cell & k-infinity (-) \\
\hline$a$ & 1.08090 \\
\hline$b$ & 1.18965 \\
\hline$c$ & 0.96711 \\
\hline c-beta & 0.98647 \\
\hline$d$ & 1.07208 \\
\hline$d$-beta & 1.09942 \\
\hline$e$ & 1.08784 \\
\hline
\end{tabular}

\begin{tabular}{|c|c|}
\hline$f$ & 1.06180 \\
\hline$g$ & 1.28519 \\
\hline$h$ & 1.20968 \\
\hline$i$ & 1.21382 \\
\hline$j$ & 0.86534 \\
\hline$k$ & 1.27004 \\
\hline$l$ & 1.33619 \\
\hline$m$ & 1.26870 \\
\hline
\end{tabular}

The following discussion is divided into three subsections: a comparison of the NEWT results shown in Table 2, a comparison of the NEWT and KENO-VI results for a few of these super-cells, and a final subsection on the flux spectra for the super-cells.

\subsubsection{Effect of Homogenized Region Composition.}

Most of the results are not comparable in terms of k-infinity from one super-cell to another, because the isotopic inventory changes significantly. It was, however, found that even super-cells that have an identical total nuclide inventory - for example cases $\mathrm{c}$ and c-beta - show significant differences $(1,936 \mathrm{pcm}$ 
in this case). These two super-cells have the same total isotopic composition and central heterogeneous block, but the rotation of the cell blocks resulted in different homogenizations for the north and south regions: the north region in super-cell c consists of two burned and one fresh block. Super-cell c-beta has three homogenized burned blocks in the north region. The comparison between super-cells d and d-beta (Figure 7) shows a similar trend, with a delta of 2,734 pcm. It is therefore evident that the homogenization process introduces significant differences in the eigenvalue results. This is not an unexpected result, but the magnitudes of the differences might be of interest.
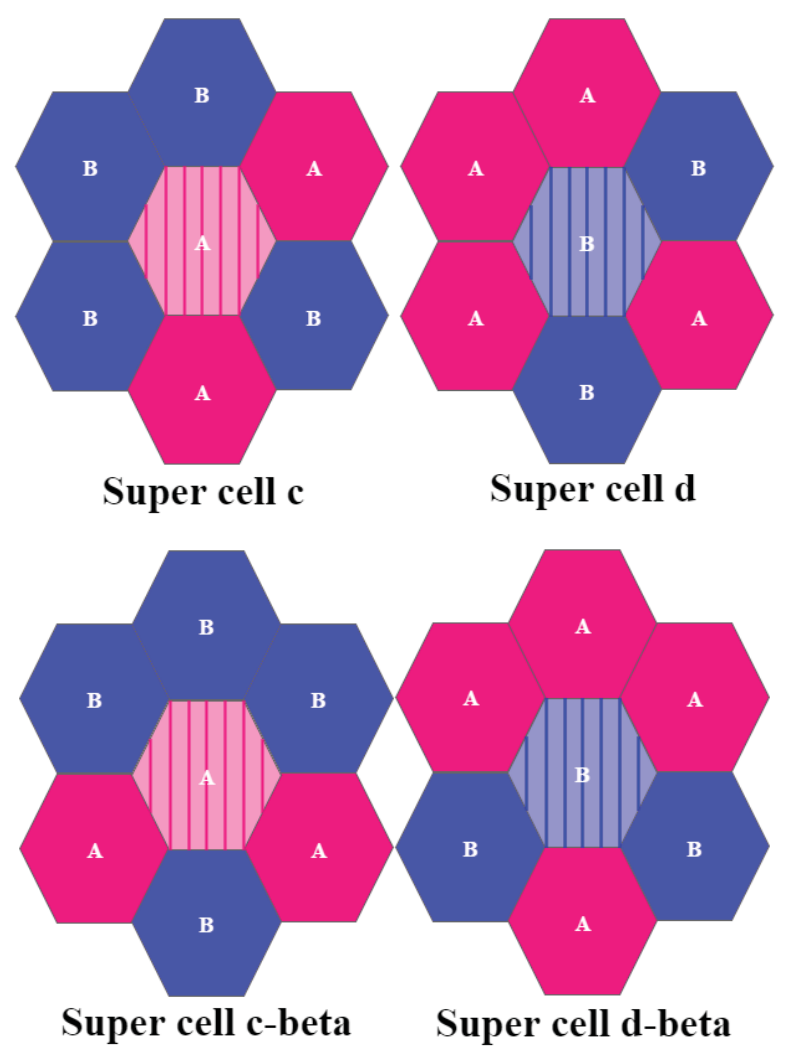

Figure 7. Super cell configuration pairs $c / c$-beta and $d / d$-beta .

The differences observed here should be placed in context: the eigenvalue variances between these super-cells are of secondary importance for the IAEA CRP on HTGR UAM, because they are only used as an interim step to provide cross-section libraries to the core phase calculations. The assessment of the differences in these libraries, caused by co-variances in the ENDF-VII libraries, remains the main focus of the HTGR UAM. This step will be reported in a follow-on INL report that will be generated towards the end of 2016, where it is currently planned to use the SCALE/SAMPLER module for a stochastic approach to this complex problem. An attempt is made in this report to isolate the effect of the super-cell modeling approach as an additional uncertainty element, i.e., answering the question, "To what degree does the model choice or construction of the lattice cells influence the few group core phase cross-section libraries?" This component will eventually be considered as part of the total HTGR simulation uncertainty assessment.

The inclusion of graphite blocks is especially important for the impact on homogenization, because the change in fuel-to-moderation ratio increases over a large spatial region. Super-cells $i, k, l$, and $m$ all contain fresh fuel and a varying number of reflector graphite blocks (Figure 8). 


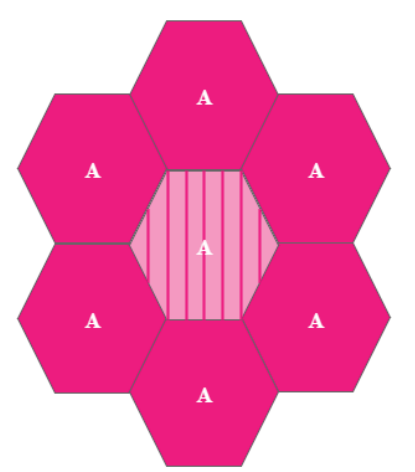

Super cell i

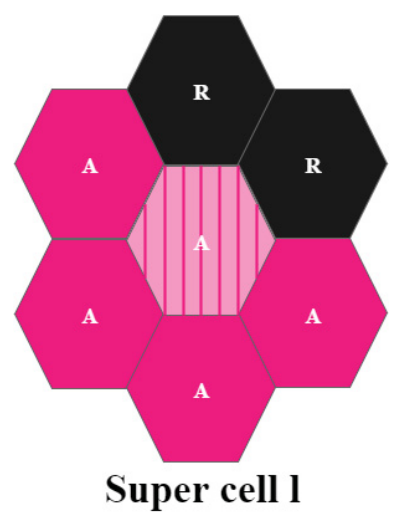

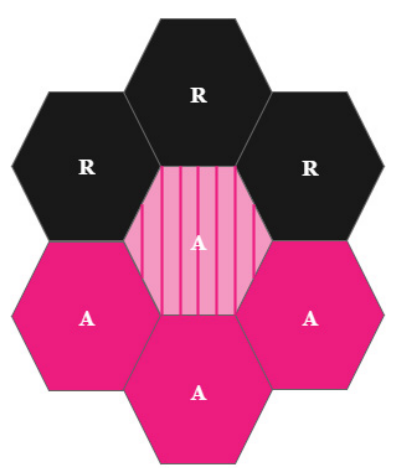

Super cell k

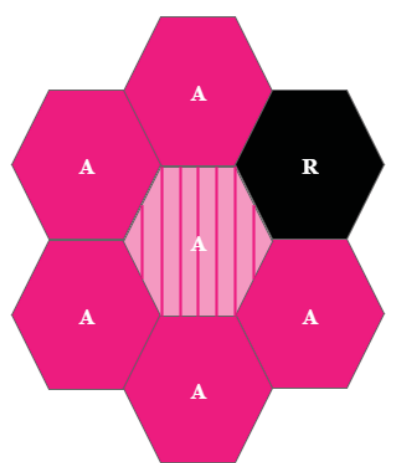

Super cell m

Figure 8. Super-cells $i, k$, $l$, and $m$.

Table 3 shows that the k-infinity increases as more graphite blocks are added (Cases $m$ and $l$ ), with the "worth" of the additional graphite block varying between 5,488 and 6,749 pcm, respectively. The addition of a third graphite block (super-cell $k$ ) in the north region decreases k-infinity by $6,615 \mathrm{pcm}$, suggesting that an optimal moderation point (for this geometry and isotopic densities) is reached somewhere between the addition of a second and third graphite block.

Table 3. Comparison of NEWT results for super-cells $i, k, l$, and $m$.

\begin{tabular}{|c|c|c|c|}
\hline \multirow{2}{*}{ Super-cell } & NEWT & $\begin{array}{c}\text { Absolute Difference with } \\
\text { Super-cell } \boldsymbol{i} \text { (pcm) }\end{array}$ & $\begin{array}{c}\text { “Worth" of Additional } \\
\text { Graphite Block (pcm) }\end{array}$ \\
\cline { 2 - 4 } & k-infinity(-) & Reference & Not applicable \\
\hline$i$ & 1.21382 & 5,488 & 5,488 \\
\hline$m$ & 1.26870 & 12,237 & 6,749 \\
\hline$k$ & 1.33619 & 5,622 & $-6,615$ \\
\hline
\end{tabular}

To verify the observation that the homogenization pattern plays a major role in the evaluation of the infinite multiplication factor, a super-cell $k$-beta variant was created where the total number densities were conserved but one graphite block was moved down from the north to the south region (shown in Figure 9). The infinite multiplication factor for this super-cell (1.50816) is $17,197 \mathrm{pcm}$ higher than Case $l$ and $23,814 \mathrm{pcm}$ higher than Case $k$. The shuffling of a single graphite block, homogenized over the south region, therefore led to a very large increase in k-infinity, demonstrating that even if the total super-cell 
number density is kept constant, the relative placing of the graphite blocks has a very significant impact on the k-infinity results.
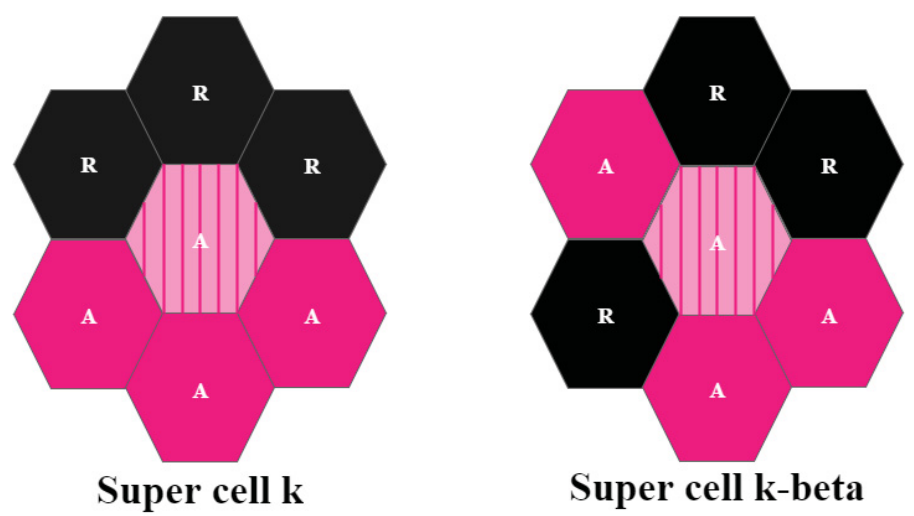

Figure 9. Super-cell $k$ and $k$-beta.

\subsubsection{Comparison of NEWT and KENO-VI Results and the Effects of BPs.}

The second point of interest in this study is the evaluation of the infinite multiplication factor obtained with KENO-VI and NEWT. The KENO-VI module is used in this context as a "reference" Monte Carlo solution to provide a comparison point for the NEWT data. This is an attempt to address possible approximations, errors, or uncertainties caused by the deterministic approach followed by NEWT.

The presence of BP compacts in the six corners of the fresh fuel block (Exercise I-2a) poses a specific challenge to the NEWT solver, and it seems to introduce a source of considerable uncertainty into the NEWT simulations. The architecture of the BPs in the central block in NEWT differs from the definition in KENO-VI, because NEWT is a two-dimensional code, implying that the BPs encapsulated in the spherical particles can only be modeled as discs, which are equivalent in a three-dimensional model to infinite cylinders. The BPs and graphite matrix were therefore homogenized as one material instead. Additionally, KENO-VI does not provide a random modeling of the BP particles. The BP compacts have therefore been modeled as regular lattices in both KENO-VI and NEWT.

The variation in the infinite multiplication factor for Exercise I-2a from the heterogeneous BPs in KENO-VI to the homogeneous BPs in NEWT has been evaluated at $-2,523 \mathrm{pcm}$ (Table 4). This suggests that the homogenization effects of the BPs induce relatively important effects on the criticality in NEWT. A second case was added where the BPs are also homogenized in the KENO-VI model. This comparison resulted in an absolute difference of $-810 \mathrm{pcm}$ compared to NEWT, so a significant difference still exists between NEWT and KENO-IV even if the BPs are homogenized. As a final test, a case with no BP compacts was also included to determine if the two SCALE modules now achieved a closer match. The difference for this case is still significant $(496 \mathrm{pcm})$, but clearly the addition of BP compacts led to large differences between NEWT and KENO-VI. Note that in the BP-free case, the ${ }^{10} \mathrm{~B}$ and ${ }^{11} \mathrm{~B}$ number densities have simply reduced to zero atoms per barns centimeter, which means the KENO-VI burnable compact still consists of heterogeneous particles with graphite centers. In NEWT, the TRISO particles' material (the silicon carbide, the carbon buffer, and the inner and outer pyrolytic carbon) remain smeared out in the carbon-graphite matrix. A similar comparison has been carried on the burned-fuel block, and a difference of $-187 \mathrm{pcm}$ has been established. Note that it has been considered that all the boron had been burned (both ${ }^{10} \mathrm{~B}$ and ${ }^{11} \mathrm{~B}$ ) in the depleted models; a simplified assumption that does not represent intermediate core states.

At this stage, a final conclusion cannot be reached just by comparing this data set: does NEWT introduces large approximations that lead to errors when BPs are added, or is the KENO-VI module susceptible to this effect (or possibly both in different aspects)? It can be observed that Monte Carlo codes are generally utilized as "reference" points for the more approximate deterministic transport codes. In this 
context, and taking into account the wide user base of KENO-VI versus NEWT, it is probable that NEWT introduces uncertainties for this specific problem. These cases will be repeated with the new Version 6.2 of SCALE, as well as the SERPENT Monte Carlo code in 2017. If the two Monte Carlo codes agree reasonably well, it can indeed point to issues with the current NEWT solver for HTGR hexagonal cells using strong local absorbers in a complex geometry. This issue has also been reported to the SCALE development team at ORNL.

The NEWT and KENO-VI results for the Exercise I-2c super-cells are shown in Table 5.

Table 4. Comparison of NEWT and KENO results for various configurations of Exercises I-2a and I-2b at HFP.

\begin{tabular}{|c|c|c|c|c|}
\hline \multirow{2}{*}{ Exercise } & NEWT & \multicolumn{2}{|c|}{ KENO-VI } & \multirow{2}{*}{$\begin{array}{c}\text { Absolute Difference } \\
\text { (pcm) }\end{array}$} \\
\cline { 2 - 5 } & $\begin{array}{c}\text { k-infinity } \\
(-)\end{array}$ & $\begin{array}{c}\text { k-infinity } \\
(-)\end{array}$ & $\begin{array}{c}\text { Standard Deviation } \\
(\mathbf{p c m})\end{array}$ & $-2,523$ \\
\hline I-2a & $1.03680^{\mathrm{a}}$ & $1.06203^{\mathrm{b}}$ & 16 & -810 \\
\hline I-2a & $1.03680^{\mathrm{a}}$ & $1.04490^{\mathrm{a}}$ & 12 & 496 \\
\hline I-2a (no BP) & 1.39487 & 1.38991 & 14 & -187 \\
\hline I-2b & $0.96421^{\mathrm{c}}$ & $0.96608^{\mathrm{c}}$ & 11 & \multicolumn{2}{|c}{} \\
\hline \multicolumn{2}{|c|}{ a. Homogenized BP compacts, b. Heterogeneous BP compacts, c. No BP in burned compacts } \\
\hline
\end{tabular}

The multiplication factor obtained in NEWT and KENO-VI shows an overestimation up to 2,244 pcm (Case I-2b). No obvious pattern related to these discrepancies is observed. The discrepancies do not seem to be related to the number of graphite blocks in the super-cell or the burned-fuel inventory. As a cross-check, the plots generated by NEWT's and KENO-VI's geometry post-processing routines are shown in Figure 10 to verify the correct modeling of the super-cells. The multiplication factor obtained with NEWT is also compared with the homogenized BP model sampled with KENO-VI. The results are compared in Table 6. The effect of the homogenization of the BPs in KENO-VI is summarized in Table 7 shows that the importance of the homogenization increases as the number of graphite blocks increases (i.e., as the spectrum becomes softer). The homogenization has no effect on the burned super-cells, because they are BP-free. 
Table 5. Comparison of k-infinity in NEWT and KENO-VI (explicit BPs) for various permutations of Exercise I-2c at HFP.

\begin{tabular}{|c|c|c|c|c|}
\hline \multirow[b]{2}{*}{ Super-cell } & \multirow{2}{*}{$\begin{array}{c}\text { NEWT } \\
\begin{array}{c}\text { k-infinity } \\
(-)\end{array}\end{array}$} & \multicolumn{2}{|c|}{ KENO-VI } & \multirow[b]{2}{*}{$\begin{array}{l}\text { Absolute Difference } \\
\text { (pcm) }\end{array}$} \\
\hline & & $\begin{array}{c}\text { k-infinity } \\
(-)\end{array}$ & $\begin{array}{c}\text { Standard } \\
\text { Deviation } \\
\text { (pcm) }\end{array}$ & \\
\hline$a$ & 1.08090 & 1.06980 & 12 & 1,110 \\
\hline$b$ & 1.18965 & 1.16721 & 14 & 2,244 \\
\hline$c$ & 0.96711 & 0.95596 & 12 & 1,115 \\
\hline c-beta & 0.98647 & 0.97762 & 11 & 885 \\
\hline$d$ & 1.07208 & 1.05649 & 12 & 1,559 \\
\hline$d$-beta & 1.09942 & 1.08681 & 14 & 1,261 \\
\hline$e$ & 1.08784 & 1.08733 & 12 & 51 \\
\hline$f$ & 1.06180 & 1.05599 & 14 & 581 \\
\hline$g$ & 1.28519 & 1.28543 & 14 & -24 \\
\hline$h$ & 1.20968 & 1.20055 & 13 & 913 \\
\hline$i$ & 1.21382 & 1.19970 & 14 & 1,412 \\
\hline$j$ & 0.86534 & 0.85291 & 12 & 1,243 \\
\hline$k$ & 1.27004 & 1.25677 & 13 & 1,327 \\
\hline$l$ & 1.33619 & 1.33562 & 14 & 57 \\
\hline$m$ & 1.26870 & 1.25997 & 13 & 873 \\
\hline
\end{tabular}
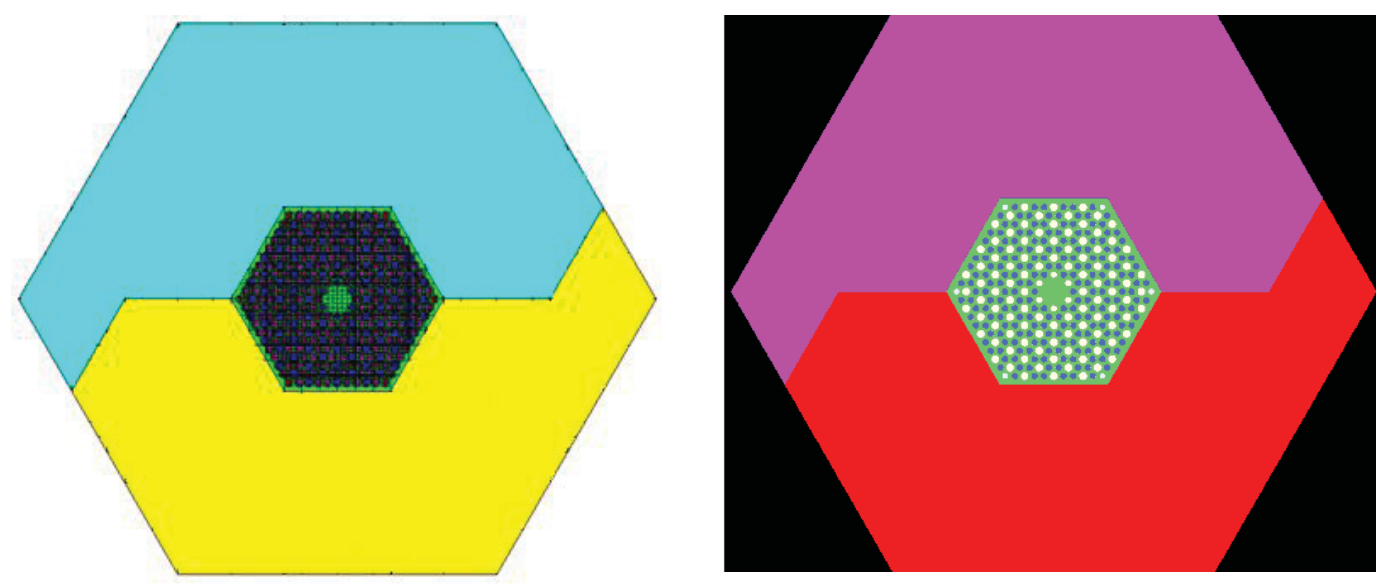

Figure 10. Exercise I-2c plots generated by NEWT (left) and KENO-VI (right). 
Table 6. Comparison of k-infinity in NEWT and KENO-VI (homogenized BPs) for various permutations of Exercise I-2c at HFP.

\begin{tabular}{|c|c|c|c|c|}
\hline \multirow[b]{2}{*}{ Super-cell } & \multirow{2}{*}{$\begin{array}{c}\text { NEWT } \\
\text { k-infinity } \\
(-)\end{array}$} & \multicolumn{2}{|c|}{ KENO-VI } & \multirow[b]{2}{*}{$\begin{array}{l}\text { Absolute Difference } \\
\text { (pcm) }\end{array}$} \\
\hline & & $\begin{array}{c}\text { k-infinity } \\
(-)\end{array}$ & $\begin{array}{c}\text { Standard Deviation } \\
(\text { pcm) }\end{array}$ & \\
\hline$a$ & 1.08090 & 1.06167 & 12 & 1,883 \\
\hline$b$ & 1.18965 & 1.16695 & 14 & 2,235 \\
\hline$c$ & 0.96711 & 0.95360 & 12 & 1,351 \\
\hline$c$-beta & 0.98647 & 0.97252 & 11 & 1,398 \\
\hline$d$ & 1.07208 & 1.05662 & 12 & 1,547 \\
\hline$d$-beta & 1.09942 & 1.08708 & 14 & 1,235 \\
\hline$e$ & 1.08784 & 1.08395 & 12 & 385 \\
\hline$f$ & 1.06180 & 1.05343 & 14 & 837 \\
\hline$g$ & 1.28519 & 1.28561 & 14 & -61 \\
\hline$h$ & 1.20968 & 1.20059 & 13 & 911 \\
\hline$i$ & 1.21382 & 1.19663 & 14 & 1,720 \\
\hline$j$ & 0.86534 & 0.85305 & 12 & 1,229 \\
\hline$k$ & 1.27004 & 1.24856 & 13 & 2,074 \\
\hline$l$ & 1.33619 & 1.33097 & 14 & 523 \\
\hline$m$ & 1.26870 & 1.25571 & 13 & 1,299 \\
\hline
\end{tabular}

The NEWT infinite multiplication factor is computed for the CZP case at $293 \mathrm{~K}$. The purpose of this analysis is to confirm the observations and conclusions made for the HFP state but also to verify the behavior of the moderator and fuel temperature coefficients. The infinite multiplication factor at CZP is summarized in Table 8; a comparison to the respective HFP calculations is also provided.

For all of the super-cells at CZP conditions, the infinite multiplication factor increases as the temperature decreases because of the moderator and fuel temperature feedback. The moderator temperature coefficient is significantly smaller than the fuel temperature coefficient in graphite-moderated designs, which is why the magnitude of the feedbacks is greater in super-cells $c, c$-beta, $d, d$-beta, $i$, and $j$ (fuel-only super-cells). When a homogenized fuel block is replaced by a graphite block at the periphery of the supercells, the amplitude of the feedbacks increases slightly compared to the HFP case. Super-cells $i, m, l$, and $k$ illustrate clearly this statement.

For the sets of equally moderated super-cells such as $[i ; j ; c ; c$-beta; $d ; d$-beta], or $[k ; a ; b]$, only the fresh to-burned-fuel ratio is modified and the moderator temperature coefficient can be assumed constant. The depleted blocks have a lower ${ }^{238} \mathrm{U}$ content, which lowers the magnitude of the Doppler effect. 
Table 7. Effect of the homogenization of the BPs in KENO-VI.

\begin{tabular}{|c|c|}
\hline Super-cell & $\begin{array}{c}\text { Abs. Diff KENO-VI } \\
\text { Homogeneous vs. } \\
\text { Heterogeneous } \\
\text { (pcm) }\end{array}$ \\
\hline$a$ & 813 \\
\hline$b$ & 26 \\
\hline$c$ & 236 \\
\hline$c b$ & 510 \\
\hline$d$ & -13 \\
\hline$d b$ & -27 \\
\hline$e$ & 338 \\
\hline$f$ & 256 \\
\hline
\end{tabular}

\begin{tabular}{|c|c|}
\hline Super-cell & $\begin{array}{c}\text { Abs. Diff KENO-VI } \\
\text { Homogeneous vs. } \\
\text { Heterogeneous } \\
\text { (pcm) }\end{array}$ \\
\hline$g$ & -18 \\
\hline$h$ & -4 \\
\hline$i$ & 307 \\
\hline$j$ & -14 \\
\hline$k$ & 821 \\
\hline$l$ & 465 \\
\hline$m$ & 426 \\
\hline
\end{tabular}

Table 8. Comparison of k-infinity in NEWT for various permutations of Exercise I-2c at CZP and HFP.

\begin{tabular}{|c|c|c|}
\hline \multirow[b]{2}{*}{ Super-cell } & \multicolumn{2}{|c|}{ NEWT } \\
\hline & $\begin{array}{l}\text { k-infinity } \\
(-)\end{array}$ & $\begin{array}{c}\text { Absolute Difference HFP-CZP } \\
(\mathrm{pcm})\end{array}$ \\
\hline$a$ & 1.14033 & $-5,943$ \\
\hline$b$ & 1.24102 & $-5,137$ \\
\hline$c$ & 1.06926 & $-10,215$ \\
\hline c-beta & 1.09005 & $-10,358$ \\
\hline$d$ & 1.18436 & $-11,228$ \\
\hline$d$-beta & 1.21163 & $-11,221$ \\
\hline$e$ & 1.15331 & $-6,547$ \\
\hline$f$ & 1.16053 & $-9,873$ \\
\hline$g$ & 1.38363 & $-9,844$ \\
\hline$h$ & 1.31769 & $-10,801$ \\
\hline$i$ & 1.33388 & $-12,006$ \\
\hline$j$ & 0.95207 & $-8,673$ \\
\hline$k$ & 1.34638 & $-7,634$ \\
\hline$l$ & 1.44061 & $-10,442$ \\
\hline$m$ & 1.38167 & $-11,297$ \\
\hline
\end{tabular}


Thus, in the groups of equally moderated super-cells mentioned above, the fuel temperature feedback increases in amplitude as the number of fresh blocks in the super-cell increases (due to the increased ${ }^{238} \mathrm{U}$ content). Also, by comparing the results for super-cells $c$ and $c$-beta, as well as cells $d$ and $d$-beta, it seems that the homogenization scheme of the north and south regions around the central heterogeneous block does not influence the temperature feedbacks significantly.

An analysis of the discretization parameters of the angle has been carried out (Appendix B). It is shown that the uncertainty contribution of the geometrical parameters utilized for the discretization in NEWT is about $200 \mathrm{pcm}$ for Exercises I2a and I-2b. Thus, the discrepancies observed between NEWT and KENO-VI cannot be entirely attributed to the angle discretization. A more detailed study on the spatial discretization parameter has to be carried out.

\subsubsection{6-Group Neutron Flux Profiles of the HFP Super-Cells' Central Block}

The neutron flux profiles in the central block of the super-cells are evaluated in a 26-group structure. The expectation of a more realistic, softer neutron flux as compared to the single blocks (Exercises $2 \mathrm{a}$ and 2b) motivates the choice of the super-cell model [8]. Considering that transport calculations and the resulting nuclear data libraries are preceded by a lattice homogenization and spectrum calculation where the reaction rates are conserved, the neutron flux plays a major role in the generation of the nuclear data. A proper neutron flux over the lattice cells influences the accuracy of the cross-section library generated from these data. The closer the lattice cell flux therefore to a full-size core flux environment is, the better the cross-section libraries. Figure 11 through Figure 20 represent the following flux profile comparisons.

Figure 11: Exercises I-2a and I-2b are compared as a confirmation of the spectra calculated for the INL Phase I study, as reported in Reference [8]. As mentioned earlier, the neutron flux in both the fresh and burned-fuel blocks is characterized by relatively hard spectrums, due to the low presence of graphite material. The plutonium content in the burned fuel leads to a harder spectrum for Exercise I- $2 \mathrm{~b}$ than Exercise I-2a. A plot of the neutron flux within the energy group corresponding to the most probable neutron energy after fission is plotted in Figure 12. A similar graph is given for highest neutron density within a thermal group in Figure 13. The features of the two groups selected for the map flux are detailed in Table 9. Those plots confirm that the behavior of the fresh and burned systems is similar, while the thermal absorption is more pronounced in burned-fuel blocks. The corners of the blocks are filled with BP pins, but the burned-fuel blocks have been chosen to be entirely boron-free, which explains the high thermal flux on the corners.

Table 9. Features of the two groups selected for the flux maps of Exercises I-2a and I-2b.

\begin{tabular}{|c|c|}
\hline Energy Group Number & Energy Boundaries [eV] \\
\hline 3 & $3.000 \mathrm{E}+06-6.700 \mathrm{E}+05$ \\
\hline 18 & $1.300 \mathrm{E}+00-6.500 \mathrm{E}-01$ \\
\hline
\end{tabular}




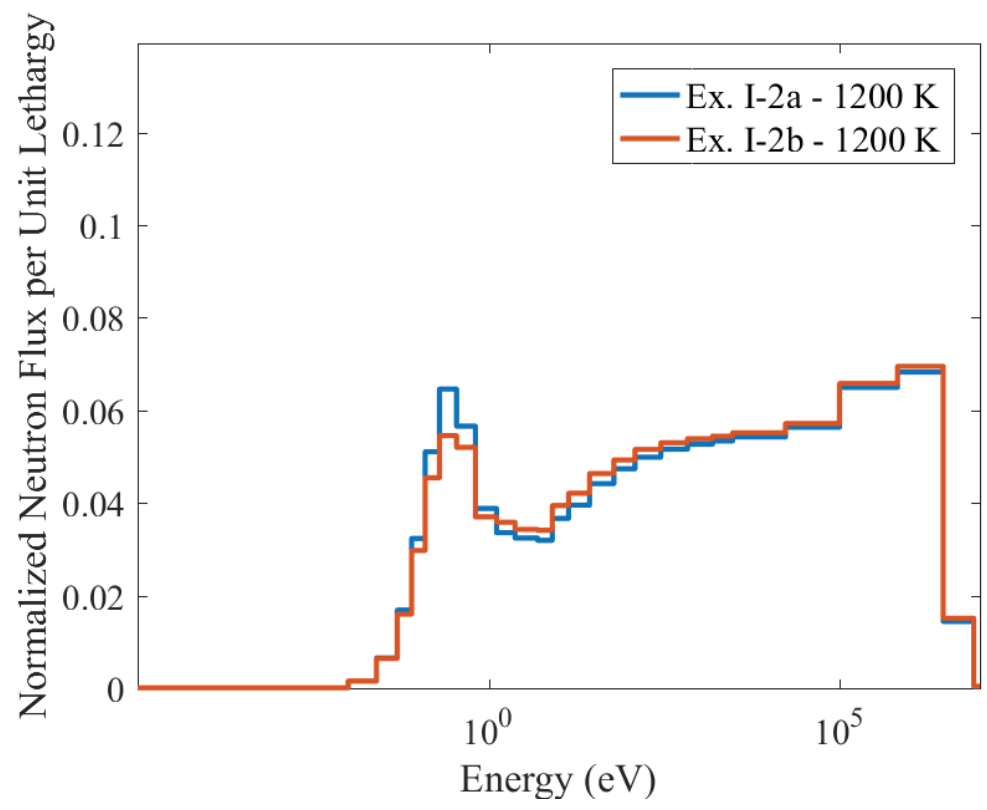

Figure 11. Normalized neutron flux per unit lethargy in 26-group structure for Exercises $2 \mathrm{a}$ and $2 \mathrm{~b}$.
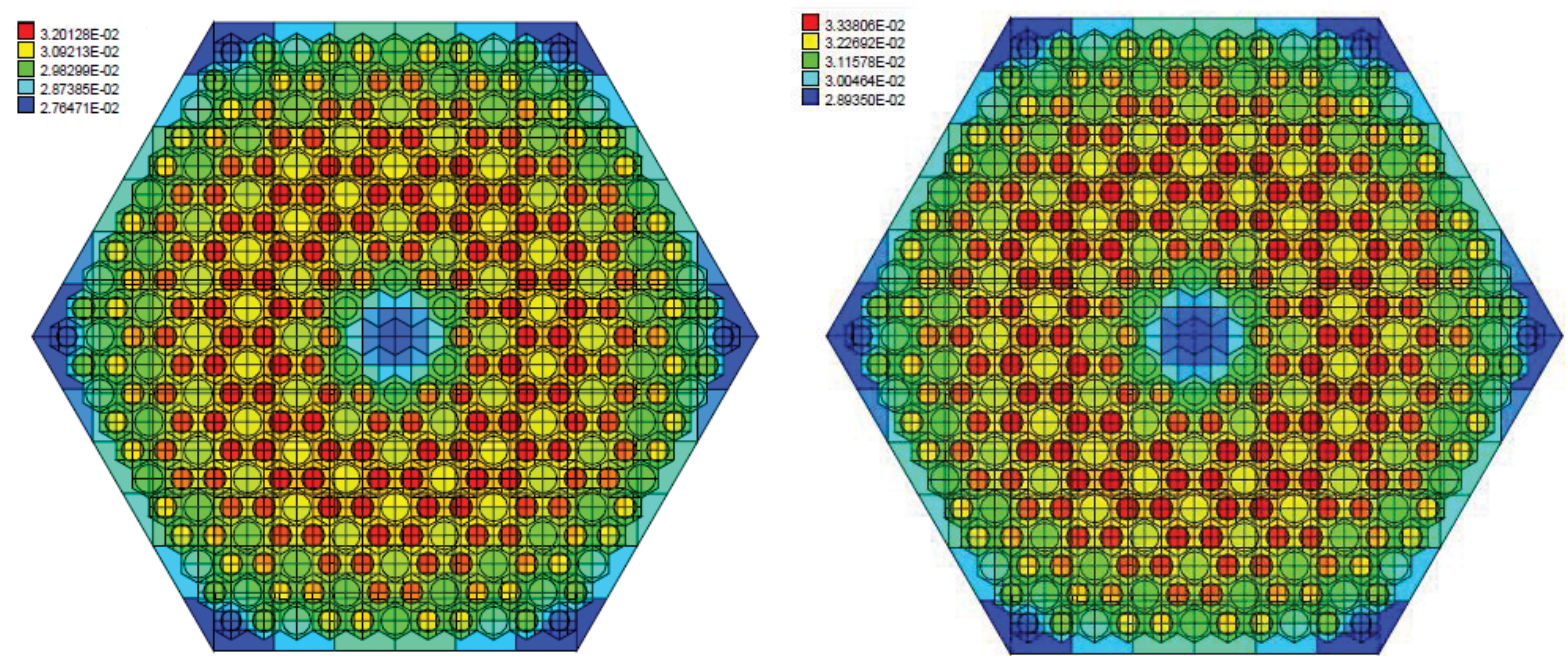

Figure 12. Neutron flux map of the Energy Group 3 at 1,200 K for a fresh-fuel block (Exercise I-2a: left) and a burned-fuel block (Exercise I-2b: right). 

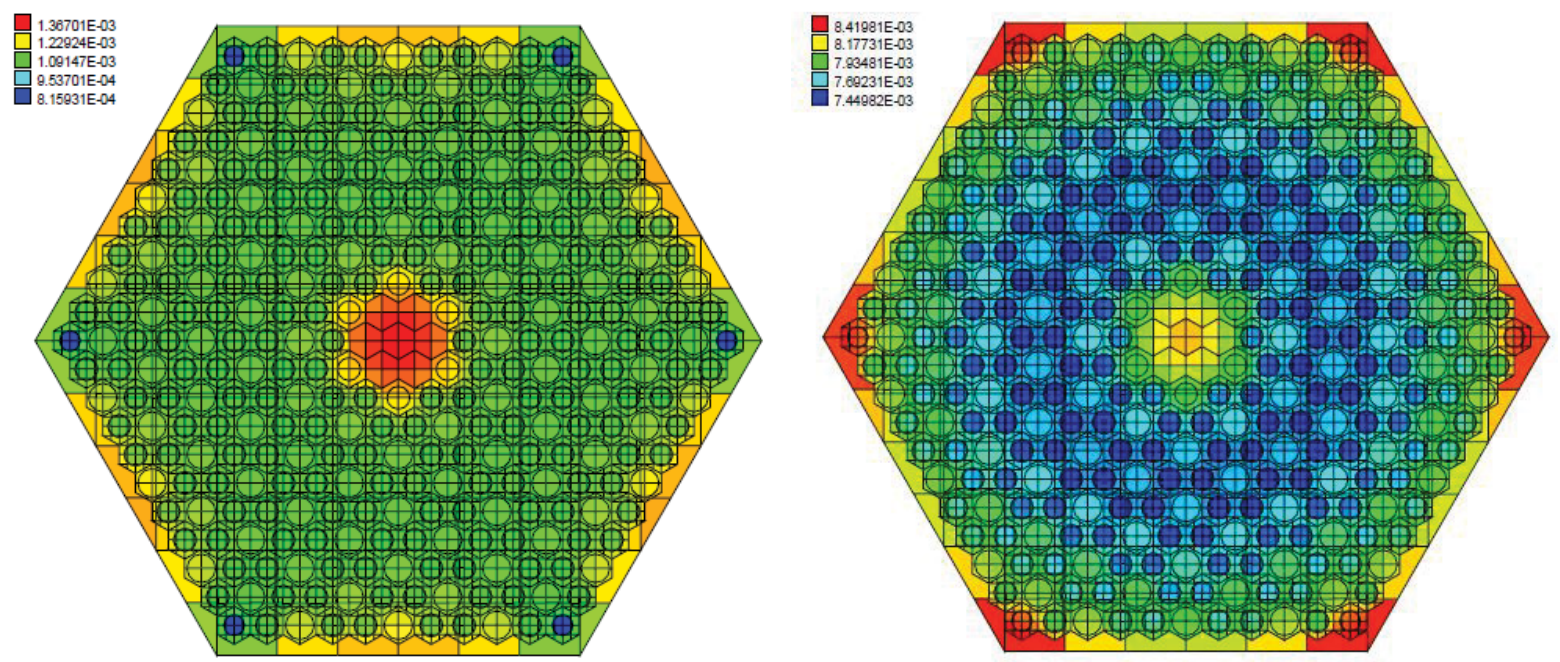

Figure 13. Neutron flux map of the Energy Group 18 at 1,200 K for a fresh-fuel block (Exercise I-2a: left) and a burned-fuel block (Exercise I-2b: right).

Figure 14: Super-cells $c$ and $c$-beta are compared to evaluate the homogenization effects with constant number densities in the fresh-fuel super-cells. The spectrum is comparable to what is found in the single blocks. Unlike the effect mentioned above regarding the multiplication factor, the different homogenization schemes for identical nuclide inventories do not change the neutron flux profile significantly. Case $c$-beta is therefore assumed to behave similar to case $c$ for the rest of this subsection.

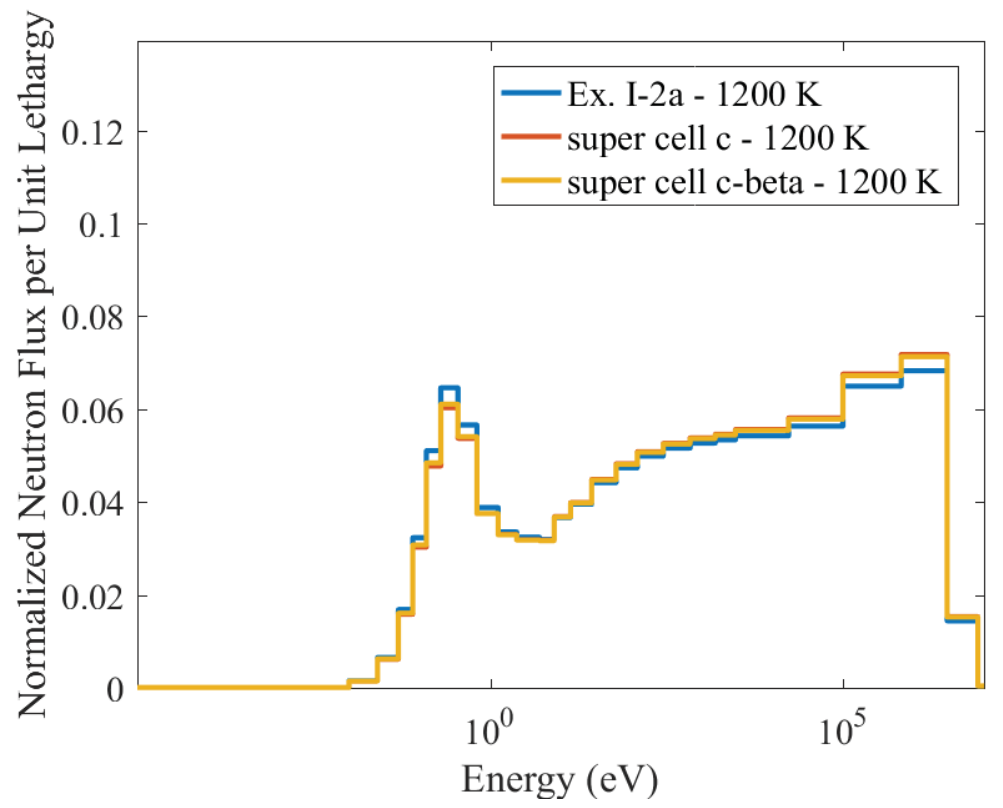

Figure 14. Normalized neutron flux per unit lethargy in 26-group structure for super-cells $c$ and $c$-beta.

Figure 15 Super-cells $d$ and $d$-beta are compared to evaluate the homogenization effects with constant number densities in the burned-fuel super-cells. The spectrum is comparable to what is found in the singleblock I-2b. Unlike the effect mentioned above regarding the multiplication factor, the different homogenization schemes for identical nuclide inventories do not significantly change the neutron flux profile. Case $d$-beta is therefore assumed to behave similar to Case $d$ for the rest of this subsection. 


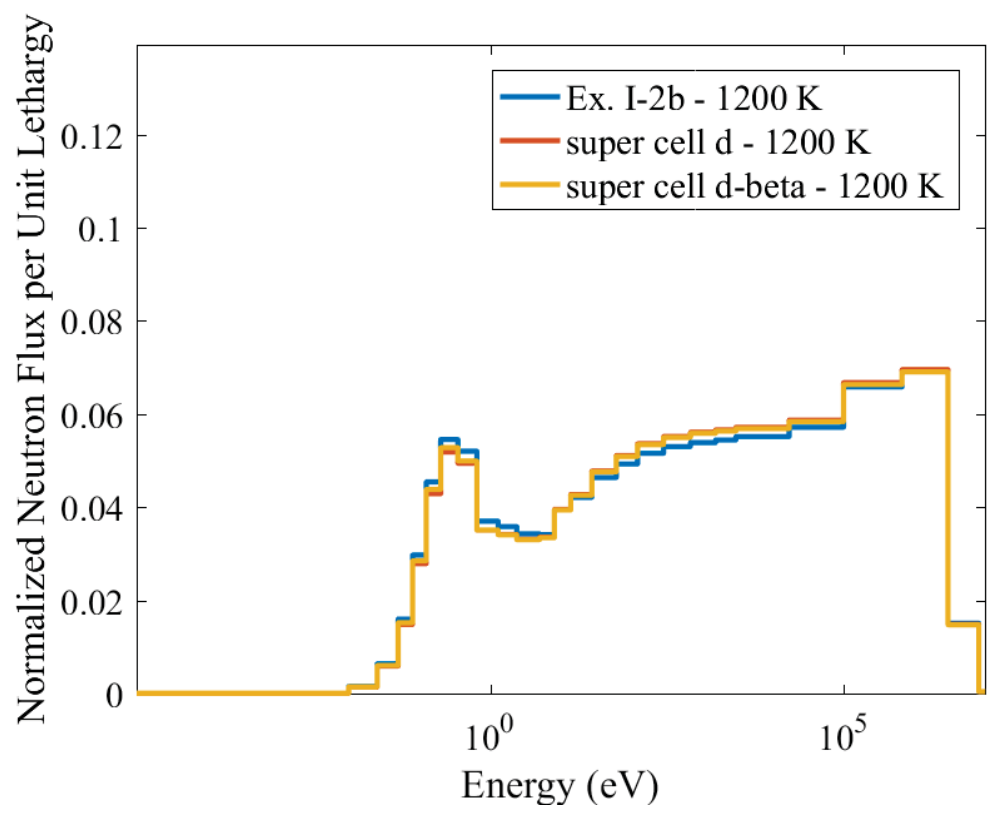

Figure 15. Normalized neutron flux per unit lethargy in 26-group structure for super-cells $d$ and $d$-beta.

Figure 16: Super-cells $r$ and $s$ are compared to measure how the reflector is impacted by the surrounding homogenized regions. The change in the fuel composition in the surrounding regions only influences the flux in the central reflector block very slightly.

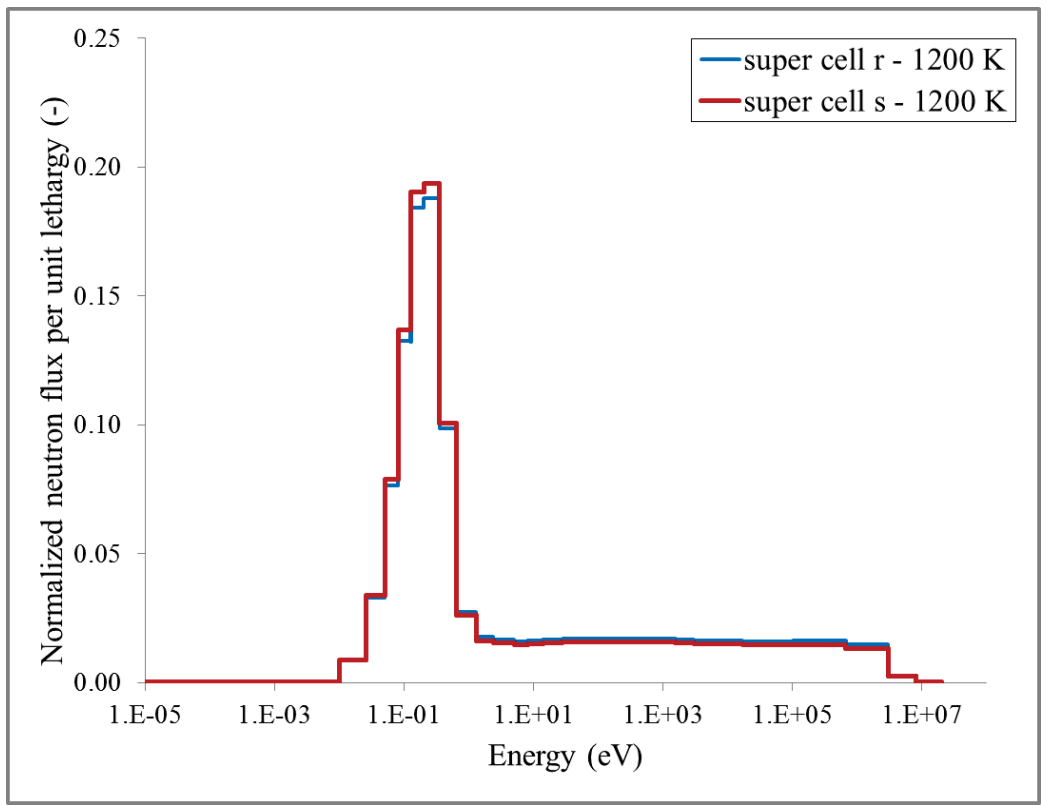

Figure 16. Normalized neutron flux per unit lethargy in 26-group structure for super-cells $r$ and $s$.

Figure 17: Super-cells $i$ and $k, l$, and $m$ and Exercise I-2a are compared to evaluate the flux difference in the fresh-fuel-only super-cells (required for a fresh MHTGR core at startup). The purely fresh supercell $i$ behaves very closely to the single-block $\mathrm{I}-2 \mathrm{a}$, although the flux in the super-cell is slightly softer, which is probably due the homogenization effect of the fuel around the central block. The neutron flux shows a very pronounced trend between the different cells: the flux becomes softer as the number of 
graphite blocks replace the homogenized fuel blocks, which is due to the increase of moderator in the supercells.

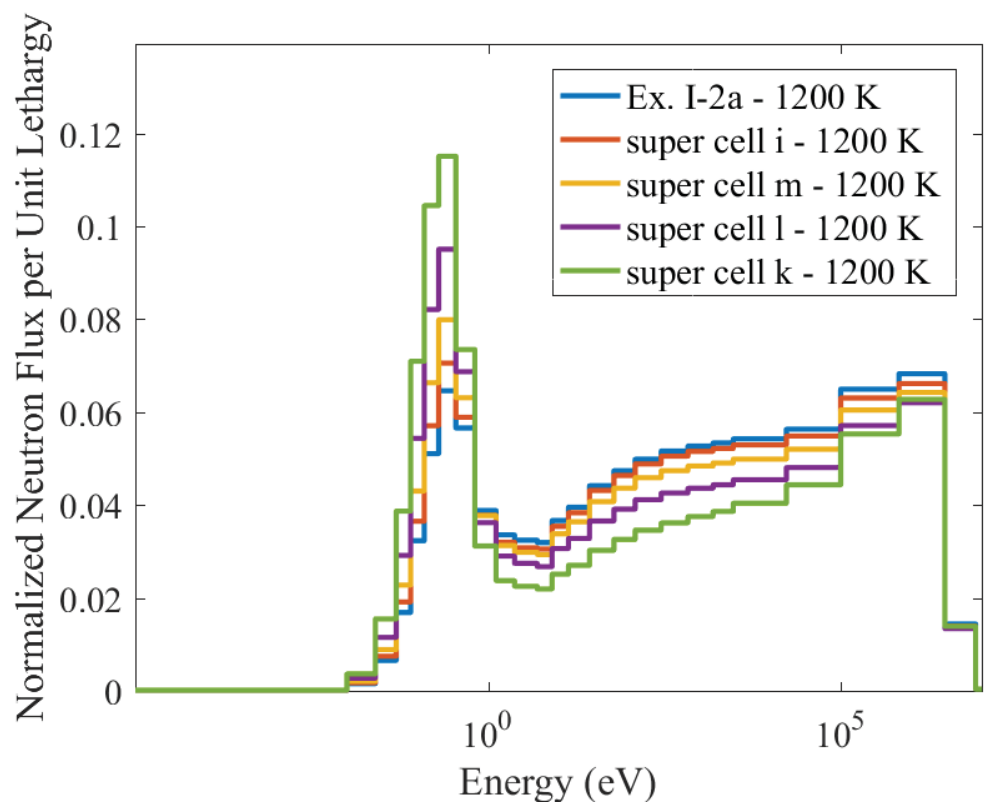

Figure 17. Normalized neutron flux per unit lethargy in 26-group structure for super-cells $i, k, l$, and $m$. Exercise $2 \mathrm{a}$ is plotted for reference.

Figure 18: Super-cell $j$ and Exercise I-2b are compared to evaluate the flux variation in burned-fuel-only models. Unlike the comparison of the fresh single block versus the fresh super-cell $i$, the homogenization around the central block in the super-cell makes the spectrum softer than the burned single block.

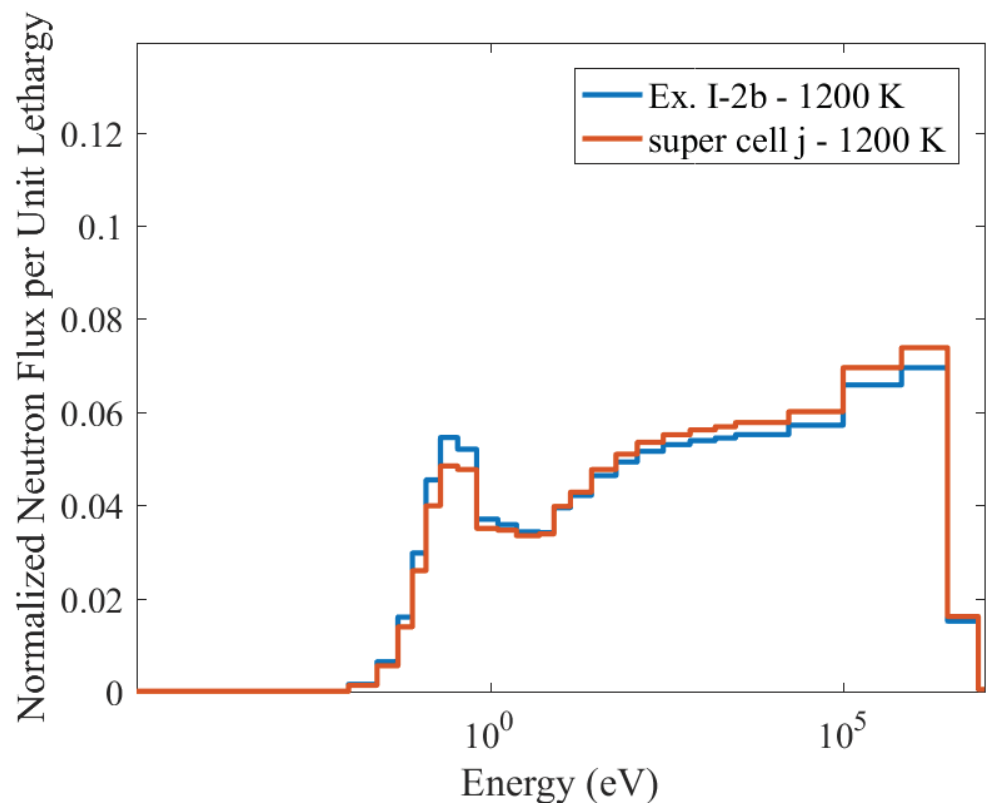

Figure 18. Normalized neutron flux per unit lethargy in 26-group structure for super-cell $j$ and Exercise 2b. 
Figure 19: Super-cells $b, d, g, h$, and $j$ are compared to evaluate the difference between super-cells containing a burned heterogeneous central block. In this plot, the relative softness of the flux is once again caused by the amount of graphite located in the super-cells.

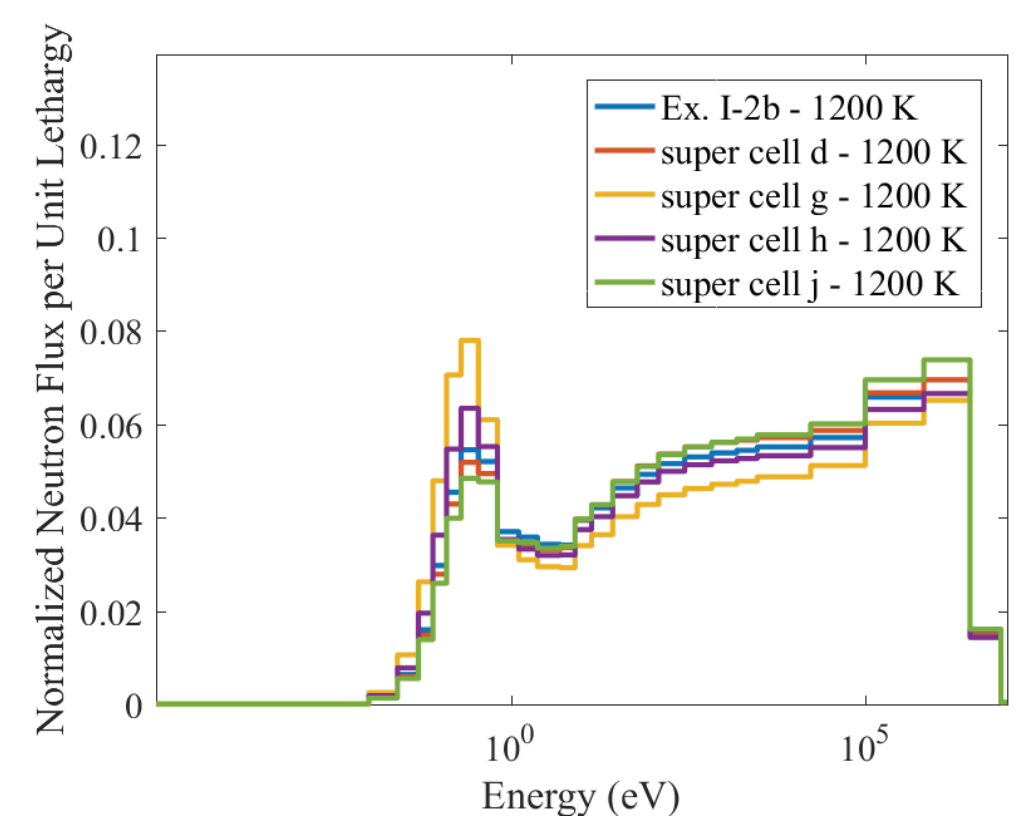

Figure 19. Normalized neutron flux per unit lethargy in 26-group structure for super-cells $b, d, g, h$, and $j$.

Figure 20: Super-cells $a, c, e$, and $f$ are compared to evaluate the difference between super-cells containing a fresh heterogeneous central block and surrounded by a fresh- and burned-fuel mix. The trend is similar to the fresh-fuel-only comparison. The flux behavior seems to be mainly governed by the amount of graphite in the super-cells.

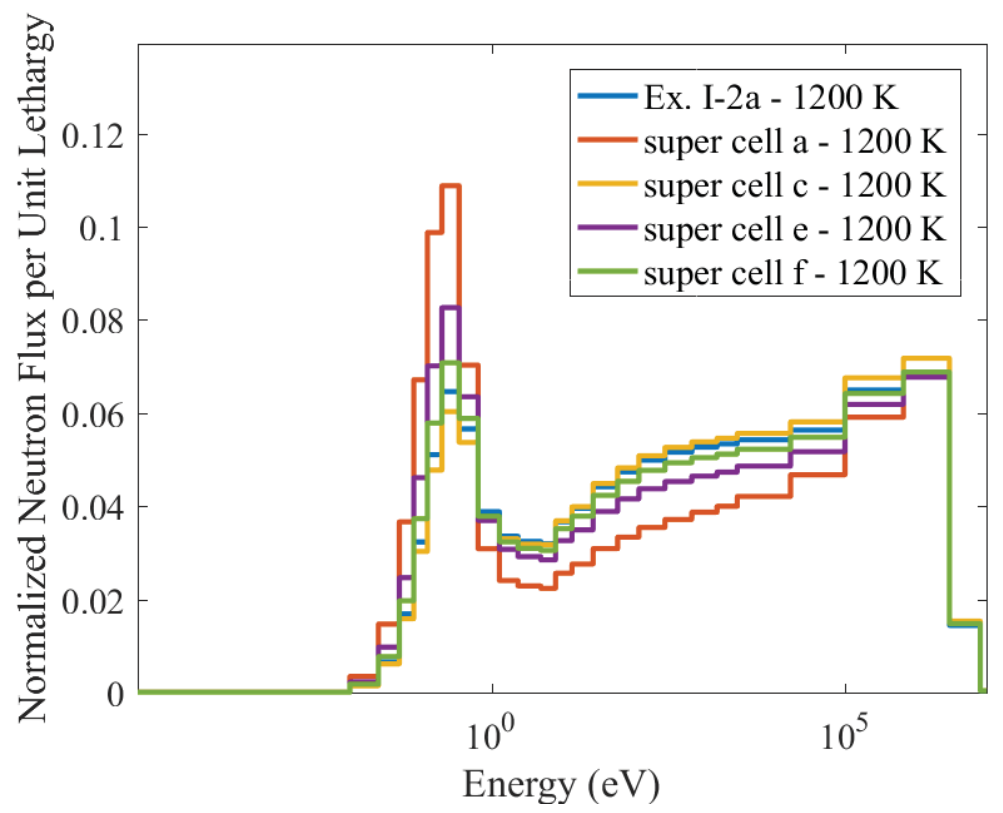

Figure 20. Normalized neutron flux per unit lethargy in 26-group structure for super-cells $a, c, e$, and $f$. Exercise $2 \mathrm{a}$ is plotted for reference. 
The relative difference of the super-cells' normalized neutron flux per unit lethargies at the center of super-cells as compared to Exercise I-2a are summarized in Figure 21 and Figure 22. The comparison with the burned-fuel block is given in Figure 23. The thermal cutoff is fixed to $2.38 \mathrm{eV}$ (Group 17). Taking only the relative differences between single blocks and super-cells as a metric for the construction of the one-third core in PHISICS, super-cells $a, b, e, g, k, l$, and $m$ are likely to produce improved library data sets and therfore a more refined Phase II core model. On the other hand, super-cells $c, c$-beta, $d, d$-beta, $f, h, i$, and $j$ show spectra sufficiently close to the single blocks and therefore do not offer much improvement over the standard single-block approach. As for the reflector, super-cells $r$ and $s$ show almost identical neutron flux through the central reflector block. Only super-cell $r$ can therefore be selected to produce the reflector nuclear cross-section data set in the one-third PHISICS core, due to its more realistic representation of the core throughout its life.

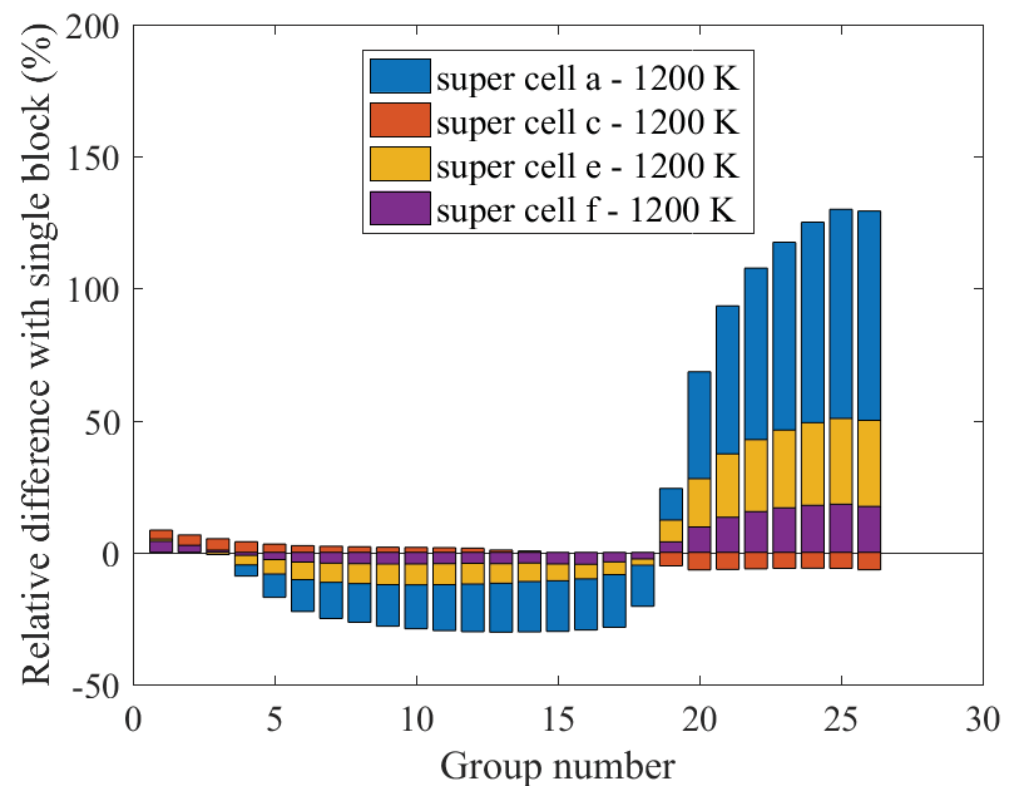

Figure 21. Relative difference (\%) of normalized neutron per unit lethargy between fresh super-cells and single blocks at HFP. 


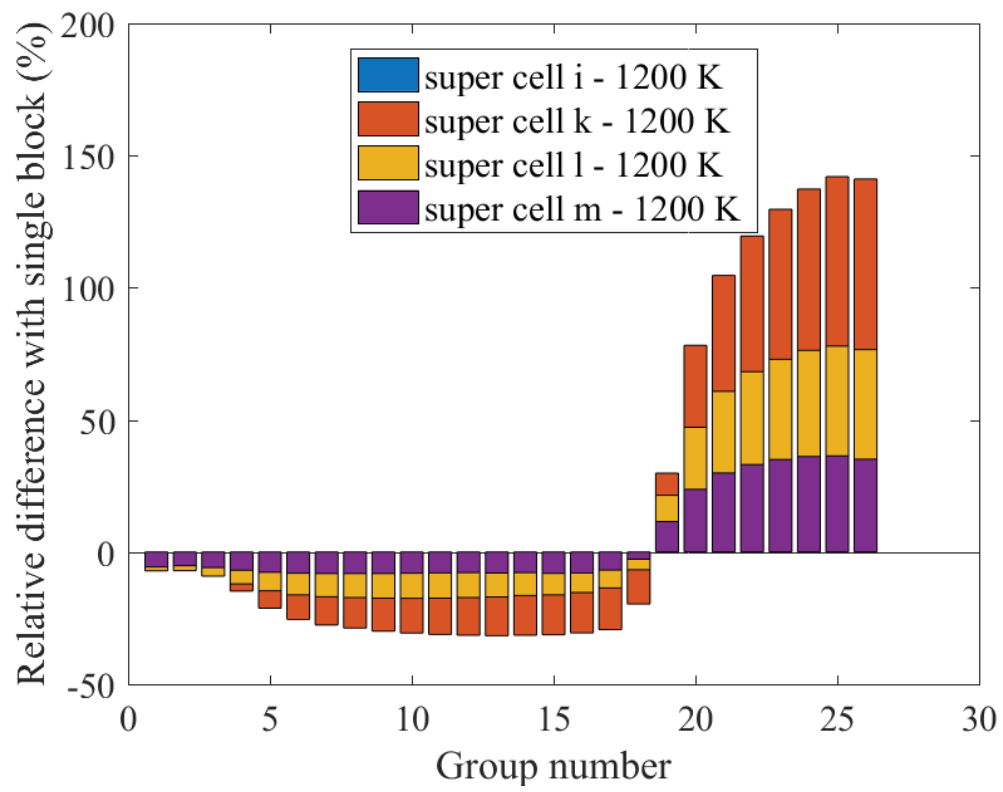

Figure 22. Relative difference (\%) of normalized neutron flux per unit lethargy between fresh supercells $(i, m, l$, and $k)$ and single blocks at HFP.

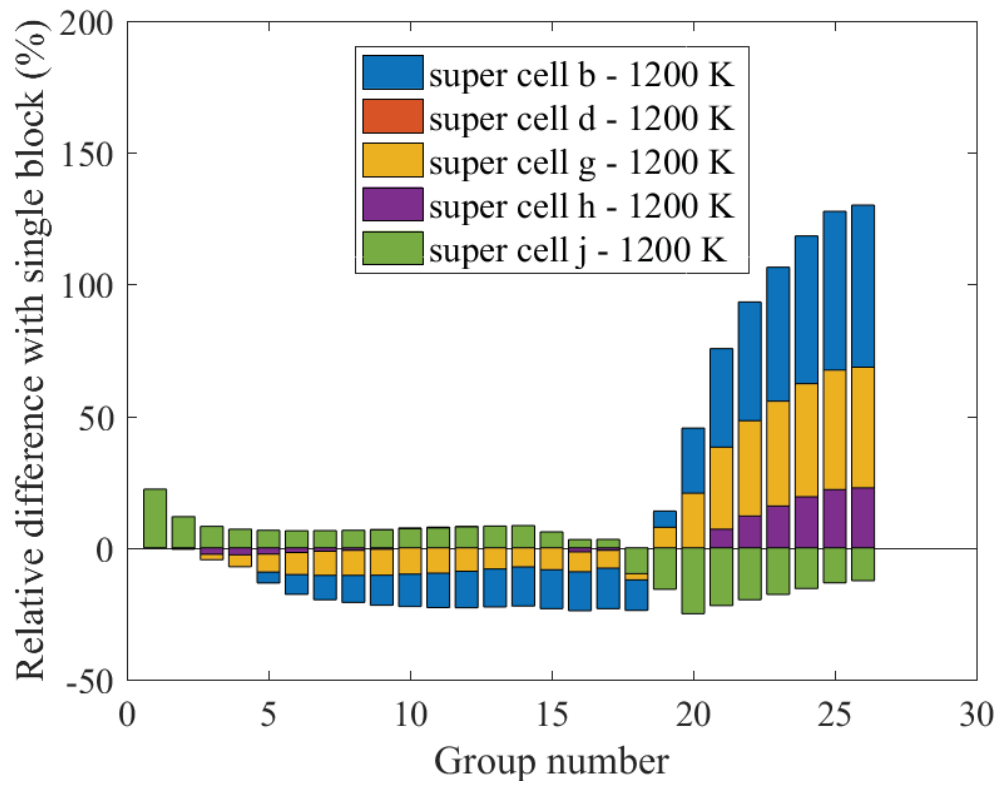

Figure 23. Relative difference (\%) of normalized neutron per unit lethargy between burned super-cells $(b$, $d, g, h$, and $j$ ) and single blocks at HFP.

\subsubsection{Evaluation of the Neutron Group Importance in the Super-cells' Central Block in 26-Group Structure at HFP}

It has been shown in Subsection 4.1.3 that neutron flux becomes more thermal as the amount of graphite increases in the super-cells. Referring to Figure 21, Figure 22, and Figure 23, the differences between the single blocks and the super-cells in normalized neutron flux can be up to about $150 \%$. Such a gap occurs in the lowest thermal neutron groups (25 and 26). The normalized neutron flux per unit lethargy represents the proportion of neutrons in a given group relative to the total number of neutrons in the central block. So 
the comparison of the normalized neutron flux per unit lethargy between different models rules out the difference existing in the absolute number of neutrons between the two models. The product of the normalized neutron flux per unit lethargy with the macroscopic group cross sections gives the relative number of reactions in a given group as compared to the others. This value helps to understand which groups are important regarding the reaction of interest and therefore how much they influence the results considered in the next sections (multiplication factor, power density, etc.).

The normalized reaction rates of super-cells $i$ and $k$ compared to the fresh single block (Exercise I-2a) are given in Figure 24 (total reaction rate), Figure 25 (absorption reaction rate), and Figure 26 (fission reaction rate). Super-cell $i$ is chosen to verify that it provides similar results to the one provided by Exercise I-2a. Super-cell $k$ has the softest spectrum among all the fresh super-cells.

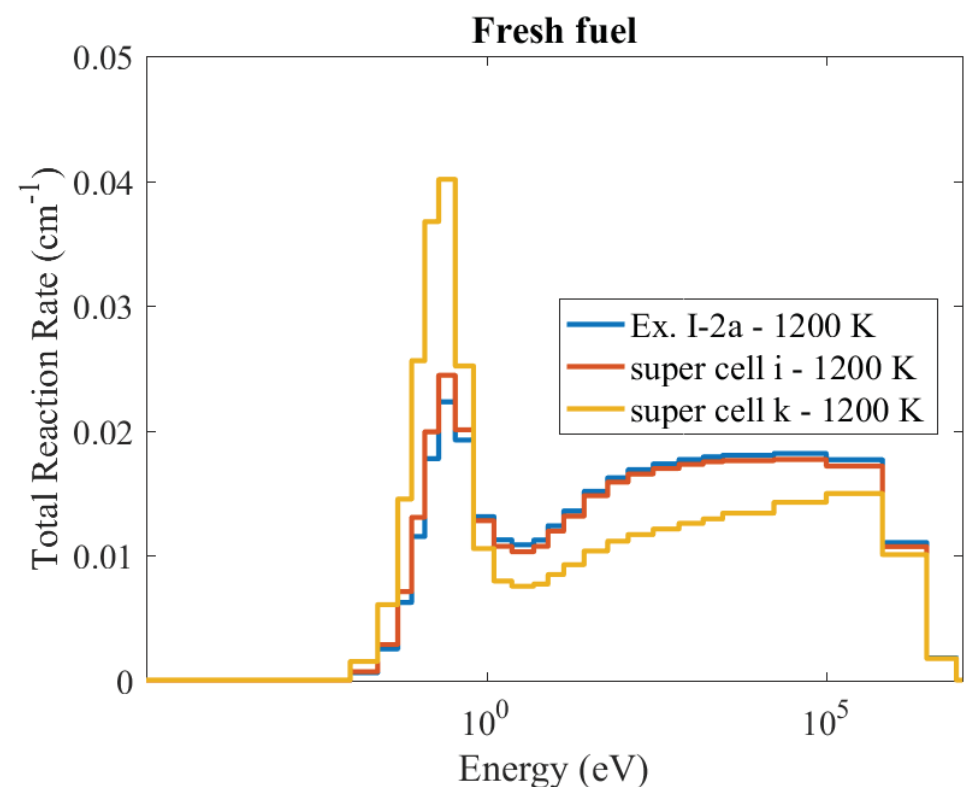

Figure 24. Normalized total reaction rate of Exercise I-2a, super-cells $i$ and $k$. 


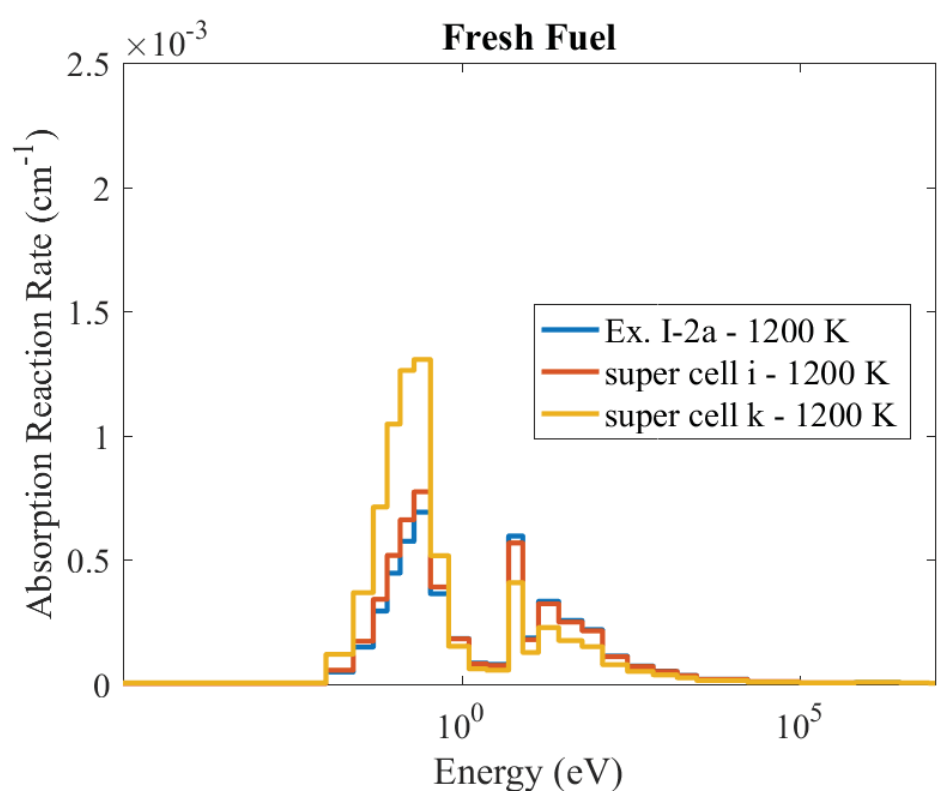

Figure 25. Normalized absorption reaction rate of Exercise I-2a, super-cells $i$ and $k$.

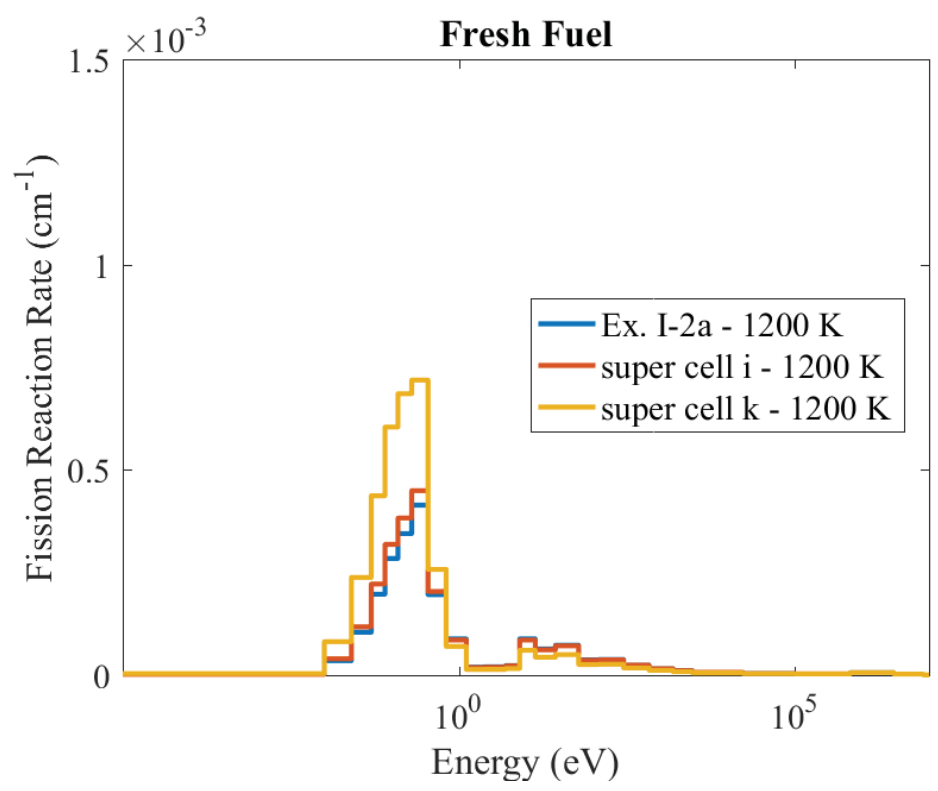

Figure 26. Normalized fission reaction rate of Exercise I-2a, super-cells $i$ and $k$.

A similar pattern is chosen for the burned-fuel super-cells and the total reaction rate (Figure 27), the absorption reaction rate (Figure 28), and the fission rates (Figure 29) of Exercise I-2b. Super cells $j$ and $b$ are plotted.

Figure 24 through Figure 29 show that:

- Exercise I-2a provides a flux and cross section similar to super-cell $i$, and Exercise I-2b provides a flux and cross section similar to super-cell $j$. This is another confirmation that the cross section originating from single-block I-2a is sufficient for non-moderated areas such as the center of the fuel ring in the core. 
- The reaction rates for energy groups below $0.01 \mathrm{eV}$ are practically equal to zero (Groups 25 and 26). This corresponds to the largest flux differences between the super-cells and the single-block models, but it seems that at these energies, those differences do not impact the system.

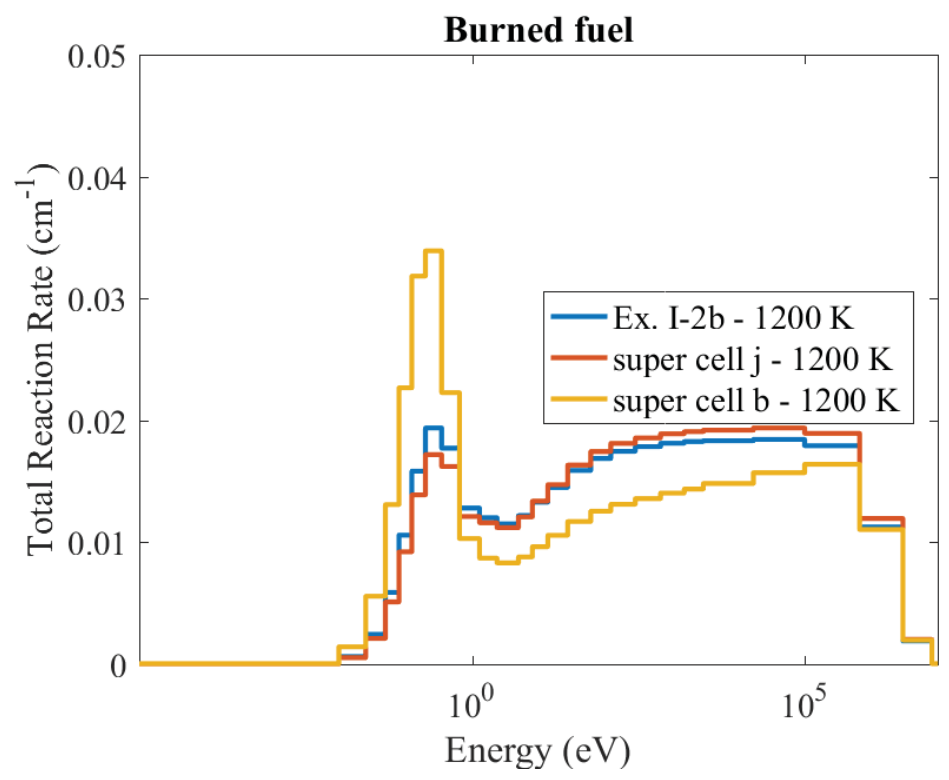

Figure 27. Normalized total reaction rate of Exercise I-2b, super-cells $j$ and $b$.

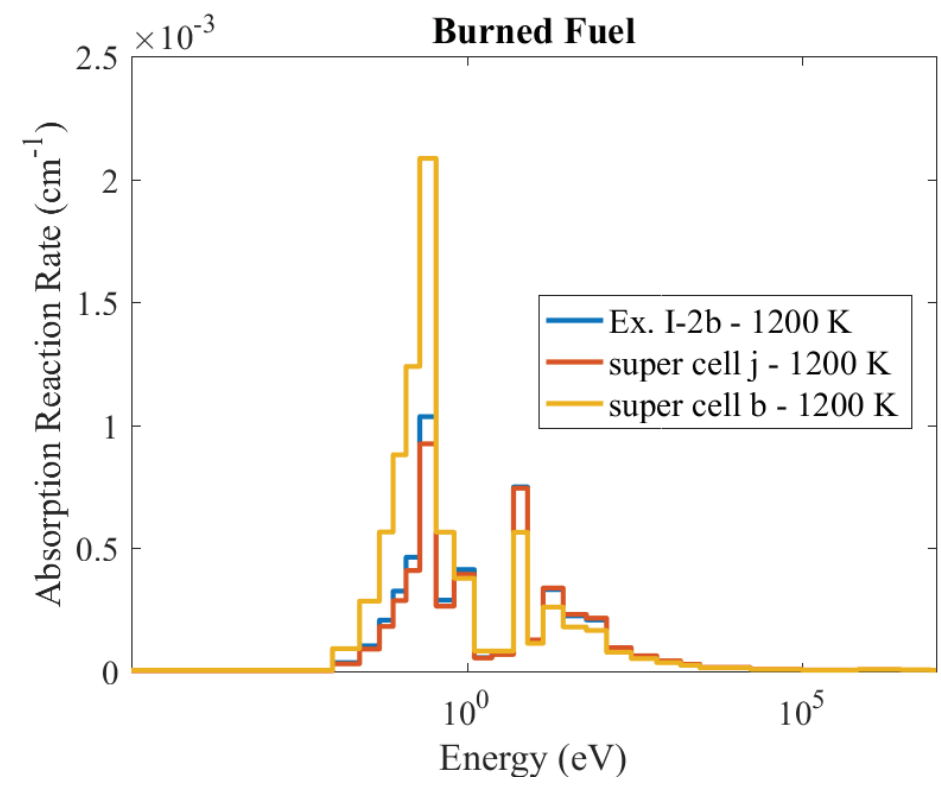

Figure 28. Normalized absorption reaction rate of Exercise I-2b, super-cells $j$ and $b$. 


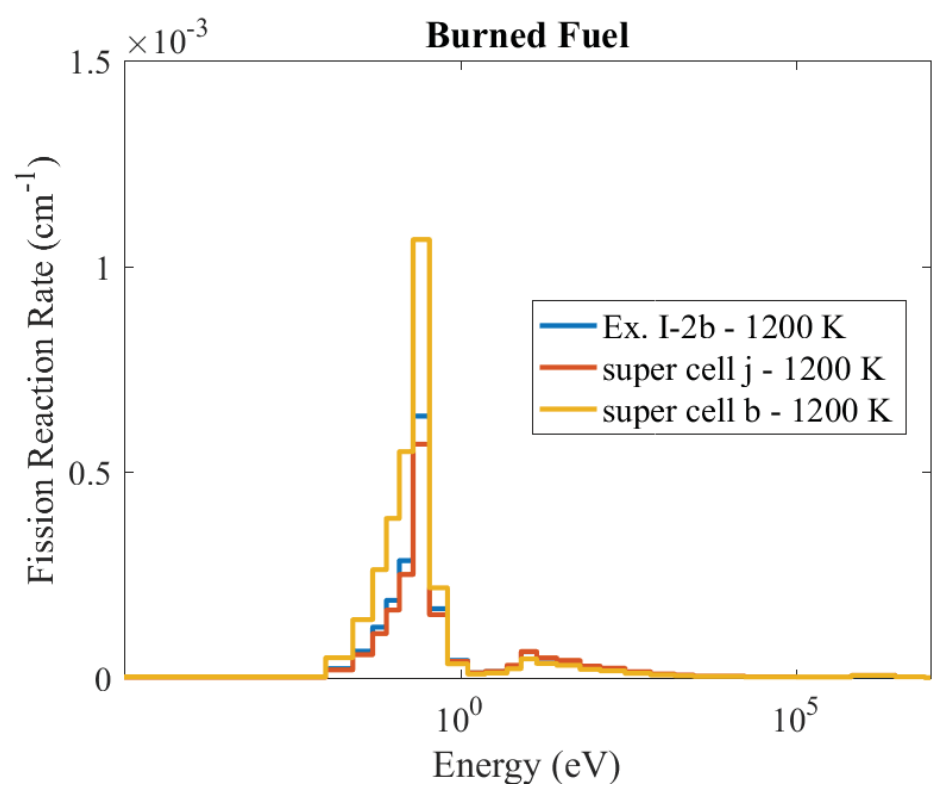

Figure 29. Normalized fission reaction rate of Exercise I-2b, super-cells $j$ and $b$.

Similar results are observed for the burned-fuel super-cells. It can be concluded that the blocks in the periphery of the core fuel ring are likely to have fairly different reaction rates as compared to the one at the center of the fuel ring. This conclusion leads to a description of an investigation of the effect of the soft super-cells $(a, b, k)$ in the next sections.

\subsubsection{Neutron Flux Profiles of Super-cells' Central Block in 26-Group Structure at CZP}

The comparison of the normalized neutron fluxes at the center of the super-cells between the HFP and CZP cases is reported in this subsection. The normalized neutron fluxes at CZP are compared one by one for each super-cell at the HFP configuration. As a reminder, the neutron flux is evaluated at the center of the super-cells, and the homogenized regions are intended to provide only a neutron flux background. The super-cells are modeled following three different central-block compositions: fresh blocks, burned blocks, and reflector blocks. To organize the study, the comparison HFP versus CZP is split in two parts, each corresponding to the central block's isotopic composition.

\subsubsection{Fresh Central Block.}

The neutron fluxes for the HFP and CZP conditions are presented for Exercise 2a (Figure 30) and super-cells $a$ (Figure 31), $c$ (Figure 32), $e$ (Figure 33), $f$ (Figure 34), $i$ (Figure 35), $k$ (Figure 36), $l$ (Figure 37), and $m$ (Figure 38).

For all of the super-cells, the flux becomes harder as the temperatures drop. This effect is decreased when the number of homogenized fuel blocks around the central block increases. This effect is well illustrated when the spectra for super-cells $i, m, l$, and $k$ are inspected, and the effect can be explained by the fact that replacing a carbon-graphite block with a fuel block is equivalent to decreasing the moderator temperature effect and increasing the Doppler temperature effect, which is larger in amplitude than the moderator temperature coefficient. 


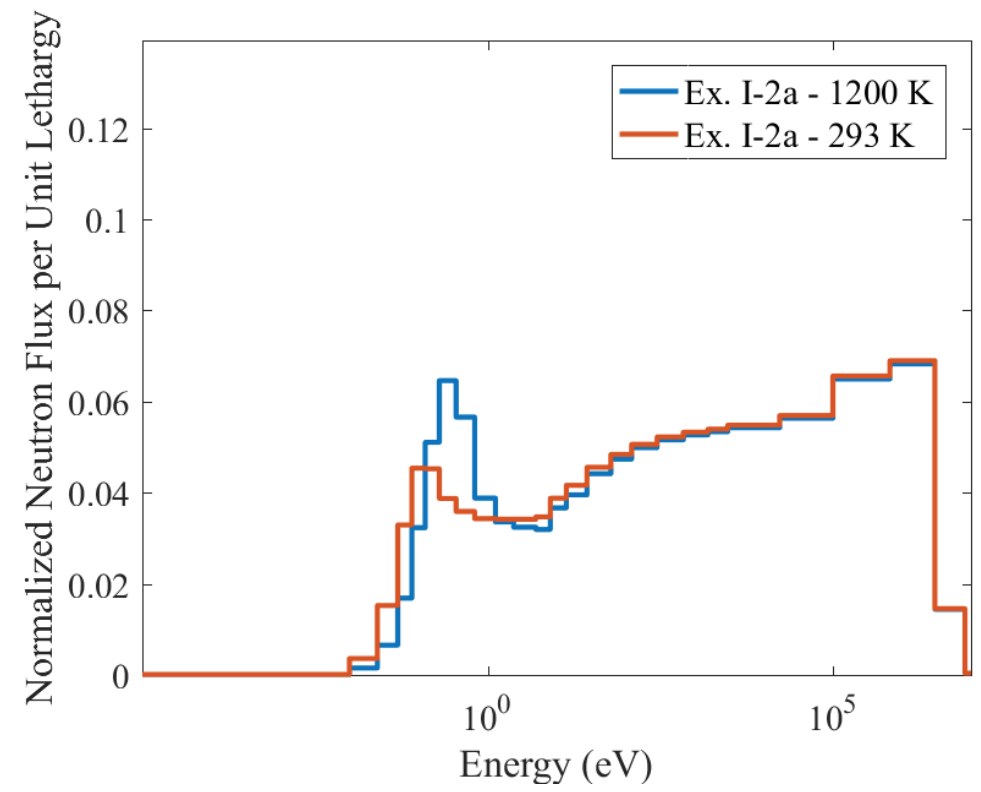

Figure 30. Comparison of normalized neutron flux per unit lethargy of Exercise 2a at HFP and CZP.

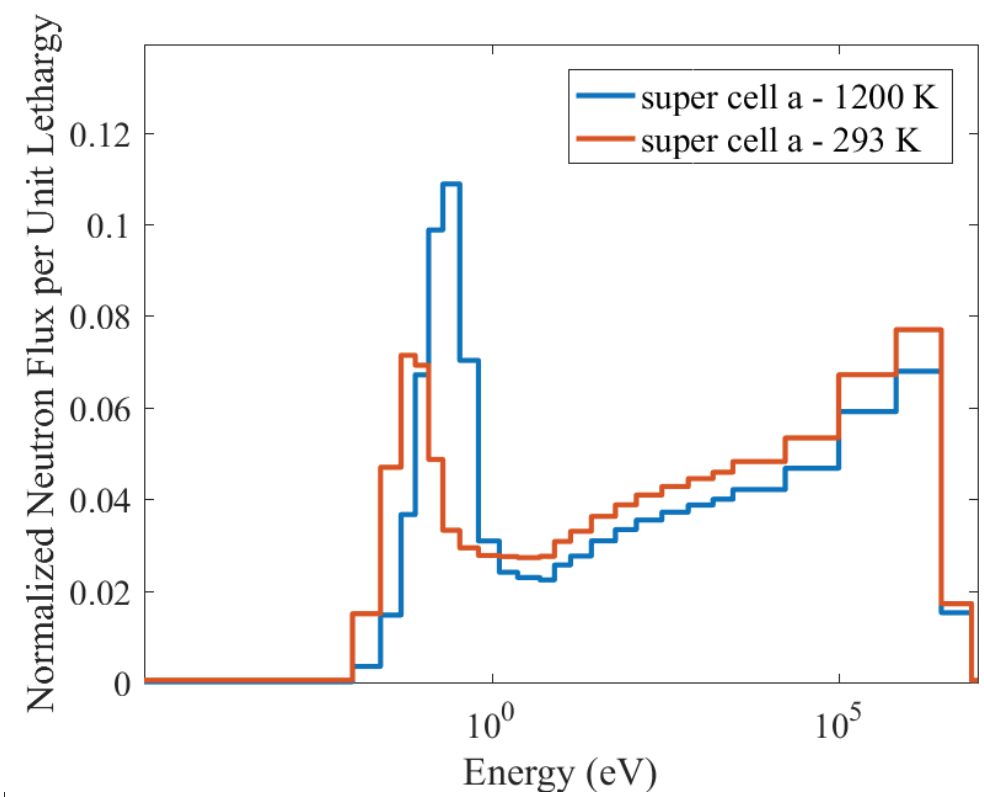

Figure 31. Comparison of normalized neutron flux per unit lethargy of super-cell $a$ at HFP and CZP. 


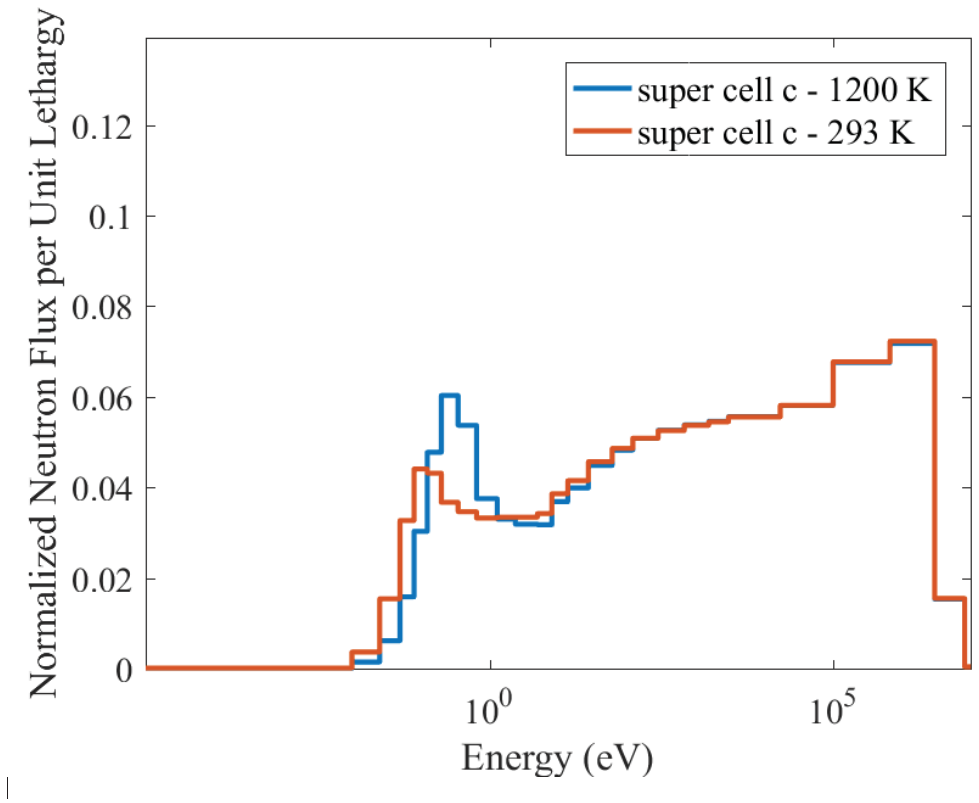

Figure 32. Comparison of normalized neutron flux per unit lethargy of super-cell $c$ at HFP and CZP.

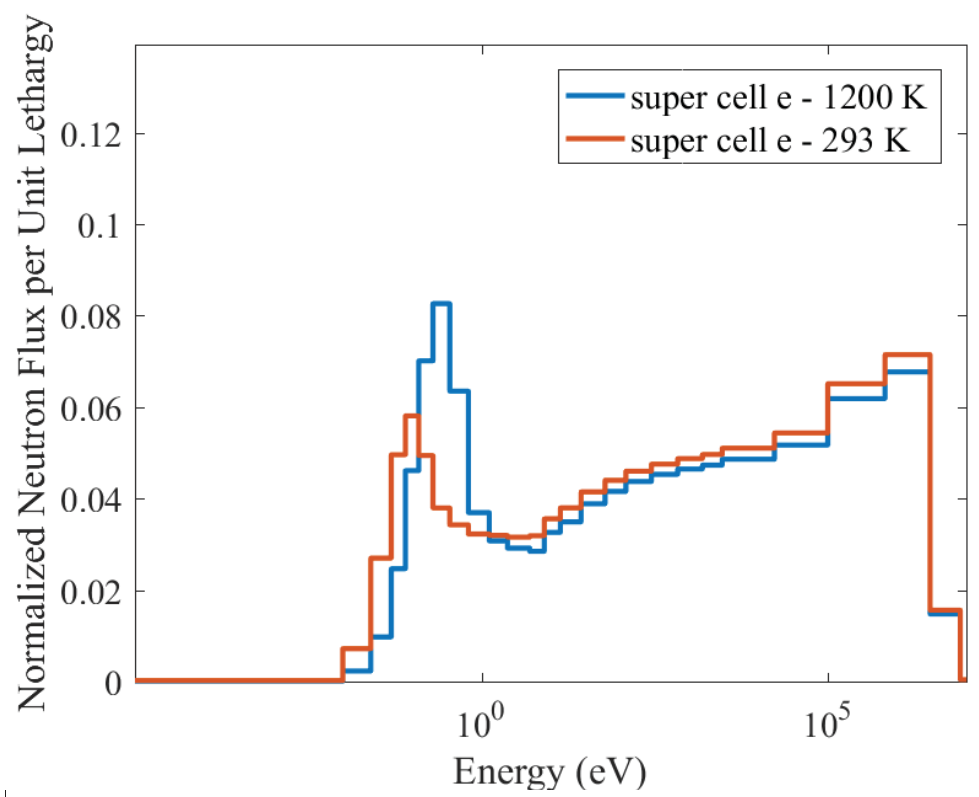

Figure 33. Comparison of normalized neutron flux per unit lethargy of super-cell $e$ at HFP and CZP. 


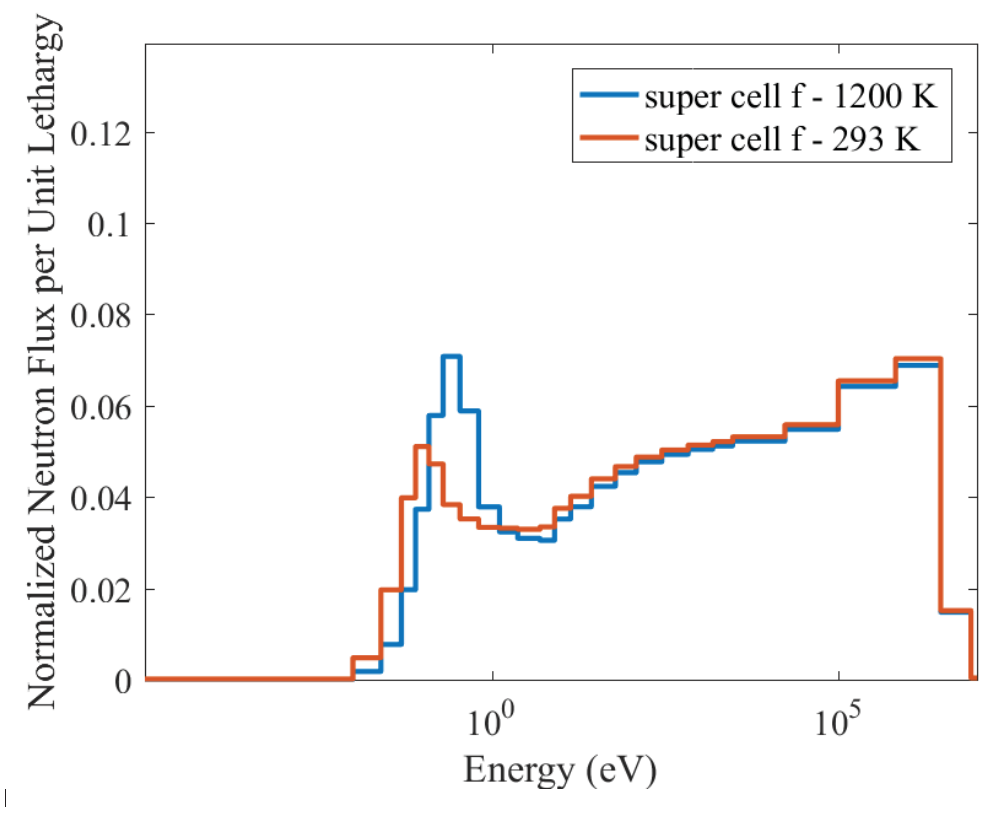

Figure 34. Comparison of normalized neutron flux per unit lethargy of super-cell $f$ at HFP and CZP.

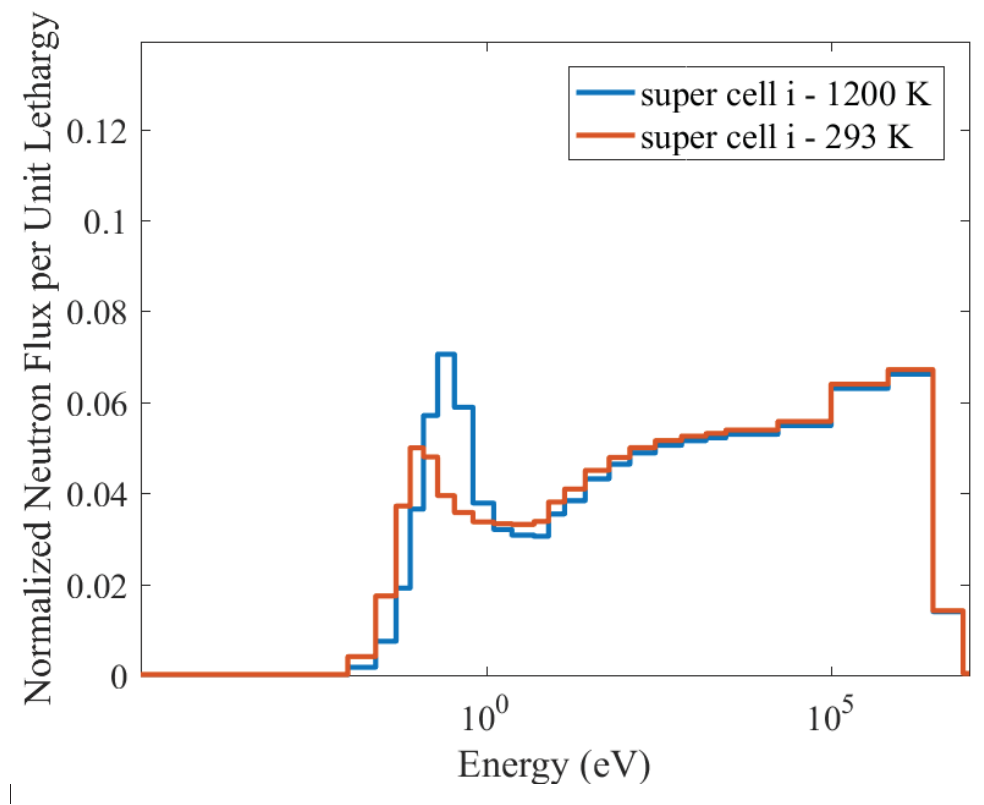

Figure 35. Comparison of normalized neutron flux per unit lethargy of super-cell $i$ at HFP and CZP. 


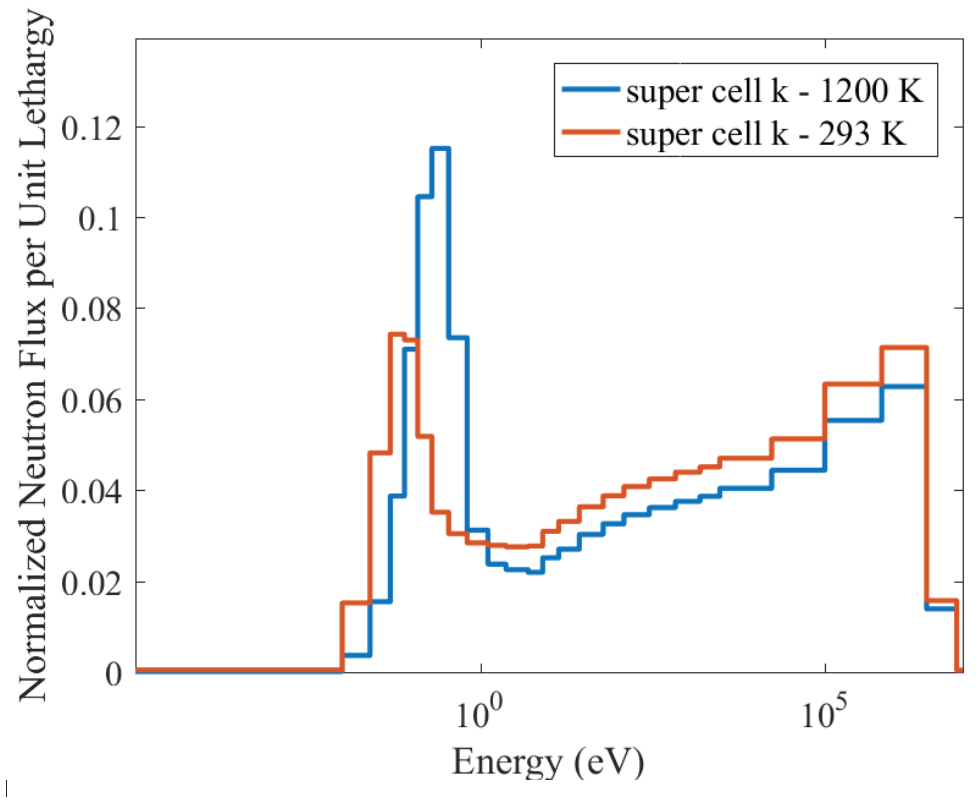

Figure 36. Comparison of normalized neutron flux per unit lethargy of super-cell $k$ at HFP and CZP.

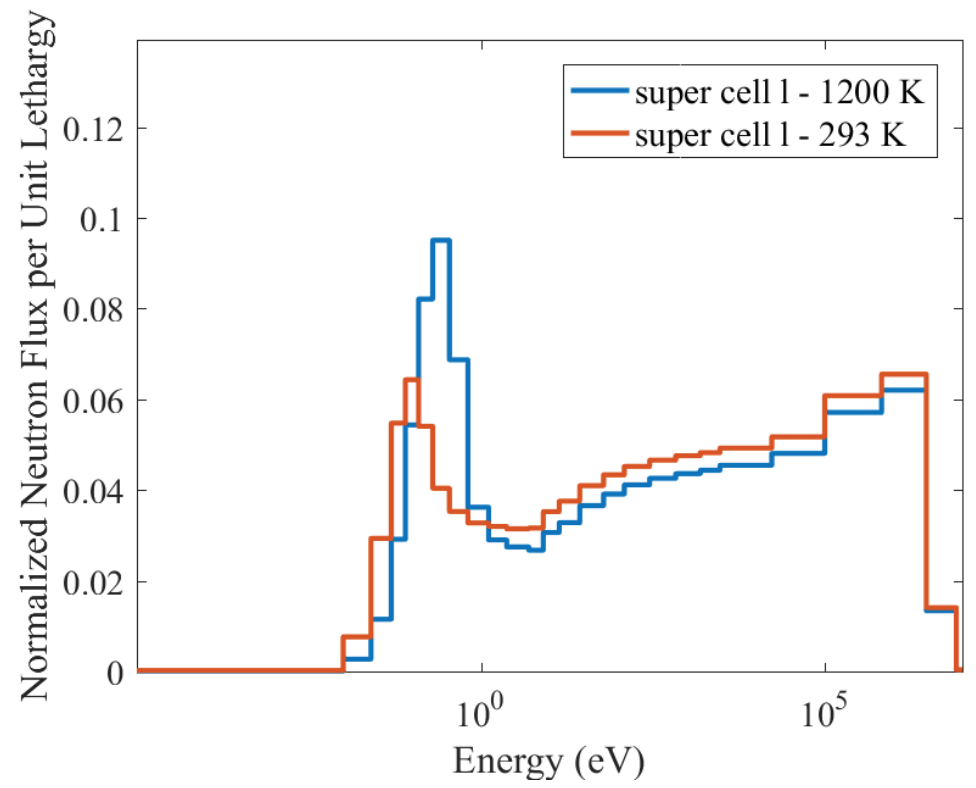

Figure 37. Comparison of normalized neutron flux per unit lethargy of super-cell $l$ at HFP and CZP. 


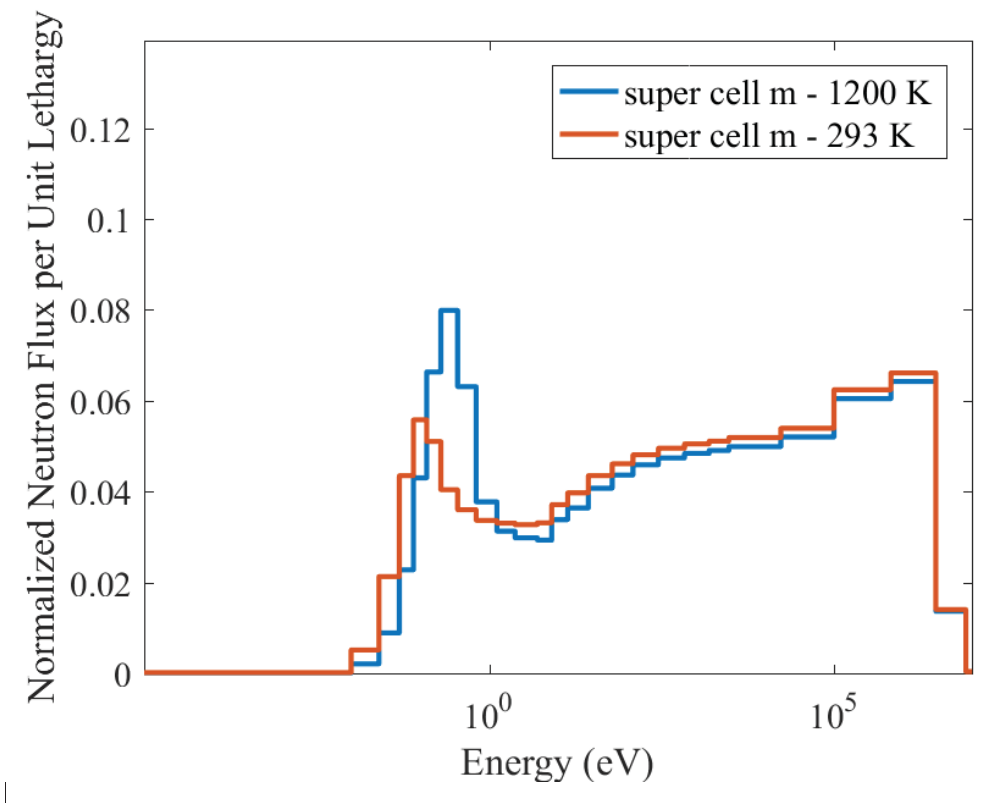

Figure 38. Comparison of normalized neutron flux per unit lethargy of super-cell $m$ at HFP and CZP.

4.1.5.2 Burned Central Block. The normalized neutron flux per unit lethargy for the burned-fuel super-cells is shown for Exercise $2 \mathrm{~b}$ (Figure 39) and super-cells $b$ (Figure 40), $d$ (Figure 41), $g$ (Figure 42), $h$ (Figure 43), and $j$ (Figure 44).

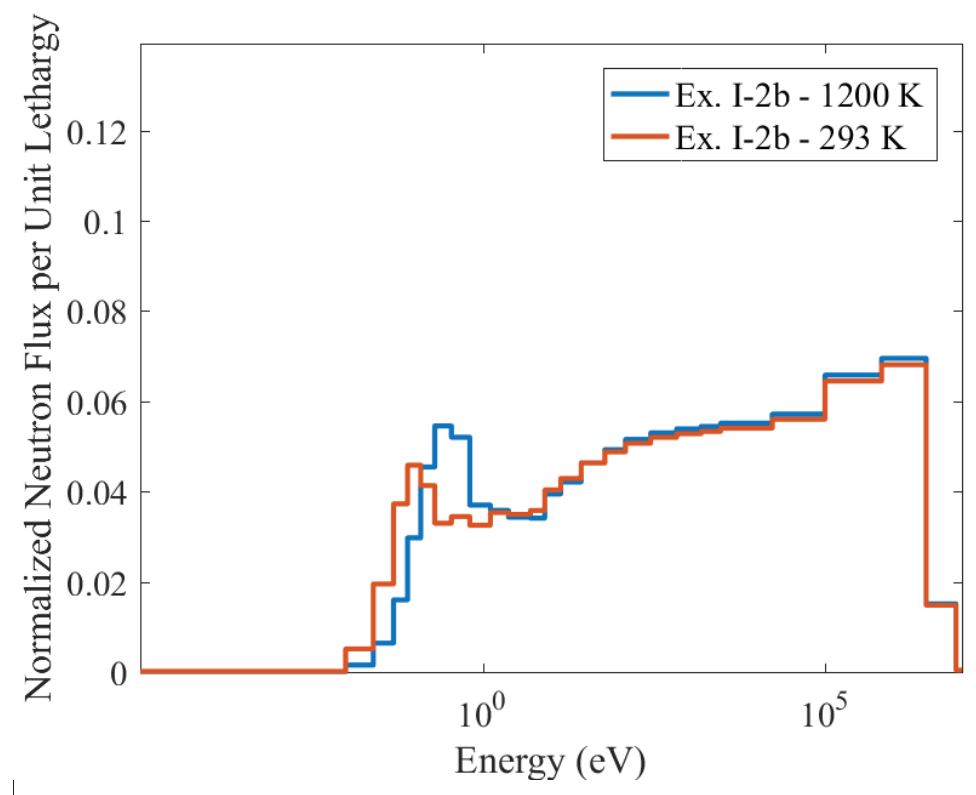

Figure 39. Comparison of the normalized neutron flux per unit lethargy of Exercise $2 b$ at HFP and CZP. 


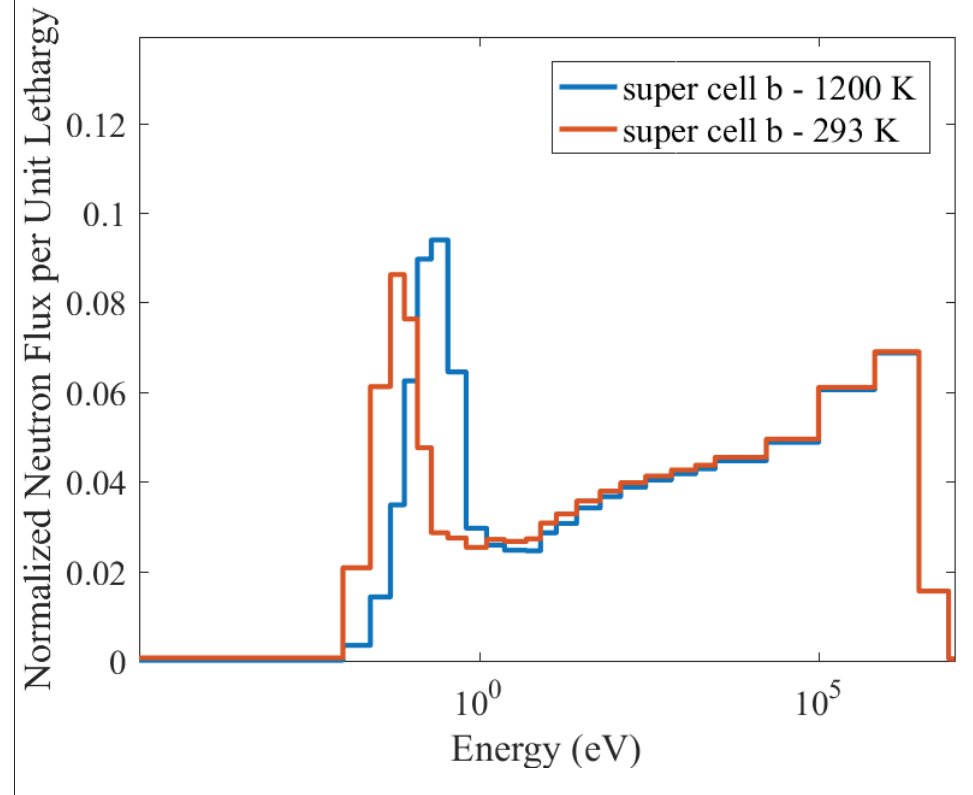

Figure 40. Comparison of the normalized neutron flux per unit lethargy of super-cell $b$ at HFP and CZP.

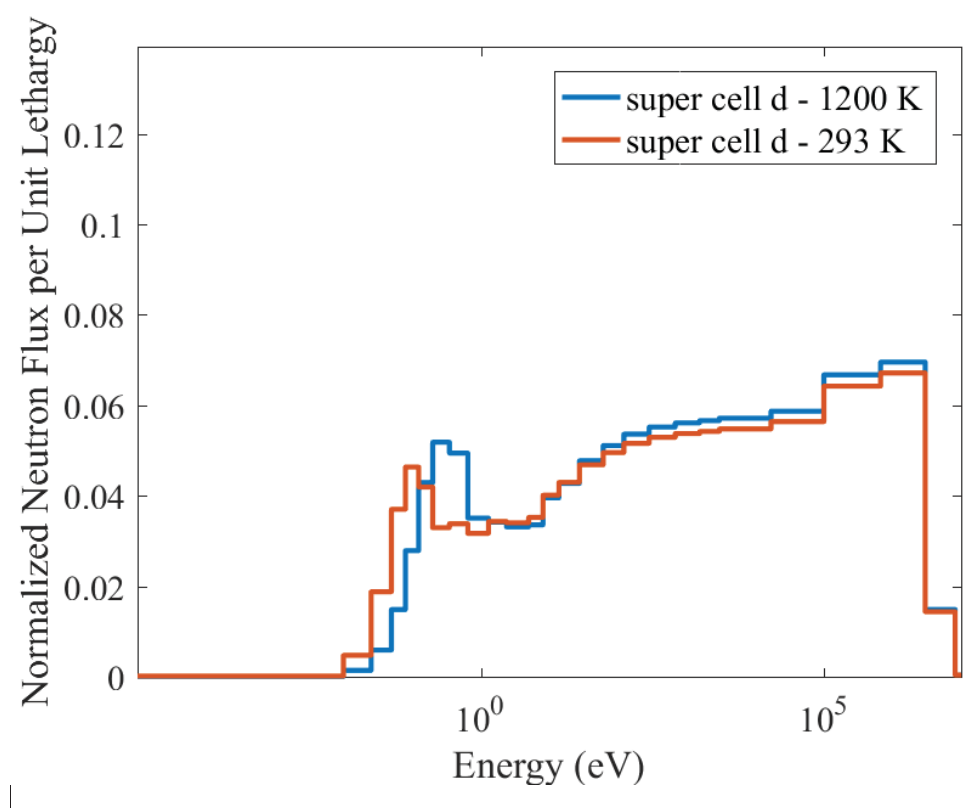

Figure 41. Comparison of the normalized neutron flux per unit lethargy of super-cell $d$ at HFP and CZP. 


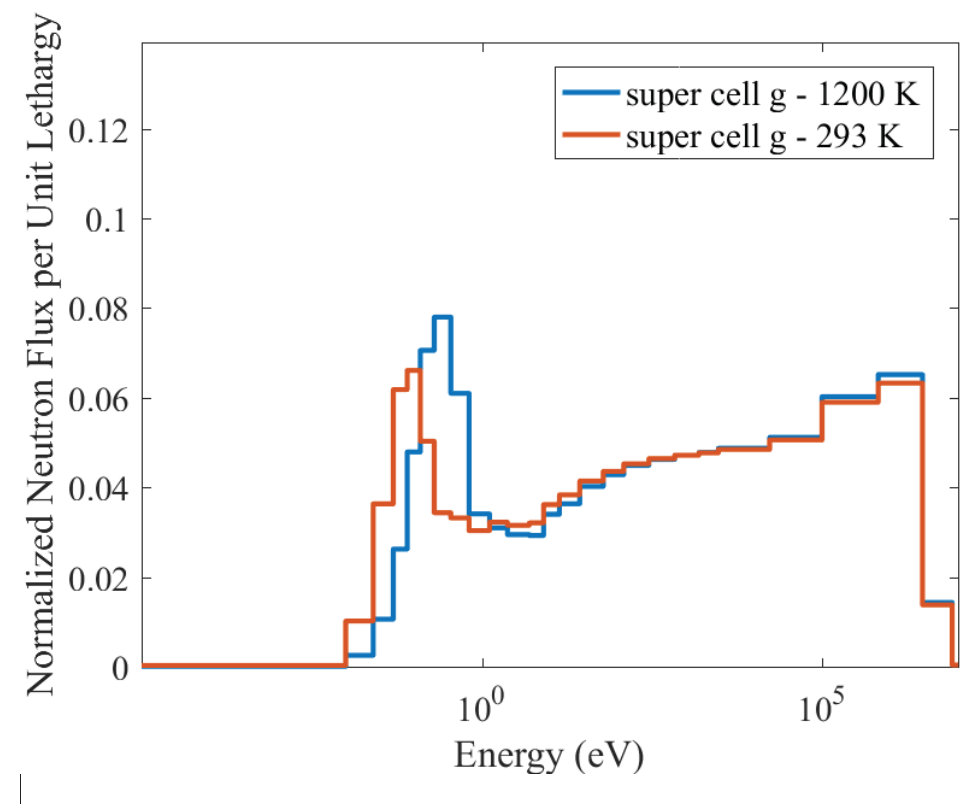

Figure 42. Comparison of the normalized neutron flux per unit lethargy of super-cell $g$ at HFP and CZP.

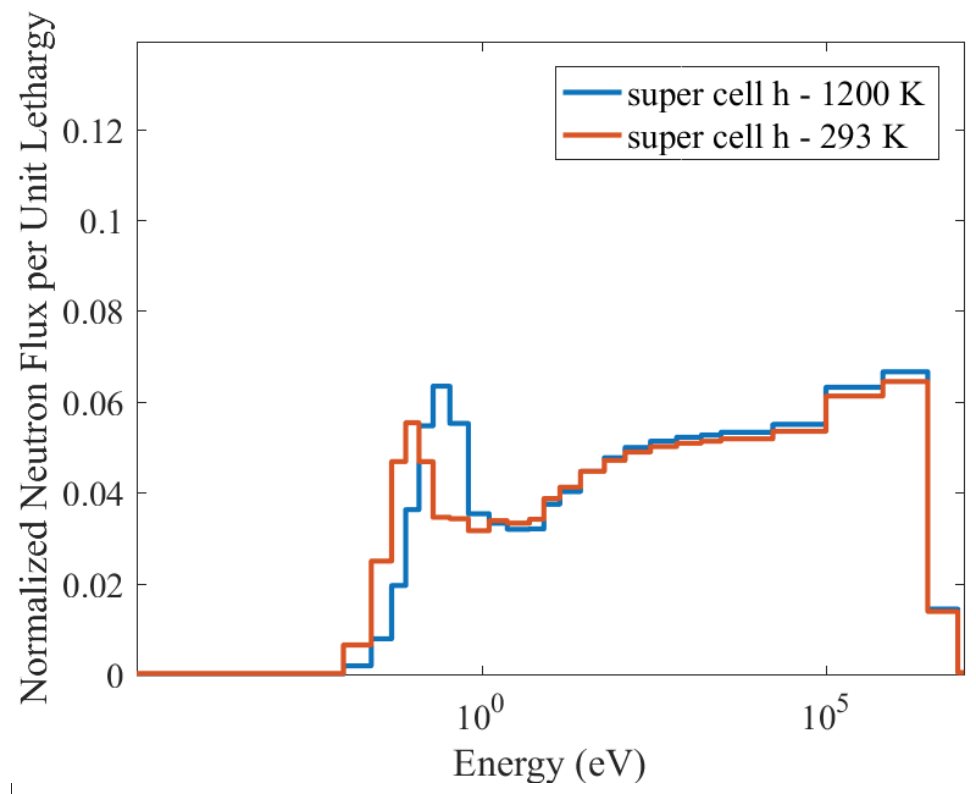

Figure 43. Comparison of the normalized neutron flux per unit lethargy of super-cell $h$ at HFP and CZP. 


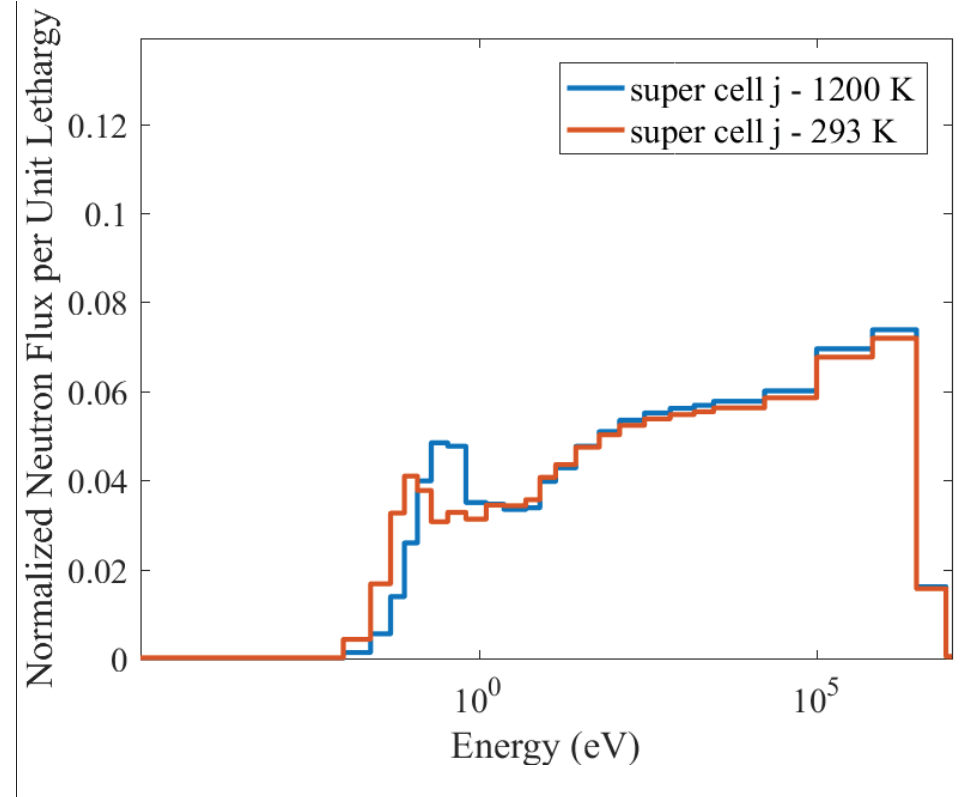

Figure 44. Comparison of the normalized neutron flux per unit lethargy of super-cell $j$ at HFP and CZP.

In the case of the central blocks filled with burned fuel, the neutron spectra appear softer overall at CZP than HFP. As with the fresh super-cells, the softening effect becomes less and less pronounced as the moderator-to-fuel ratio increases. The reflector-free super-cell spectra tend to be slightly softer at CZP than at HFP.

\subsubsection{Description of Model}

\subsection{Super-cells Surrounded by Six Homogenized Regions}

The purpose of the analysis in this section is to evaluate in more detail the influence of the homogenization scheme on the infinite multiplication factor and neutron flux spectra, and to explain some of the discrepancies observed in the super-cell model. This analysis is carried out only for the HFP condition. Unlike the approach followed in Subsection 4.1, the central heterogeneous block of the supercell is surrounded by six independent homogenized regions composed of fresh fuel, burned fuel, or graphite. The composition and design of the super-cells remain based on a heterogeneous central block coated by its six immediate neighbors found in the core arrangement. The layout of these super-cells for Exercise I-2c, as generated by NEWT's and KENO-VI's geometry generators, is shown in Figure 45.

It is intended to verify that the differences in the multiplication factors of super-cells $c$ versus $c$-beta, and $d$ versus $d$-beta are actually due to the homogenization of the surrounding blocks into a three-blocked north and south region. The second topic of interest is to evaluate whether NEWT and KENO-VI show better agreement than the two-homogenized-region model described in Subsection 4.1 if the super-cell is constructed in a more explicit way. In addition to the comparisons of super-cells $c$ versus $c$-beta and $d$ versus $d$-beta, a reduced set of super-cells is considered, ruling out the fresh-fuel-only $(i, l, m)$ and burnedfuel-only $(j)$ super-cells. A third part is focused on the flux spectra differences in the two-region model versus the six-region model.

\subsubsection{Criticality Calculations}

The NEWT and KENO infinite multiplication factors for the different super-cells at HFP conditions are presented in Table 10. 

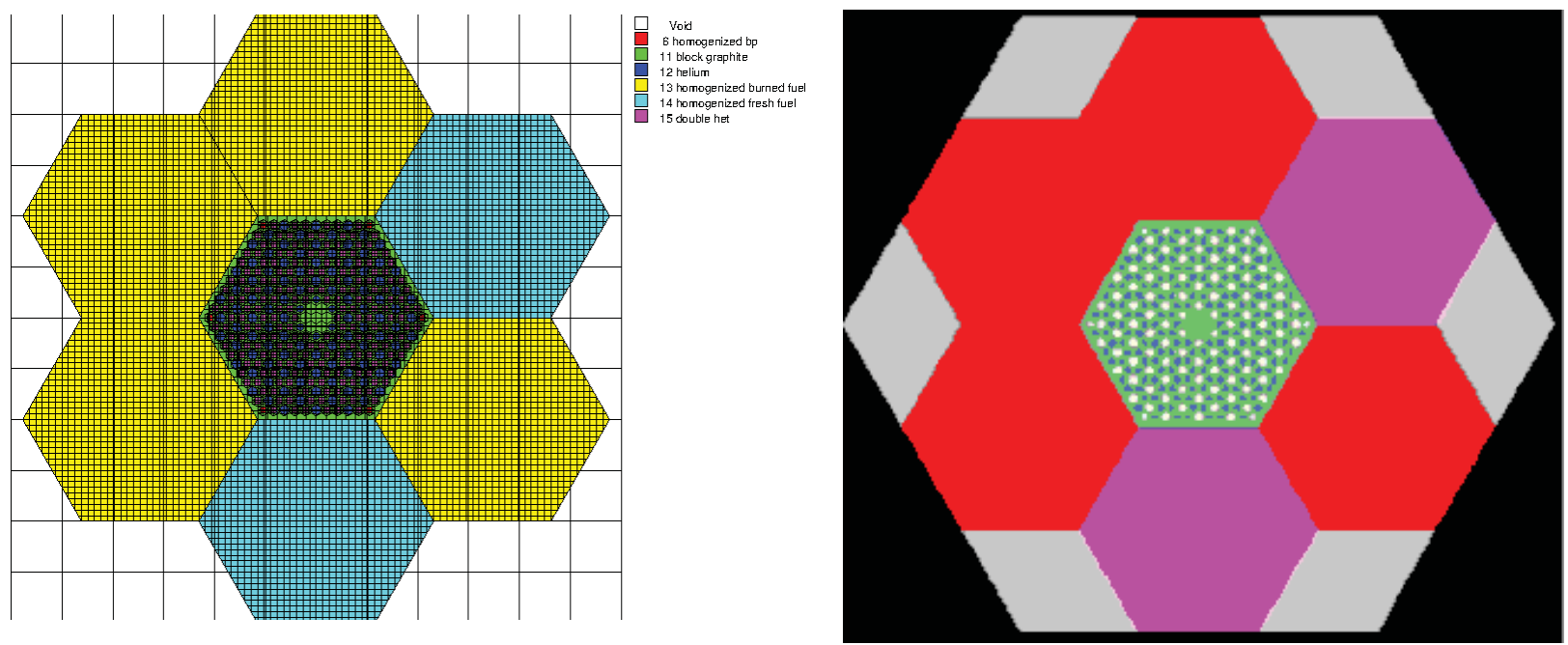

Figure 45. Plots of super-cell $c$ generated by NEWT (left) and KENO-VI (right) for the six homogenized regions.

Table 10. Infinite multiplication factors computed by NEWT and KENO-VI for the six-region model. Explicit BPs in KENO-VI.

\begin{tabular}{|c|c|c|c|c|}
\hline \multirow[b]{2}{*}{ Super-cell } & \multirow{2}{*}{$\begin{array}{c}\text { NEWT } \\
\begin{array}{c}\text { k-infinity } \\
(-)\end{array}\end{array}$} & \multicolumn{2}{|c|}{ KENO } & \multirow[b]{2}{*}{$\begin{array}{l}\text { Absolute Difference } \\
\qquad(\mathrm{pcm})\end{array}$} \\
\hline & & $\begin{array}{l}\text { k-infinity } \\
(-)\end{array}$ & $\begin{array}{c}\text { Standard } \\
\text { Deviation } \\
(\mathrm{pcm})\end{array}$ & \\
\hline$a$ & 1.11143 & 1.09460 & 13 & 1,683 \\
\hline$b$ & 1.24254 & 1.21928 & 13 & 2,326 \\
\hline$c$ & 0.98489 & 0.97655 & 12 & 834 \\
\hline c-beta & 0.98456 & 0.97636 & 12 & 820 \\
\hline$d$ & 1.08750 & 1.07440 & 13 & 1,310 \\
\hline$d$-beta & 1.08706 & 1.07431 & 13 & 1,276 \\
\hline$e$ & 1.06696 & 1.05579 & 11 & 1,117 \\
\hline$f$ & 1.09448 & 1.09172 & 13 & 276 \\
\hline$g$ & 1.23933 & 1.22137 & 14 & 1,796 \\
\hline$h$ & 1.22967 & 1.21855 & 13 & 1,112 \\
\hline$k$ & 1.28864 & 1.27173 & 13 & 1,691 \\
\hline
\end{tabular}

The multiplication factors in super-cells $c$, c-beta, $d$, and $d$-beta show that the homogenization scheme for two identical super-cells can introduce a difference of around 2,000 pcm. The discrepancies also exist when the homogenization of the regions is changed from two to six regions. Table 11 presents a comparison 
of the multiplication factors between the six-region models in NEWT and KENO where the BPs have been smeared out in an identical manner.

Table 11. Infinite multiplication factors computed by NEWT and KENO-VI for the six-region model. Homogenized BPs in KENO-VI.

\begin{tabular}{|c|c|c|c|c|}
\hline \multirow{2}{*}{ Super-cell } & NEWT & \multicolumn{2}{|c|}{ KENO } & \multirow{2}{*}{ A-infinity } \\
\cline { 2 - 5 }$(-)$ & $\begin{array}{c}\text { k-infinity } \\
(-)\end{array}$ & $\begin{array}{c}\text { Standard } \\
\text { Deviation } \\
(\mathbf{p c m})\end{array}$ & $\begin{array}{c}\text { Absolute Difference } \\
\text { (pcm) }\end{array}$ \\
\hline$a$ & 1.11143 & 1.08577 & 13 & 2,566 \\
\hline$b$ & 1.24254 & 1.21933 & 13 & 2,321 \\
\hline$c$ & 0.98489 & 0.97351 & 13 & 1,138 \\
\hline$c$-beta & 0.98456 & 0.97359 & 11 & 1,097 \\
\hline$d$ & 1.08750 & 1.07431 & 12 & 1,320 \\
\hline$d-b e t a$ & 1.08706 & 1.07431 & 11 & 1,741 \\
\hline$e$ & 1.06696 & 1.04955 & 13 & 741 \\
\hline$f$ & 1.09448 & 1.08707 & 15 & 1,792 \\
\hline$g$ & 1.23933 & 1.22141 & 14 & 1,142 \\
\hline$h$ & 1.22967 & 1.21825 & 14 & 2,667 \\
\hline$k$ & 1.28864 & 1.26197 & 13 & \\
\hline
\end{tabular}

The agreement with NEWT is not improved if the BP's topology is identical in both the NEWT and KENO model. The influence of the homogenization of the BPs is given in Table 12. It can be seen that the homogenization of the BPs has a higher influence on the model if the moderator nuclide inventory increases (see super-cells $a, k, l$, and $m$ ). This softens the spectrum and increases the importance of boron in the absorption rate. The absolute difference in the multiplication factor induced by the homogenization of the BPs is significantly lower in burned-fuel super-cells $(b, d, d$-beta, $g, h$, and $j)$ and independent of the moderation, because all of the BPs were depleted. It does not matter then how the BPs are modeled for burned-fuel super-cells.

The results obtained with the six-region model remain very similar to the two-region model and do not seem to results in any improvement. The computation time remains equivalent as well, but the complexity of the input is enhanced in the six-region configuration. Because the multiplication factor is only an integral result, the neutron flux is compared in the next section between the two models to evaluate the potential change in the nuclear data generation.

\subsubsection{6-Group Neutron Flux Differences for the Super-cells' Central Block}

The differences between the neutron flux profiles in the super-cells' heterogeneous central block obtained in a two-homogenized-region model versus a six-homogenized-region model are shown in this subsection. The relative differences between two models are summarized in Figure $46(a, c, e, f$, and $i$ ), Figure $47(I, k, l$, and $m)$, and Figure $48(b, d, g, h$, and $j)$, respectively, for the fresh super-cells. 
Table 12. Influence of the homogenization of the BPs obtained with KENO-VI.

\begin{tabular}{|c|c|c|c|}
\hline Super-cell & $\begin{array}{c}\text { KENO Heterogeneous } \\
\text { BP }\end{array}$ & $\begin{array}{c}\text { KENO Homogeneous } \\
\text { BP }\end{array}$ & $\begin{array}{c}\text { Absolute Difference } \\
\text { (pcm) }\end{array}$ \\
\hline$a$ & 1.09460 & 1.08577 & 883 \\
\hline$b$ & 1.21928 & 1.21933 & -5 \\
\hline$c$ & 0.97655 & 0.97351 & 304 \\
\hline$c-b e t a$ & 0.97636 & 0.97359 & 277 \\
\hline$d$ & 1.07440 & 1.07431 & 9 \\
\hline$d-b e t a$ & 1.07431 & 1.07431 & 624 \\
\hline$e$ & 1.05579 & 1.04955 & 465 \\
\hline$f$ & 1.09172 & 1.08707 & -4 \\
\hline$g$ & 1.22137 & 1.22141 & 30 \\
\hline$h$ & 1.21855 & 1.21825 & 976 \\
\hline$k$ & 1.27173 & 1.26197 & \\
\hline
\end{tabular}

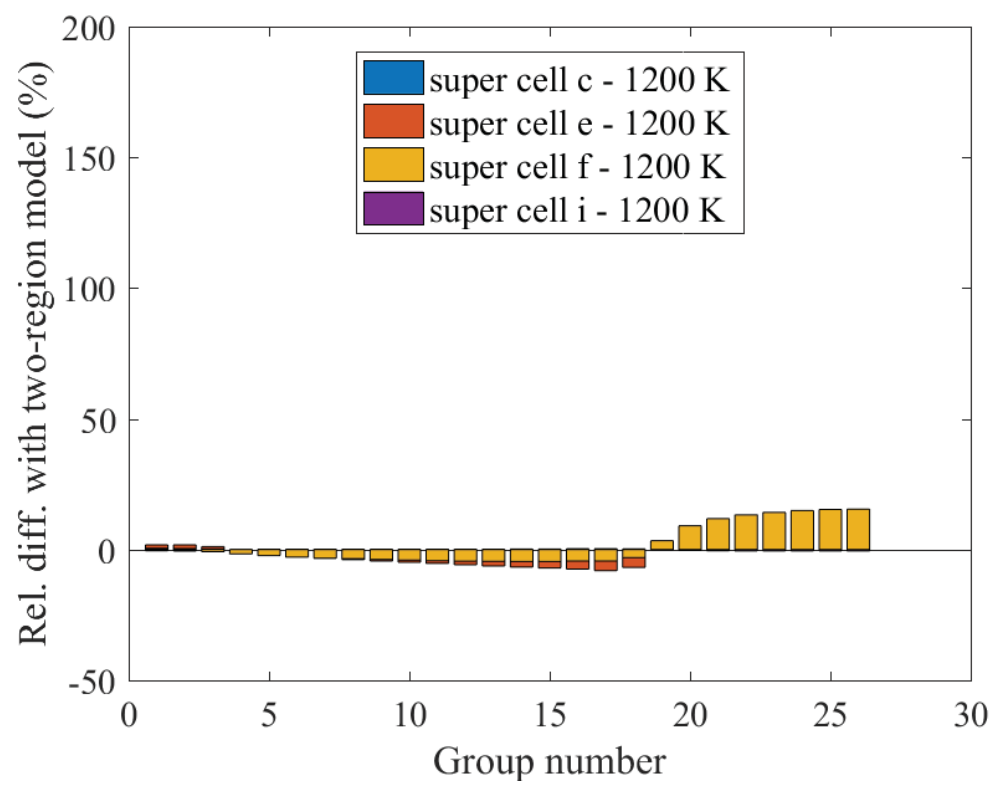

Figure 46. Relative difference (in \%) of neutron flux profiles of two versus six homogenized regions in the fresh-fuel super-cells $c, e, f$, and $i$.

The neutron flux variation between the two models is negligible when the surrounding regions are not made of pure graphite. The spatial contribution of graphite does not vary from the two-region to the six-region models when the north or south region of the two-region model is only made of graphite (supercells $a, b$, and $k$ ). In the remaining super-cells $(e, f, g, h, l$, and $m)$, the homogenization of the graphite in the two-region model distributes the graphite over the north and/or the south region, which explains the more significant flux variations between the two models. The relative flux differences remain relatively small in all cases. A similar observation is valid in the burned-fuel super-cell. The neutron flux in super- 
cell $h$ is the most perturbed, while all of the other super-cells conserve a similar neutron flux behavior as compared to the two-region model.

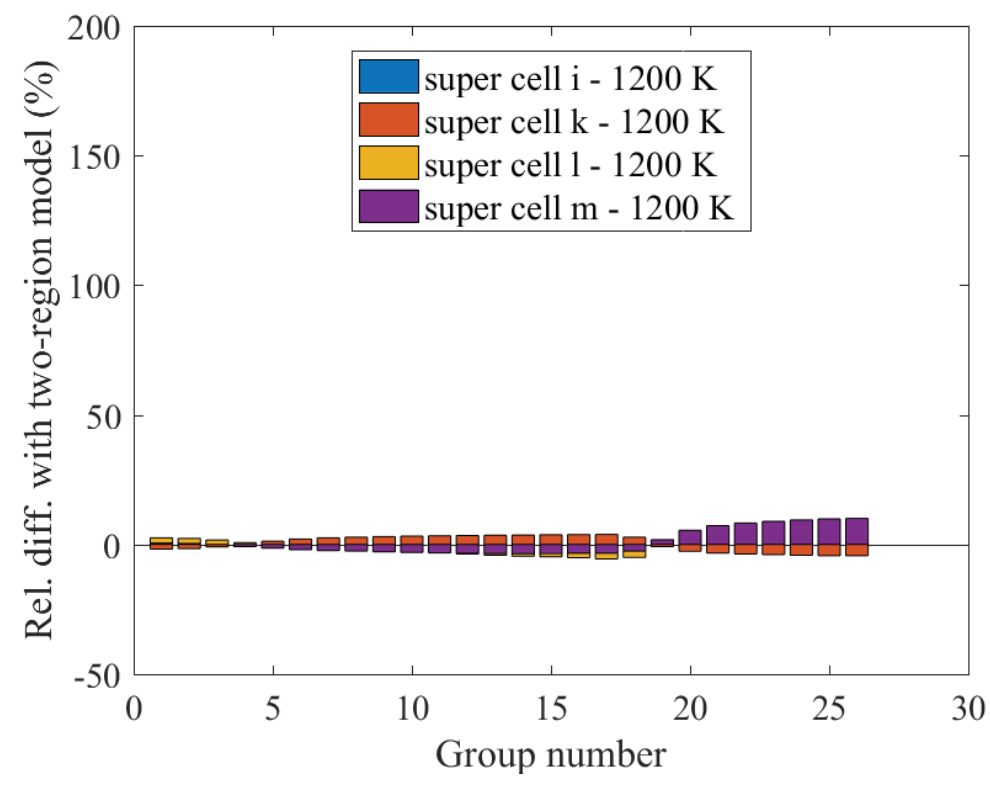

Figure 47. Relative difference (in \%) of neutron flux profiles of two versus six homogenized regions in the fresh-fuel super-cells $i, k, l$, and $m$.

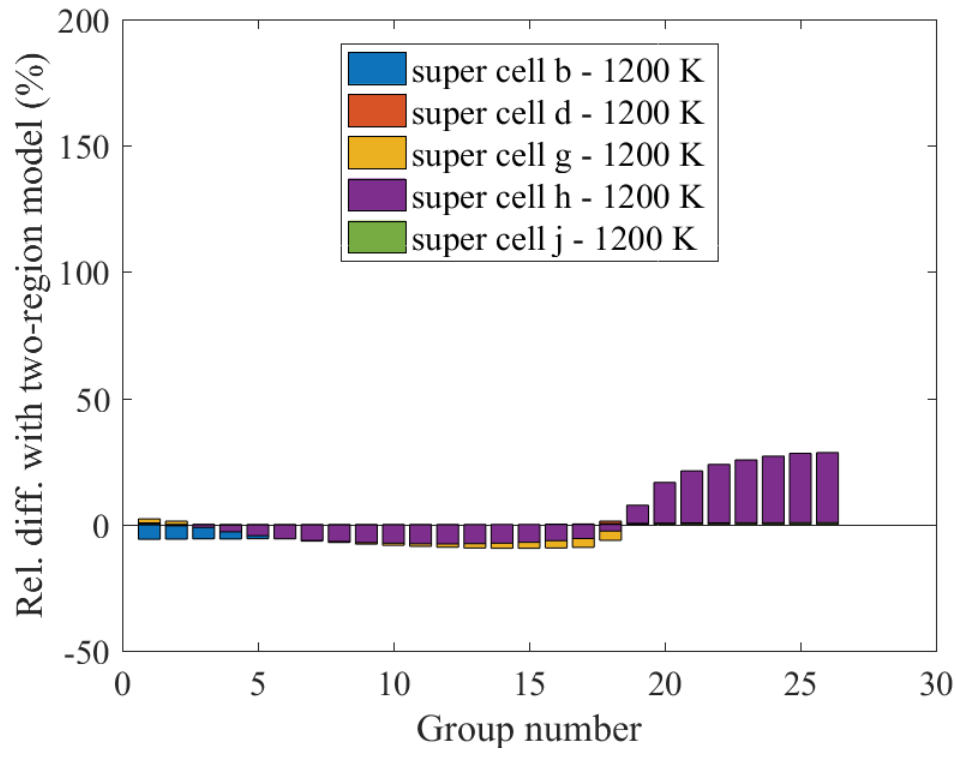

Figure 48. Relative difference (in \%) of neutron flux profiles of two versus six homogenized regions in the fresh-fuel super-cells $b, d, g, h$, and $j$.

Overall, the six-region model slightly improves the accuracy of the cross sections for super-cells having one graphite block surrounding the central block (typically super-cell $f$ or $h$ ). But it is important to remember that cross sections obtained from these super-cells are only intended to be used at a few locations in the core. Referring to Figure 2, super-cell $f$ 's cross sections correspond only to Block 11 in the one-third core. The additional accuracy brought by such a model is entirely trumped by other design choices, such as 
the reflector cross-section generation. As concluded in Subsection 4.2.2, the six-model region does not improve the model enough (if not at all) to justify its use over the two-region model, considering the increased complexity of the model.

\subsection{Heterogeneous Super-cell Surrounded by Heterogeneous Blocks}

\subsubsection{Description of Model}

It has been established that the neutron flux profile is relatively softer in the super-cell than the singlefuel blocks. It has also been proved that the neutron flux profile at the center of the super-cell depends only weakly on the homogenization scheme of the super-cells and depends strongly on the super-cells' composition. Because a realistic neutron flux is a necessary condition for generating the nuclear data libraries, the last step of the analysis consists of the comparison of a fully heterogeneous super-cell to the previous models. Such a detailed model is usually beyond the scope of normal lattice calculations, which aim to make use of approximations to simplify the hundreds of fine-group transport calculations typically required.

The cost of a fully heterogeneous calculation increases greatly ( $\sim 12$ hours for the heterogeneous case versus 4.5 hours for the homogeneous case). Only the neutron flux profile of one super-cell is therefore investigated in this subsection instead of the entire set of super-cells. Super-cell $k$ (Figure 49) at HFP conditions is chosen for this analysis, using fresh fuel only. The reflector's cross sections are obtained from the north region of super-cell $k$ in order to be able to evaluate the differences between KENO and NEWT, and also with PHISICS/RELAP5-3D when the NEWT-generated cross sections are packed in a third-core model.

The geometry plots generated by NEWT and KENO-VI are provided in Figure 50. The BP compacts are not removed from the peripheral heterogeneous fuel blocks, i.e., the four fresh blocks are identical, and all of them contain BP compacts.

The infinite multiplication factor obtained at HFP with both NEWT and KENO-VI for the heterogeneous fresh-fuel super-cell is shown in Table 13. Because NEWT is a two-dimensional code, the TRISO particles containing the BPs have been homogenized with the carbon-graphite matrix in the six corners allocated to the BP channels. Hence, KENO-VI's and NEWT's modeling of the BPs differ in terms of geometry.

The results are not directly compared to the two-homogenized-region super-cells, because the addition of the BPs to the four heterogeneous fuel blocks resulted in a multiplication factor that is significantly smaller in this fully heterogeneous case (1.09273 - Table 13) as compared to the two-homogenized-region model (1.27004 - Table 5) and the six-region model (1.28864 - Table 10). As a reminder, the BPs in the two-region model (Subsection 4.1) were removed from the homogenized regions in order to avoid spreading the boron over the whole super-cell volume. In the case of the heterogeneous super-cell k, the BPs are conserved to obtain a model that matches the actual fuel and core design as much as possible. It is also important to remember that due to the self-shielding effects in the homogenized regions in the two-region homogeneous case, the infinite multiplication factor would not be comparable to the heterogeneous super-cell even if the BP inventory was conserved. Additionally, the multiplication factor is only a preliminary check and does not symbolize a parameter of interest in the analysis; the nuclear data and consequently the neutron flux are the key FOMs of the NEWT calculation.

The infinite multiplication factor between NEWT and KENO-VI does not show a better agreement in the heterogeneous case $(1,795 \mathrm{pcm}$ - Table 13$)$ than the two-region heterogeneous case $(1,237 \mathrm{pcm}$ - Table $5)$ or the six-region model $(1,691 \mathrm{pcm}-$ Table 10). No new conclusions can therefore be reached from this data point alone. An investigation of the neutron flux obtained is carried out next in section 4.3.2. 


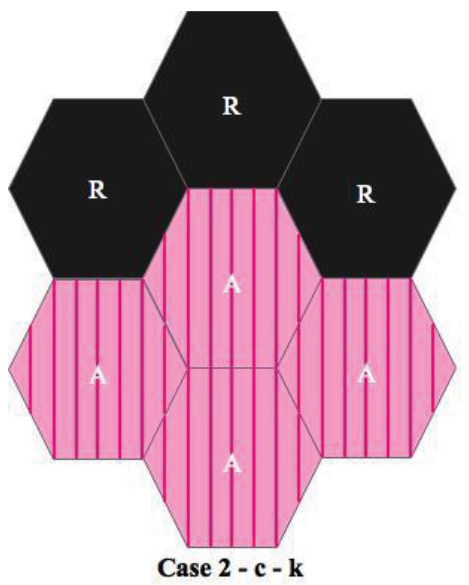

Figure 49. Diagram of the heterogeneous version of super-cell $k$.
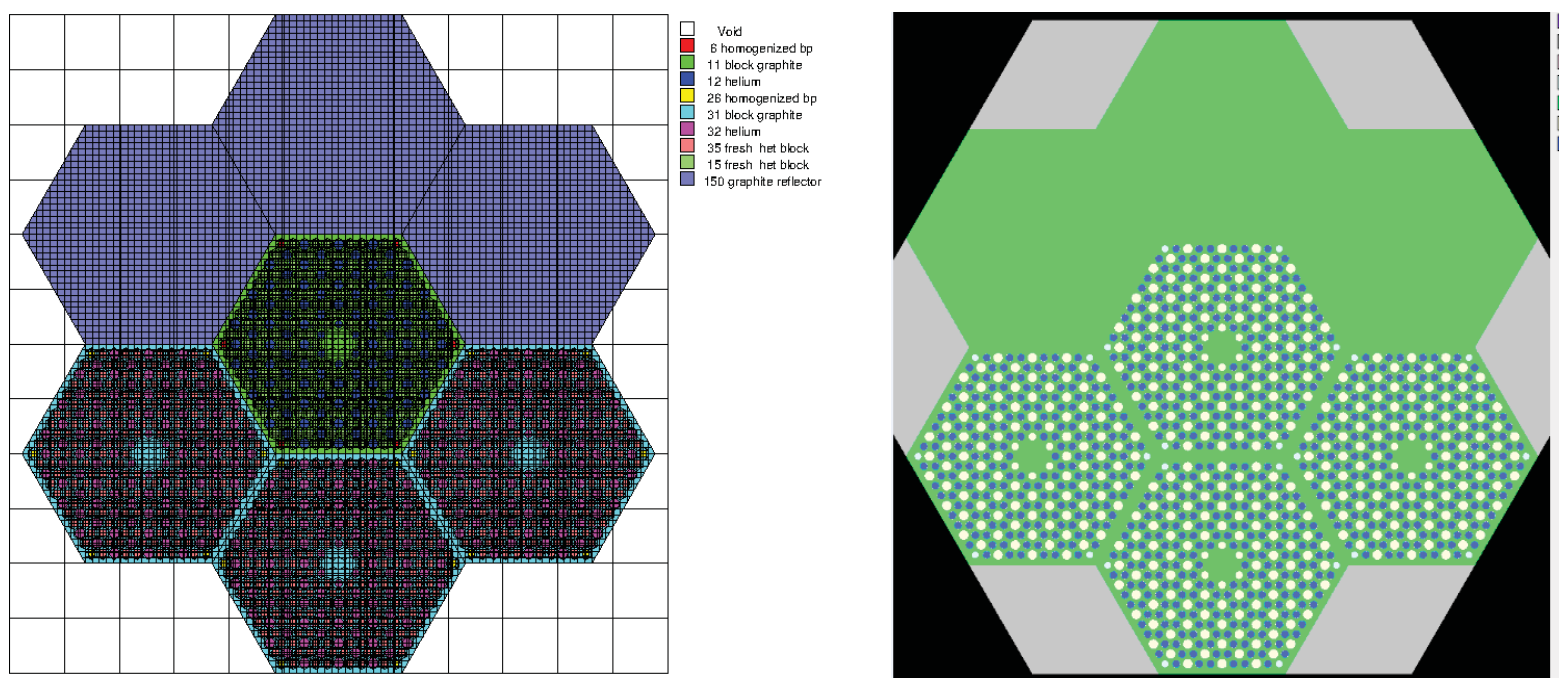

Figure 50. Geometrical layout of the heterogeneous super-cell $k$ generated by NEWT (left) and KENO-VI (right).

Table 13. Infinite multiplication factor computed by NEWT and KENO for heterogeneous super-cell $k$.

\begin{tabular}{|c|c|c|c|c|}
\hline \multirow[b]{2}{*}{ Super-cell } & \multirow{2}{*}{$\begin{array}{c}\text { NEWT } \\
\text { k-infinity } \\
(-)\end{array}$} & \multicolumn{2}{|c|}{ KENO-VI } & \multirow{2}{*}{$\begin{array}{c}\text { Absolute Difference } \\
\text { KENO/NEWT } \\
(\mathrm{pcm})\end{array}$} \\
\hline & & $\begin{array}{c}\text { k-infinity } \\
(-)\end{array}$ & $\begin{array}{l}\text { Standard Deviation } \\
(\mathrm{pcm})\end{array}$ & \\
\hline$k_{\text {het }}$ & 1.09273 & 1.11068 & 14 & $-1,795$ \\
\hline
\end{tabular}

\subsubsection{Neutron Flux Profile of Super-cells' Central Block in 26-Group Structure}

The neutron flux profile of the heterogeneous super-cell $k$ is compared to the previous flux profile obtained for a two-homogenized-region case (referred to as " $k$ " on the plot) and a fresh single block (Figure 51). The comparison of the results in the two-region and six-region model for super-cell $k$ shows that flux profiles differ only by at most $2.3 \%$ (see Figure 47 ) in the 26 groups of interest, which is why the neutron flux profile of the six-region model has not been plotted on Figure 51. 


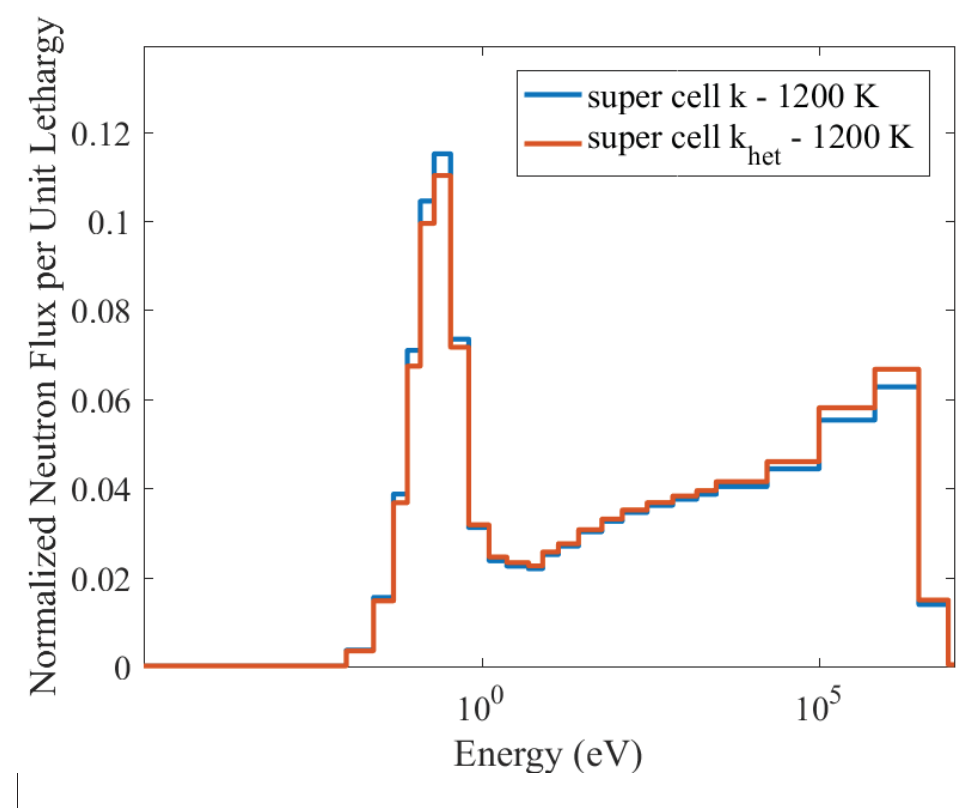

Figure 51. Normalized neutron flux per unit lethargy of super-cells $k$ and $k$ het and Exercise 2a.

The neutron fluxes in the homogeneous and heterogeneous super-cells $k$ are rather similar, which implies that the homogenization around the central block does not have a significant effect on the spectrum at the center.

\subsection{Conclusion: Lattice Calculations}

The super-cell model improves (softens) the neutron flux obtained in the central block as compared to a single-block model, because the super-cell model is a more realistic representation of the graphite-dominated, full-core spectrum. Considering the locations of fuel blocks in a whole-core situation, it seems clear that the prismatic blocks are spatially subject to various neutron spectra that are radially softer in the periphery of the core's fuel ring and harder at the center of the core's fuel region. Increasing the number of super-cell configurations by varying the central block's environment is therefore one way to improve the accuracy of the lattice nuclear data generated in the AMPX working library format that will be used in the core simulations.

The following conclusions are drawn based on the material presented in section 4 :

- The modeling approach and topology of the super-cell has a weak influence on the resulting flux spectrum at the center of the super-cell. The two-region, six-region, or fully heterogeneous models provide comparable neutron flux spectra in the central block. The computing time greatly increases if a fully heterogeneous model is adopted, so this is not recommended. Considering the comparable running time, the two- or six-region models are both valid choices.

- The neutron flux in the central block depends strongly on the super-cell nuclide inventory, i.e. the composition of the north and south regions. The major parameter that governs the neutron flux is the fuel-to-moderator ratio. The second parameter to account for is the fresh-to-burned fuel ratio, especially at HFP conditions with the different behavior of the Doppler effect.

It can also be concluded that it is not be necessary to generate all 17 possible super-cell configurations. Based on the data obtained for the neutron flux spectra, it seems reasonable to conclude that a reduced set of super-cells can capture most, if not all, of the spectral variations over the core region. The suggested combination of super-cells for the fresh and mixed core configurations can be reduced to four and seven super-cells each, as listed below. 
- Fresh core (four super-cells): For a fresh core, it would be sufficient to select only the fresh single block I-2a to represent a fresh fuel block surrounded by other fuel bocks (blocks 15-17, 19-21 in the bottom right numbering of Figure 52). The cross-sections required for the peripheral fuel blocks [23, $28,31]$ and $[8-14,18,24,25,29,30]$ can be obtained using super-cells $k$ and $l$, respectively. The reflector cross-sections for blocks $1-7,22,27$ and 32-91 can be generated from super-cell $s$. The application of these reflector cross-sections for blocks 1-3 and 44-91 is clearly a simplification that needs to be assessed, since these blocks are fully surrounded by other graphite blocks. The generation of cross-sections for the blocks in the side reflector that contains the control rods are likewise not discussed here; as a minimum one borated and one empty control rod cross-section set would be required.
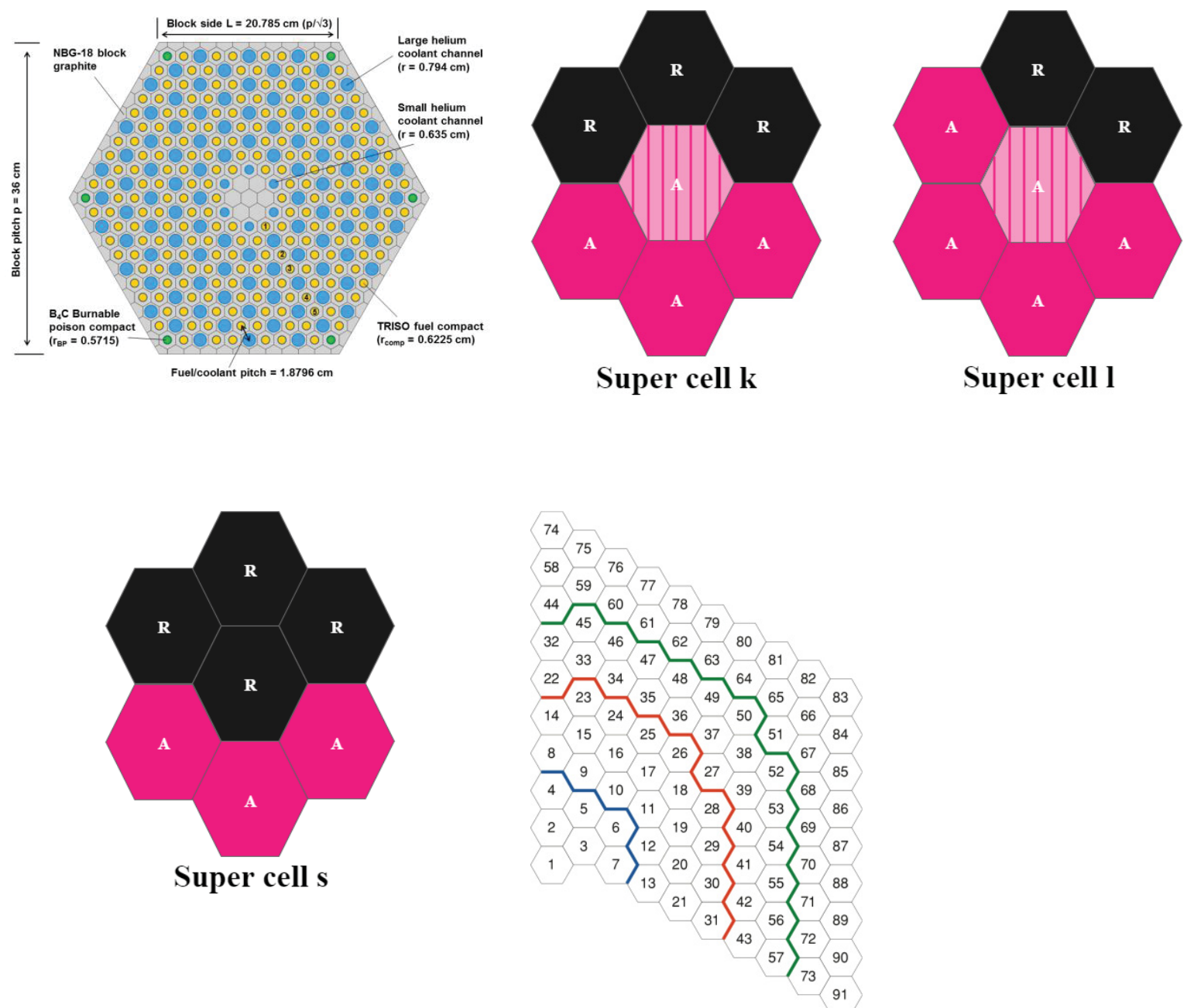

Figure 52. Lattice cells selected for fresh full core simulation

- Mixed core (seven super-cells): For a mixed fresh and depleted core, the fresh I-2a $(15,17,19,21)$ and depleted I-2b $(16,20)$ single blocks can be used for the central fuel region cross-sections, if a simplified approach is desired. The five super-cells a $(26), \mathrm{b}(23,28)$, e $(9,11,13,24,29,31) \mathrm{g}(8,10$, $12,14,25,30)$, and $\mathrm{r}(1-7,22,27,32-91)$ can be used to represent the remaining peripheral fuel block and the reflector cross sections. 


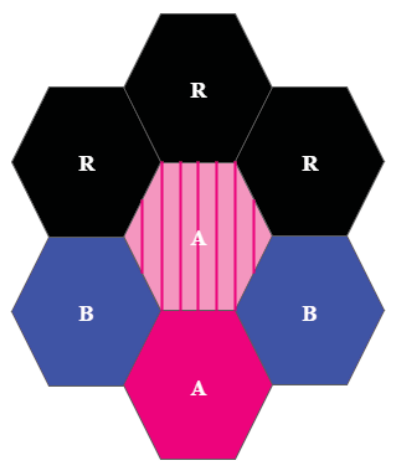

Super cell a

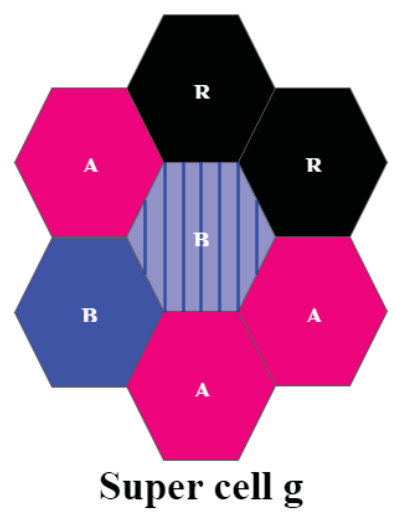

Figure 53. Lattice cells selected for mixed full core simulation. Fresh (A) and depleted (B) mixed core

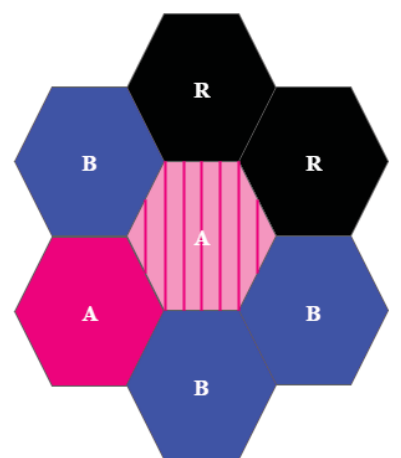

Super cell e
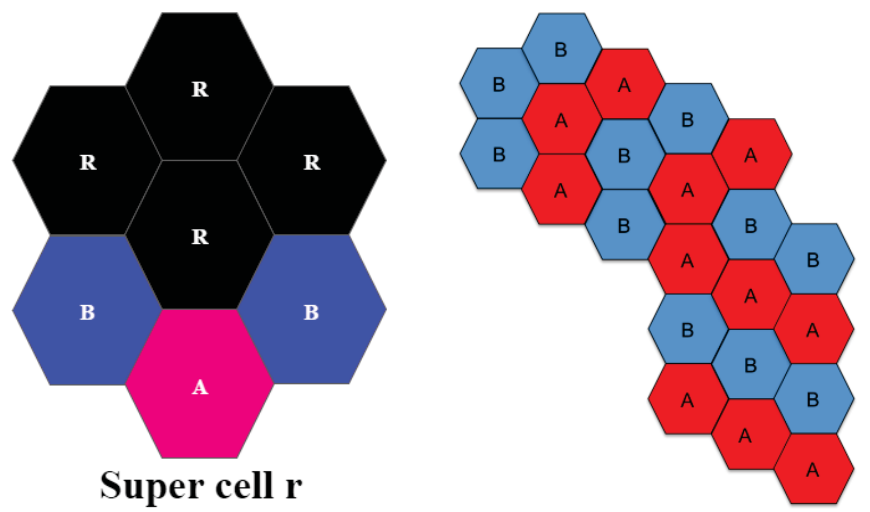

\section{loading shown in bottom right.}

\section{PHASE II CORE CALCULATIONS: EXERCISE II-1a}

This section describes calculations that used the cross-section libraries generated by NEWT in the PHISICS/RELAP5-3D one-third core model simulation of the MHTGR-350 design. Three important aspects should be noted.

First, the CRP prismatic specifications for Phase II do not yet exist. This study is, in effect, the start of the specification process, i.e., it forms part of the INL pre-specification contribution to ensure that certain aspects are explored before the first draft of Phase II is released to the CRP group.

Second, the scope of this work is such that most of the focus for these studies in 2015/2016 was on the lattice calculations. This core simulation section should therefore be seen as an introduction to a larger effort that will continue over the next few years at INL if sufficient funding can be maintained. All of the results presented here are for nominal (best-estimate) input values only, i.e., the actual uncertainty propagation work will only start once these modeling issues and approach have been settled.

Third, the MHTGR-350 has been analyzed at INL as part of the OECD/NEA MHTGR-350 benchmark since 2011 [5,10]. The CRP on HTGR UAM utilizes the same core model for the Phase II simulations. The major difference is that the OECD/NEA benchmark used cross-section data prepared with the DRAGON code, whereas the INL's contribution to Phase II of this CRP will use the SCALE/NEWT-generated data. A future one-third SERPENT model of the full MHTGR-350 core is also planned as a reference solution, but it does not have the highest priority at this stage.

The PHISICS/RELAP5-3D one third model is analyzed at the equilibrium HFP conditions, with the temperature profile shown in Figure 54. In Figure 54, the axial profiles are shown for the inner reflector, fuel region, outer reflector, and permanent reflector rings. The bottom of the core is defined at $0 \mathrm{~cm}$, and 
the top of the core is located at $1,090 \mathrm{~cm}$. Because all calculations in this report use the same PHISICS/RELAP5-3D model, relative comparisons of the various super-cell cross-section sets can be compared. This equilibrium model will also be used for Exercise III-1 (coupled steady state). For the stand-alone neutronics Exercise II-1, two isothermal CZP and HFP PHISICS/RELAP5-3D models were developed, but due to time restraints, these models were not yet used for the NEWT super-cell tests. An assessment of the isothermal cases is planned for 2017.

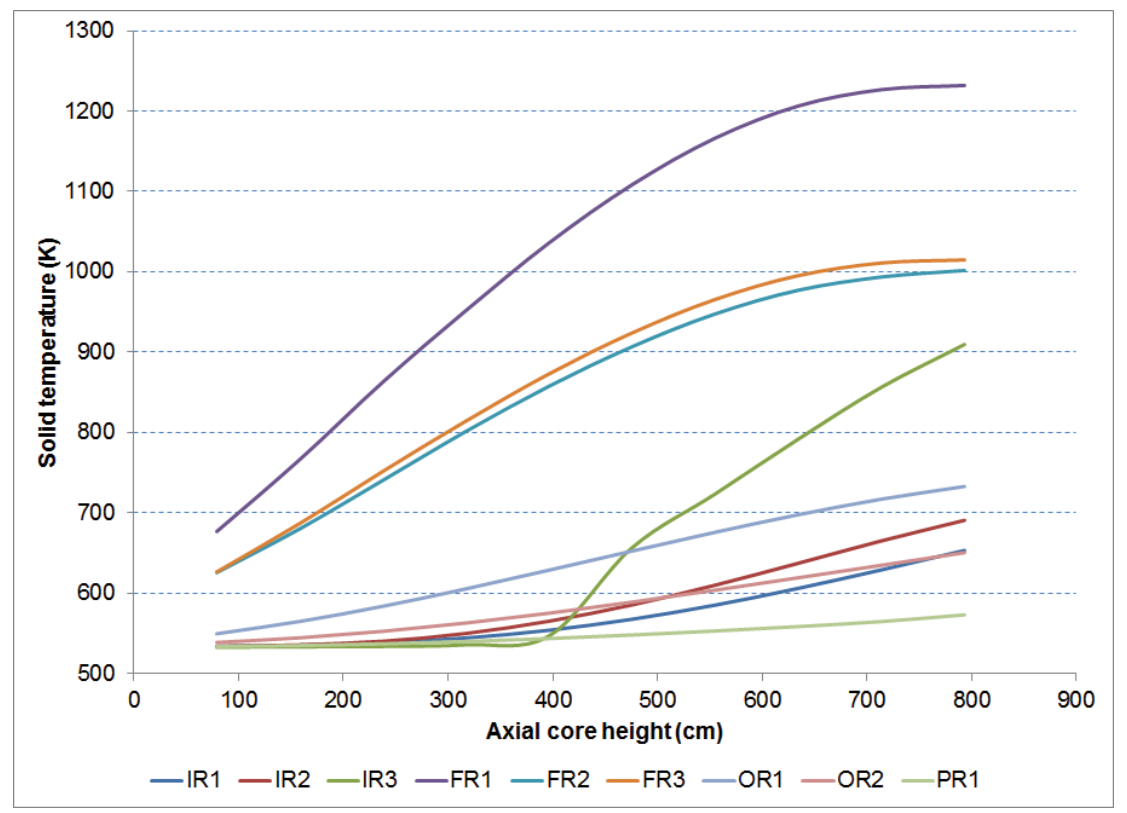

Figure 54. Axial temperature profiles in MHTGR-350 core and reflector regions (K).

In the OECD/NEA MHTGR-350 MW benchmark specification, the PHISICS model defines three graphite regions with unique cross-section sets: the inner replaceable reflector (Cross-Section [XS] Set 225), outer replaceable reflector (XS Set 226), and permanent reflector region (XS Set 227) (see Figure 55). For the scoping test reported in this study, only one cross-section set was applied to all three reflector regions (originating from super-cell $r$ ). This approach is acceptable for the blocks close to the fuel regions but could possibly be improved for the permanent reflector region (XS Set 227) at a later stage. 


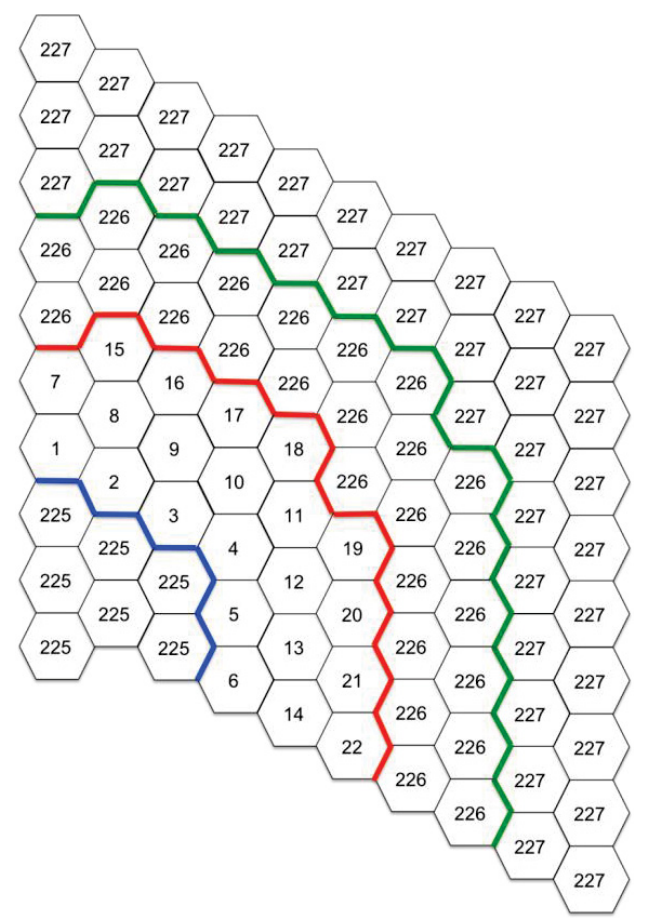

Figure 55. Cross-section numbering for Active Core Level 1.

\subsection{Description of PHISICS/RELAP5-3D Model}

In this subsection, no thermal feedback effects are taken into account, so that the temperature profile in RELAP5-3D will be fixed along the axial height of the core. As described in the previous sections, three methodologies have been selected for the AMPX working library format generation with NEWT in the double heterogeneous configuration. Because the super-cell including six homogenized regions and the fully heterogeneous model around the central block have been ruled out, only the cross sections generated through the two-region model will be implemented in PHISICS to perform the core calculations, in addition to the single-block model (Exercise $2 \mathrm{a}$ and $2 \mathrm{~b}$ )

The NEWT nuclear data of interest originate from the center of the super-cells, i.e. in the central heterogeneous block. The microscopic cross-section libraries generated by NEWT in 238 groups are collapsed into 26 groups and used as input to the PHISICS/RELAP5-3D core model. The flexibility of PHISICS is such that each spatial region defined in RELAP5-3D can be assigned to the cross-section library of the user's choice in PHISICS. In other words, each block can be assigned with a different cross-section library.

Due to PHISICS's geometry definition scheme, each prismatic block is defined by a homogenized nuclide density composition. This is much less of concern compared to the homogenization issues encountered in NEWT, because the microscopic cross sections used in PHISICS have been flux weighted by NEWT. There is one major difference to point out between the NEWT-modeled heterogeneous central block and the PHISICS-modeled homogenized blocks. In the PHISICS core, the BPs have been removed in order to avoid a spatial spreading of the boron all over the blocks and therefore all over the core, while in the fully explicit fresh core model, the BPs occupy discrete locations at the corner of a few specific blocks. This outstanding issue will be addressed at a later stage.

The core modeled in PHISICS/RELAP5-3D consists of 22 homogenized hexagonal fuel blocks. Six and one-third reflector blocks lay at the center of the core, and 60 reflector blocks are located on the outer perimeter of the third core. Each block is assigned a specific NEWT-generated cross-section library. All reflector blocks are packed with the same reflector cross-section library originating from super-cell $r$. 
Super-cell $s$ is an acceptable choice as well, especially for the fresh core calculations, but considering the small difference between the neutron fluxes in those two reflector super-cells, only the one that includes both depleted and fresh fuel has been selected for simplification.

Figure 56 shows how the AMPX cross-section libraries are packed in the PHISICS/RELAP5 core model. The west and south regions of these one-third cores are characterized by reflective boundary conditions, while the north and east regions simply represent the physical outer boundary of the core and are described with vacuum boundary conditions. The labels indicated at the center of each block in Figure 56 refer to the Exercise I-2c super-cells' nuclear data sets, as generated by NEWT and described in Subsection 4.1. The pink blocks symbolize homogenized fresh fuel (it is intended to follow the legend chosen throughout the report if other cores are designed later on: the blue blocks symbolize homogenized burnt fuel, and the black blocks symbolize graphite reflector). Note that Figure 55 and Figure 56 are equivalent geometrically speaking. Figure 55 is simply the geometry of the core specified in the benchmark; it is characterized by an axis of rotation located at the bottom left Block 225 to simulate the third core geometry. Due to the geometry implemented in the RELAP5-3D input deck, the third core geometry in Figure 56 is represented by two axes of symmetry. Thus, the entire core has 271 hexagonal blocks.

The five core loadings in PHISICS/RELAP5-3D are purely fresh fuel cores. Burned cores and mixed cores prescribed in Figure 3 will be implemented in later versions of the report. For each category, a reference core is chosen, consisting solely of the single block's cross sections.

The fresh cores are not detailed in the benchmark specifications and are intended to provide a first estimation of the effects of the different cross sections generated by NEWT. As a reminder, super-cell $i$ is the closest representation of Exercise 2a (same fuel-to-moderator ratio and same nuclide inventory). The neutron flux profile remains similar to Exercise 2a's neutron flux (refer to Figure 17). The second core illustrated in Figure 56 utilizes only super-cell $i$ 's nuclear data to evaluate the magnitude of the difference induced by the closest-to-Exercise 2a super-cell model. Super-cell $k$, on the other hand, represents the super-cell that is achievable with fresh fuel and is the most different from Exercise $2 \mathrm{a}$ due to the severely perturbed moderating conditions.

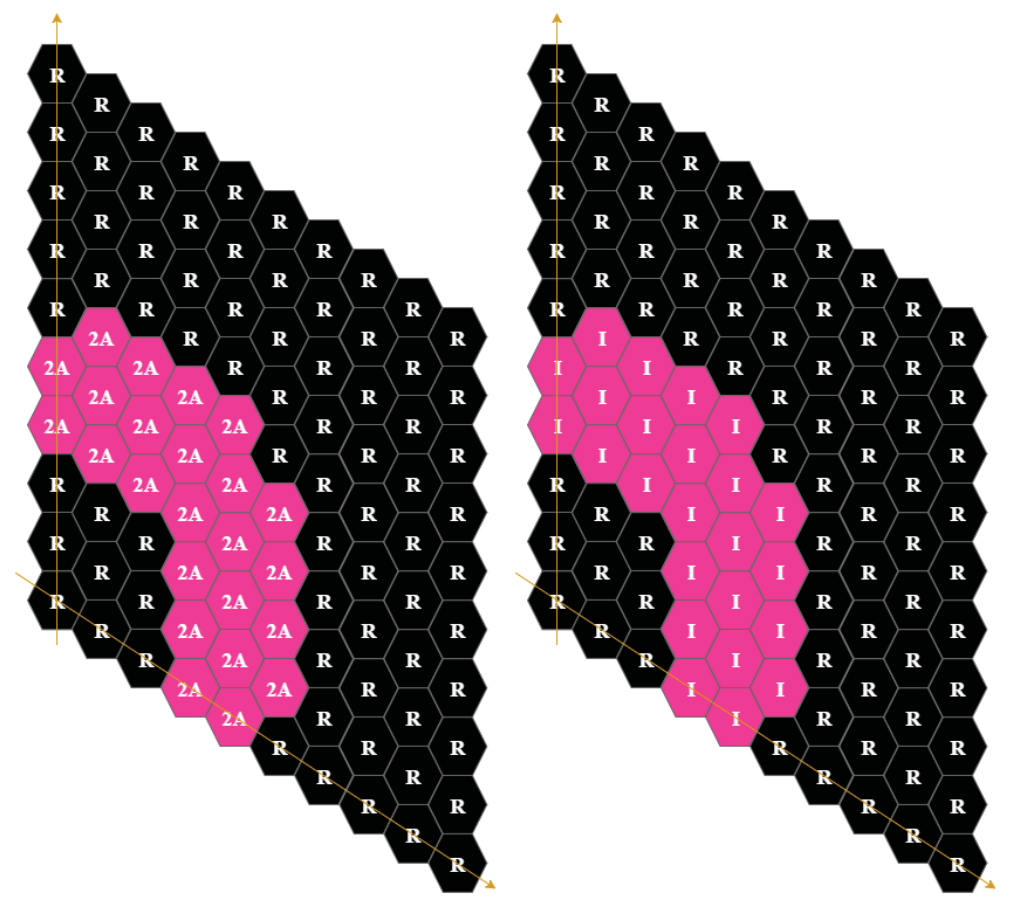



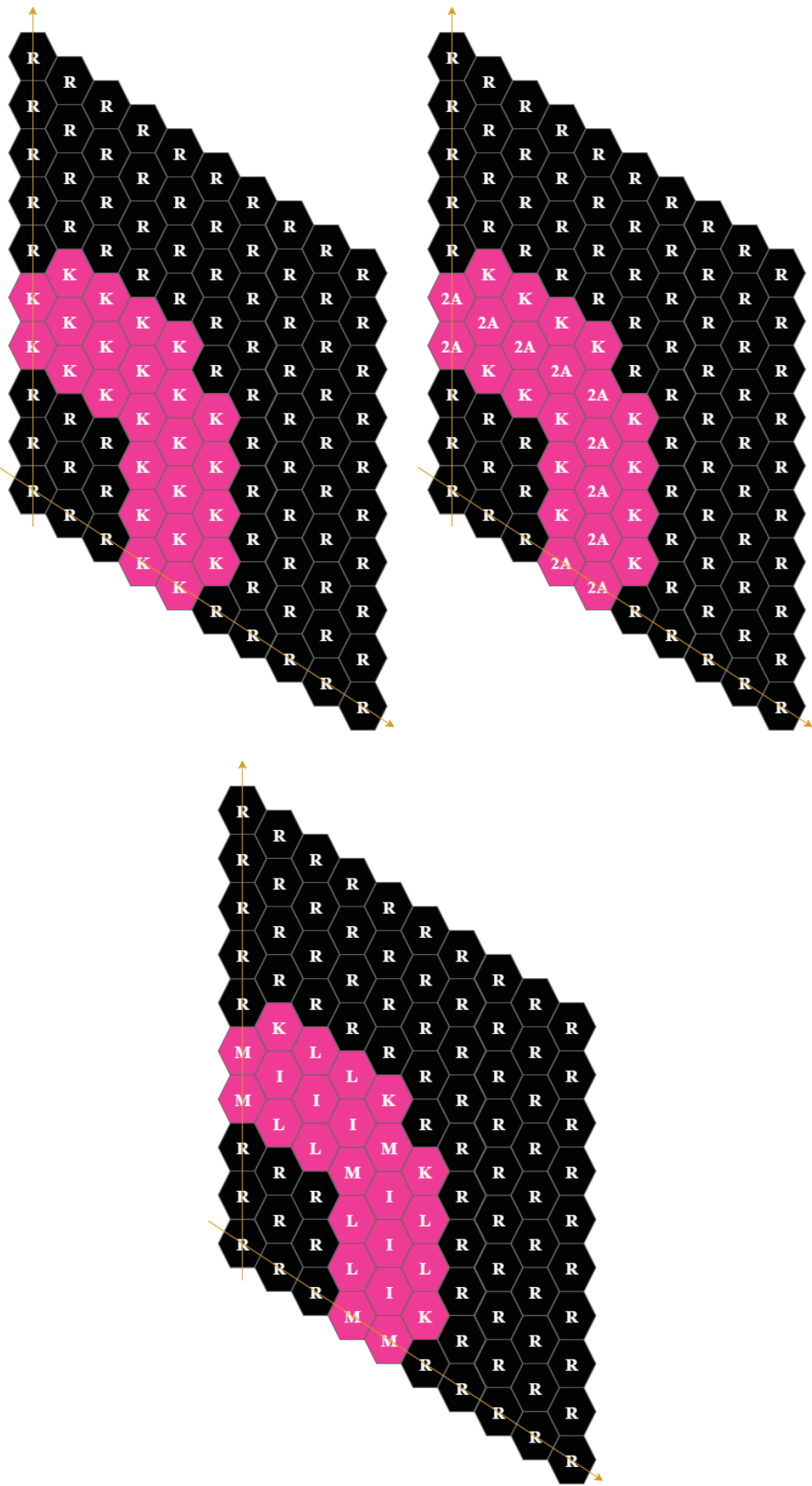

Figure 56. PHISICS/RELAP5-3D core loading patterns with AMPX nuclear data libraries.

The neutron flux profile varies greatly as a consequence (see Figure 17), which is why the largest amplitude of results for the multiplication factor is to be expected when compared to the " $2 a$ " core. The " $k-2 a$ " core intends to represent a more realistic design that accounts for the local flux effects in the neighborhood of the fuel blocks and reflector. Hence, the most moderated region (located on the periphery of the fuel region) is loaded with super-cell $k$ 's nuclear data, while the inner regions of the fuel are packed with Exercise 2a's nuclear data. Note that Locations 1, 4, 7, and 11 in Figure 55 are all next to one graphite block. Acknowledging that these blocks would be effectively represented by nuclear data from super-cell 
$m$ and considering the neutron profiles of super-cell $m$ and $k$ and single Block $2 a$ in Figure 17, super-cell $m$ has been chosen to pack these fuel locations with the single block's cross sections. Core " $i-k-l-m$ " is the most realistic fresh core achievable, where each fuel block is loaded with its most suitable cross section coming from the NEWT super-cells.

\subsection{Criticality Calculation with PHISICS/RELAP5}

The first step of this analysis is the evaluation of the cross sections' effect on the effective multiplication factor in the core model. The k-effective obtained for the core described in Subsection 5.1 is summarized in Table 14. The cross-section libraries obtained with Exercises $2 a$ and $2 b$ in NEWT serve as the reference for the fresh core (and later on burned core and mixed core), because these are the simplest representations of the core loading options.

The cores loaded with libraries $i, i-k-l-m$ are compared to the core loaded with Library $2 a$ (fresh cores in pink cells in Table 14).

The difference between the fresh single block and fresh super-cell $i$ is relatively small (i.e., $-96 \mathrm{pcm}$ ). For the most extreme case, which is the softer spectrum obtained in a fresh super-cell (Case $k$ ), the gap between the $2 a$ reference and $k$ is only $106 \mathrm{pcm}$. The core loaded with the Libraries $i-k-l-m$ represents the most accurate design of the core in terms of spectrum provided by the super-cells. The result for such core is logically included between the two extreme loadings: $2 a$ and $k$. Overall, despite the relatively large neutron flux differences observed in Section 4, none of those cores shows large multiplication factor differences with the reference core " $2 a$ ", with the total spread between these options less than $202 \mathrm{pcm}$.

Table 14. PHISICS/RELAP5-3D effective multiplication factors for different core loading options with NEWT-generated nuclear data libraries.

\begin{tabular}{|c|c|c|}
\hline $\begin{array}{l}\text { NEWT Libraries Loaded in } \\
\text { PHISICS/RELAP5-3D Core }\end{array}$ & k-effective & $\begin{array}{l}\text { Absolute Difference between } \\
\text { Reference and Test Cases } \\
\text { (pcm) }\end{array}$ \\
\hline $2 a^{a}$ & 1.39849 & Reference fresh core \\
\hline$i$ & 1.39753 & -96 \\
\hline$m$ & 1.39894 & 45 \\
\hline$k$ & 1.39955 & 106 \\
\hline$k-2 a$ & 1.39929 & 80 \\
\hline$i-k-l-m$ & 1.39902 & 53 \\
\hline
\end{tabular}

A reflector block that is flux weighted with heterogeneous fuel blocks differs by only $28 \mathrm{pcm}$ from the reflector weighted with homogeneous fuel blocks. Hence, the flux weighting of the reflector seems to weakly influence the core results. This statement has to be interpreted carefully, because at no point has the fuel-to-graphite distance been evaluated in the analysis. Only one reflector cross section has been chosen to load the core, but it is obvious that the neutron flux in the outer parts of the core is different from the neutron flux at the periphery of the fuel ring. Hence, the reflector cross section in contact with the fuel might vary significantly compared to the outer region reflector. Such a configuration should be tested in NEWT and propagated to PHISICS in an updated version of this report. 
These results only apply to the chosen 26-group structure. A group-sensitivity analysis could be carried out to evaluate the effect of different group structures on the accuracy achieved, using mainly the multiplication factor and reaction rates/fluxes as figures of merit. The decrease of the number of groups (e.g. to less than 8) would result in a significantly shorter running time calculation, which is especially valuable for transient events, but at the cost of decreased accuracy.

The multiplication factor results obtained here are encouraging in terms of the relative insensitivity to super-cell options, but on its own it does not provide a complete picture yet. The next step is the assessment of fluxes and power densities obtained for the fresh and depleted core options. This work will be completed in 2017, firstly to define the Phase II specifications, and secondly to illustrate the impact that the choice of super-cell lattice models has on the full core simulation.

\section{CONCLUSIONS}

The first part of the analysis is the comparison of the infinite multiplication factor between the different super-cells. It constitutes a preliminary study to assess to what extent the modeling approach of the supercells represents an additional uncertainty component. It turns out that the super-cell model prescribed in the benchmark, made of a heterogeneous central block surrounded by two homogenized regions at the north and the south, is strongly dependent on the homogenization scheme selected. Hence, the multiplication factor can vary by more than $2 \%$ by shuffling the composition of the north and south homogenized region for a given isotope inventory. This is amplified when the shuffling involves the carbon graphite, which is the moderating material.

The calculations have been compared to an identical model implemented in KENO-VI to evaluate the possible errors and uncertainties engendered by the deterministic methods. The comparison suggested that the approximate design of the BPs in NEWT introduces an error of several hundred pcm when the spectrum softens. Additional runs will be performed with SCALE 6.2 and described in the next version of this report. Tests have been carried out on super-cells made of one central heterogeneous block and six individual homogenized blocks. In that scenario, the artificial spread of the material disappears, and thus the shuffling effects on k-infinity vanish. The discrepancies with KENO-VI observed in the six-region model remain, which means no significant improvement can be obtained using this approach. A similar conclusion is drawn for fully heterogeneous super-cells. The temperature effects have been evaluated at CZP and HFP for the two-region model. A straight relationship between temperature and the infinite multiplication factor can be established in both NEWT and KENO-VI and behaves according to the expectations. The multiplication factor responds to the temperature rise and corresponds with the two feedback effects induced. The magnitude of the feedback will increase as the amount of graphite decreases, because the moderator temperature coefficient is smaller than the Doppler temperature coefficient.

The comparison of the normalized neutron fluxes for both fresh and depleted fuels showed that the neutron flux in the super-cell is globally softer than single-block lattices. The neutron flux variations are especially pronounced for highly moderated super-cells. Therefore, such a model is more suitable to model graphite-moderated prismatic cores. The results obtained with super-cells $c, c$-beta, $d$, and $d$-beta prove that shuffling the blocks for a given nuclide inventory in the two-region homogenized model does not affect the neutron flux profiles, but the increase of graphite in the super-cells softens the neutron flux significantly. This observation differs from what has been found for the multiplication factor. The super-cells generated by a simple permutation of blocks (rotation) have been removed for the following steps of the study due to the very limited information they provided. The simple consideration of the flux profiles leads to the recommendation to use at least the following super-cells coupled to the cross section from Exercise I-2a:

- $\quad a$ fresh fuel at the periphery of the fuel ring and $b$ burned fuel at the periphery of the fuel ring (for mixed cores)

- $\quad k$ at the periphery of the fuel ring (for fresh cores). 
A more extensive set that includes super-cells $e, l$, and $g$ is reasonable, too. Super-cells $c, d, c$-beta, $d$-beta, $i$, and $j$ give similar flux shapes to Exercise I-2a. At least one set has to be added to these cross sections for the reflector. The flux profile in the reflector depends weakly on the nature of the neighbors (fresh or burned fuel), which makes the use of cross-section $r$ in the core $(r)$ sufficient, at least for one given reflector ring.

The results acquired with the six-region model show that the neutron flux difference never exceeds $19 \%$ compared with the two-region model. The flux distributions for the two models mostly stay within $10 \%$ of each other. Such amplitude only occurs in a very limited amount of groups (in most of the cases, the two slowest groups, which are characterized by a very low neutron density anyway). As concluded for the infinite multiplication factor, the six-region model as well as the heterogeneous model do not result in particular interest for the generation of the nuclear data. Thus, the single-block model and the two-region super-cell model distinguish themselves by different spectrum shapes and have been tested for core loading in PHISICS/RELAP5-3D.

The final part of this report focuses on the implementation of the pre-generated cross section with NEWT in PHISICS/RELAP5-3D using a combination of the three models of interests described abovethe single-block model, the two-region model, and the heterogeneous super-cell. For now, only the effective multiplication factor has been estimated with PHISICS/RELAP5-3D. The cross section implemented in the one third core shows that the k-effective varies only weakly for each loading, with a maximum difference of $202 \mathrm{pcm}$ obtained between the most extreme cases. One super-cell representing the softer neutron spectrum at the periphery of the core seems sufficient, while the use of the single block Exercise I.2a crosssections is applicable to all center fuel regions.

Those results are subject to variation if the reflector cross sections are refined, as suggested earlier in the conclusion. It is also important to mention that only the multiplication factor has been estimated in this analysis. In future studies, the flux and power profiles obtained with and without feedback effects will be investigated to confirm the conclusions drawn regarding the multiplication factor with PHISICS in this report.

The 200 pcm "model" uncertainty observed here for the fresh core models should be placed in context: it has already been shown that cross-section uncertainties alone are responsible for variations in the multiplication factor of more than $500 \mathrm{pcm}$ for the simple Phase I lattice problems [12]. The assessment of the differences in these libraries, caused by co-variances in the ENDF-VII libraries, remains the main focus of the HTGR UAM. This step will be reported in a follow-on INL report that will be generated towards the end of 2016, where it is currently planned to use the SCALE/SAMPLER module for a stochastic approach to this complex problem.

\section{REFERENCES}

[1] IAEA, "Evaluation of High Temperature Gas Cooled Reactor Performance: Benchmark Analysis Related to Initial Testing of the HTTR and HTR-10," International Atomic Energy Agency IAEA-TECDOC-1382, 2003.

[2] F. Reitsma, et al., "The OECD/NEA/NSC PBMR400 MW Coupled Neutronics Thermal Hydraulics Transient Benchmark - Steady-state Results and Status," Proceedings of PHYSOR-2008, Interlaken, Switzerland, 2008.

[3] G. Strydom, et al., "THE OECD/NEA/NSC PBMR 400 MW Coupled Neutronics Thermal Hydraulics Transient Benchmark: Transient Results," Proceedings of PHYSOR-2010, Pittsburgh, USA, 2010. 
[4] OECD Nuclear Energy Agency NEA/NSC/DOC, "Benchmark for Uncertainty Analysis in Modelling (UAM) for Design, Operation and Safety Analysis of LWRs, Volume I: Specification and Support Data for the Neutronics Cases (Phase I)," Version 2.0, 2012.

[5] OECD Nuclear Energy Agency, "Prismatic Coupled Neutronics/Thermal Fluids Transient Benchmark of the MHTGR-350 MW Core Design: Benchmark Definition," OECD Nuclear Energy Agency NEA/NSC/DOC(2013), 2013.

[6] G. Strydom and F. Bostelmann, "HTGR Reactor Physics, Thermal-Hydraulics and Depletion Uncertainty Analysis. Prismatic Benchmark Definition: Phase I," INL/EXT-15-34868, Rev. 1, 2016.

[7] ORNL/TM-2005/39, "SCALE: A comprehensive modeling and simulation suite for nuclear safety analysis and design," Version 6.1, Oak Ridge National Laboratory, 2011.

[8] G. Strydom, F. Bostelmann, and Su-Jong Yoon, "Results for Phase I of the IAEA CRP on HTGR Uncertainties," INL/EXT-14-33944, Rev. 2, 2016.

[9] C. Rabiti, A. Alfonsi, and A. Epiney, "New Simulation Schemes and Capabilities for the PHISICS/RELAP5-3D Coupled Suite," Nuclear Science and Engineering, Vol. 182, No. 1, 2016.

[10] G. Strydom, et al., "Comparison of the PHISICS/RELAP5-3D Ring and Block Model Results for Phase I of the OECD MHTGR-350 Benchmark," Nuclear Technology, Vol. 193, pp. 15-35, 2016.

[11] B. Tyobeka, K. Ivanov, and A. Pautz, "Utilization of two-dimensional deterministic transport methods for analysis of pebble bed reactors," Annals of Nuclear Energy, Vol. 34, pp. 396-405, 2007.

[12] T. Y. Han, H. C. Lee and J. M. Noh, "Development of a sensitivity and uncertainty analysis code for high temperature gas-cooled reactor physics based on the generalized perturbation theory," Annals of Nuclear Energy, Vol. 85, pp. 501-511, 2015. 


\section{Appendix A}

\section{Nuclide Inventory List for Burned-Fuel Blocks}

This side-study is meant to optimize the number of fission products selected for the burned fuel calculation in NEWT and subsequent PHISICS/RELAP5-3D calculations. Because a complete study of the influence of each isotope on different key parameters would be difficult to carry out, several sets of nuclides are selected from existing nuclide lists. A sensitivity study is carried out on the multiplication factor for each isotopic list. Five predefined nuclide lists were used in the TRITON module of SCALE 6.1.2. These lists are initially established to include the effects of trace isotopes at the beginning of depletion calculations. The two most extensive lists incorporate 388 and 230 nuclides, which was too large for the calculations carried out in the analysis. The least extensive list only includes a few actinides and no fission products, which is too restrictive to model burned-fuel blocks. Two of the remaining options, which contained 64 and 94 nuclides, respectively, were investigated, as shown in Table A-1.

Table A-1. SCALE 6.1.2/TRITON inventory of trace isotopes.

\begin{tabular}{|c|c|c|}
\hline \multicolumn{3}{|c|}{ List of 64 Isotopes } \\
\hline \multicolumn{2}{|l|}{$\begin{array}{l}{ }^{234} \mathrm{U}^{235} \mathrm{U}^{236} \mathrm{U} \\
{ }^{238} \mathrm{U}^{237} \mathrm{~Np}^{238} \mathrm{Pu}{ }^{239} \mathrm{Pu} \\
{ }^{240} \mathrm{Pu}{ }^{241} \mathrm{Pu}{ }^{242} \mathrm{Pu}{ }^{241} \mathrm{Am} \\
{ }^{242} \mathrm{Am}^{243} \mathrm{Am}^{242} \mathrm{Cm}^{243} \mathrm{Cm}\end{array}$} & 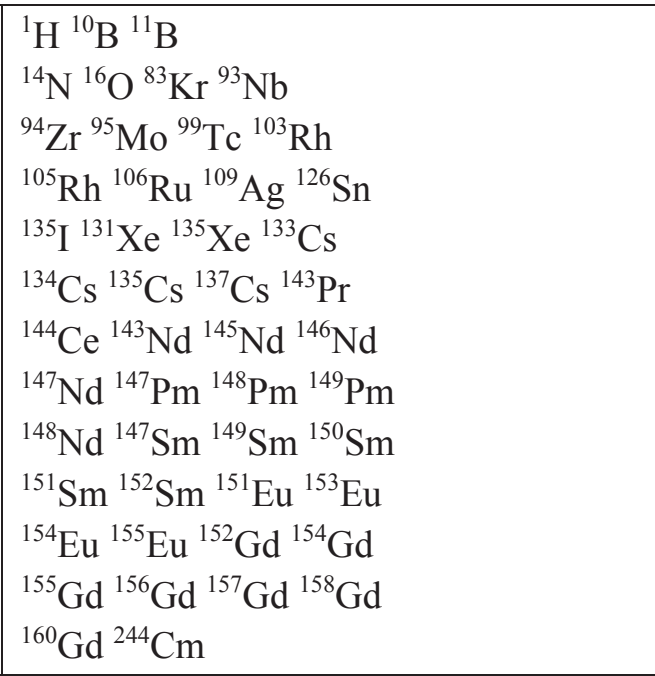 \\
\hline \multicolumn{3}{|c|}{ List of 94 Isotopes } \\
\hline $\begin{array}{l}{ }^{234} \mathrm{U}^{235} \mathrm{U}^{236} \mathrm{U} \\
{ }^{238} \mathrm{U}^{237} \mathrm{~Np}^{238} \mathrm{Pu}{ }^{239} \mathrm{Pu} \\
{ }^{240} \mathrm{Pu}{ }^{241} \mathrm{Pu}{ }^{242} \mathrm{Pu}{ }^{241} \mathrm{Am} \\
{ }^{242} \mathrm{Am}^{243} \mathrm{Am}^{242} \mathrm{Cm}^{243} \mathrm{Cm}\end{array}$ & $\begin{array}{l}{ }^{1} \mathrm{H}^{10} \mathrm{~B}^{11} \mathrm{~B} \\
{ }^{14} \mathrm{~N}^{16} \mathrm{O}^{83} \mathrm{Kr}{ }^{93} \mathrm{Nb} \\
{ }^{94} \mathrm{Zr}^{95} \mathrm{Mo}{ }^{99} \mathrm{Tc}^{103} \mathrm{Rh} \\
{ }^{105} \mathrm{Rh}{ }^{106} \mathrm{Ru}{ }^{109} \mathrm{Ag}{ }^{126} \mathrm{Sn} \\
{ }^{135} \mathrm{I}^{131} \mathrm{Xe}^{135} \mathrm{Xe}^{133} \mathrm{Cs} \\
{ }^{134} \mathrm{Cs}{ }^{135} \mathrm{Cs}{ }^{137} \mathrm{Cs}{ }^{143} \mathrm{Pr} \\
{ }^{144} \mathrm{Ce}^{143} \mathrm{Nd}{ }^{145} \mathrm{Nd}^{146} \mathrm{Nd} \\
{ }^{147} \mathrm{Nd}^{147} \mathrm{Pm}{ }^{148} \mathrm{Pm}{ }^{149} \mathrm{Pm} \\
{ }^{148} \mathrm{Nd}^{147} \mathrm{Sm}^{149} \mathrm{Sm}^{150} \mathrm{Sm} \\
{ }^{151} \mathrm{Sm}^{152} \mathrm{Sm}^{151} \mathrm{Eu}^{153} \mathrm{Eu} \\
{ }^{154} \mathrm{Eu}^{155} \mathrm{Eu}{ }^{152} \mathrm{Gd}{ }^{154} \mathrm{Gd} \\
{ }^{155} \mathrm{Gd}^{156} \mathrm{Gd}{ }^{157} \mathrm{Gd}{ }^{158} \mathrm{Gd} \\
{ }^{160} \mathrm{Gd}^{244} \mathrm{Cm}\end{array}$ & $\begin{array}{l}{ }^{91} \mathrm{Zr}^{93} \mathrm{Zr}^{95} \mathrm{Zr}{ }^{96} \mathrm{Zr} \\
{ }^{95} \mathrm{Nb}{ }^{97} \mathrm{Mo}{ }^{98} \mathrm{Mo}{ }^{99} \mathrm{Mo} \\
{ }^{100} \mathrm{Mo}{ }^{101} \mathrm{Ru}{ }^{102} \mathrm{Ru}{ }^{103} \mathrm{Ru} \\
{ }^{104} \mathrm{Ru}{ }^{105} \mathrm{Pd}{ }^{107} \mathrm{Pd}{ }^{108} \mathrm{Pd} \\
{ }^{113} \mathrm{Cd}^{115} \mathrm{In}^{127} \mathrm{I}^{129} \mathrm{I} \\
{ }^{133} \mathrm{Xe}^{139} \mathrm{La}^{140} \mathrm{Ba}{ }^{141} \mathrm{Ce} \\
{ }^{142} \mathrm{Ce}^{143} \mathrm{Ce}^{141} \mathrm{Pr}^{144} \mathrm{Nd} \\
{ }^{153} \mathrm{Sm}{ }^{156} \mathrm{Eu}\end{array}$ \\
\hline
\end{tabular}


The infinite multiplication factor was evaluated at both CZP and HFP for 10 super-cells and compared in the two cases. The results are summarized in Table A-2. Super-cells $i, m, l$, and $k$ are entirely composed of fresh fuel or reflector blocks, which explains why they have not been considered in this analysis.

Table A-2. Infinite multiplication factor at CZP and HFP of 10 super-cells characterized by two SCALE 6.1.2/TRITON inventories of trace isotopes.

\begin{tabular}{|c|c|c|c|c|}
\hline \multirow[b]{2}{*}{ Parameter } & \multirow[b]{2}{*}{ Super-cell } & \multicolumn{2}{|c|}{ k-infinity } & \multirow{2}{*}{$\begin{array}{l}\text { Absolute Difference } \\
\text { (pcm) }\end{array}$} \\
\hline & & 64 Isotopes & 94 Isotopes & \\
\hline \multirow{10}{*}{$\mathrm{CZP}$} & $a$ & 1.16704 & 1.16270 & 434 \\
\hline & $b$ & 1.18530 & 1.18109 & 421 \\
\hline & $c$ & 1.07562 & 1.06936 & 625 \\
\hline & c-beta & 1.09148 & 1.08594 & 554 \\
\hline & $d$ & 1.15503 & 1.15032 & 471 \\
\hline & $d$-beta & 1.17572 & 1.17196 & 376 \\
\hline & $e$ & 1.15829 & 1.15251 & 577 \\
\hline & $f$ & 1.16285 & 1.15782 & 503 \\
\hline & $g$ & 1.32344 & 1.32066 & 278 \\
\hline & $h$ & 1.27413 & 1.27142 & 271 \\
\hline \multirow{10}{*}{ HFP } & $a$ & 1.10511 & 1.10130 & 381 \\
\hline & $b$ & 1.12720 & 1.12341 & 379 \\
\hline & $c$ & 0.97271 & 0.96728 & 543 \\
\hline & c-beta & 0.98780 & 0.98296 & 484 \\
\hline & $d$ & 1.04445 & 1.04031 & 414 \\
\hline & $d$-beta & 1.06515 & 1.06184 & 332 \\
\hline & $e$ & 1.08931 & 1.08434 & 497 \\
\hline & $f$ & 1.06338 & 1.05898 & 440 \\
\hline & $g$ & 1.22049 & 1.21791 & 258 \\
\hline & $h$ & 1.16536 & 1.16292 & 244 \\
\hline
\end{tabular}


The average difference between the 64-isotope list and 94 -isotope list is $465 \mathrm{pcm}$ with a standard deviation of $165 \mathrm{pcm}$. The absolute difference is clearly correlated to the number of burned-fuel blocks in the super-cells. For the burned-fuel super-cells, the difference goes up to $811 \mathrm{pcm}$. Due to the significant differences observed, the 94-isotope list is considered more accurate and was selected for the super-cell analysis and whole-core model in PHISICS/RELAP5-3D. However, it should be noted that a Monte Carlo comparison using the full isotope list would be the only way to compare the accuracy of this reduced 94isotope list. Furthermore, the data presented here only included eigenvalues; a more exhaustive study should compare reaction rates and spectral profiles across the cells as well. 


\section{Appendix B}

\section{NEWT Parametric Study on Solver Settings}

Considering the discrepancies observed between NEWT and KENO-VI for the super-cell models and the relatively good agreement between KENO-VI and SERPENT-2 measured for Exercises $2 \mathrm{a}$ and $2 \mathrm{~b}$, the question of the convergence of the results in NEWT can be raised. The objective of this appendix is to refine the geometrical discretization parameters in the NEWT model as compared to the settings adopted in Section 4 in the main body of the report and evaluate the differences that can be observed.

In the SCALE 6.1 model, the geometrical parameters selected for the NEWT calculations are listed below. No analysis has been carried out on the multiplication factor convergence criteria, but they have been included in the following listing:

- The number of equally spaced azimuthal directions is set to 3

- The number of polar angles is set to 3

- The convergence of the eigenvalues is set to $1 \mathrm{pcm}$

- The maximum number of outer iterations is set to 500

- The number of inner iterations is set to 50

- The convergence of the outer iterations is set to $100 \mathrm{pcm}$

- The convergence of the inner iterations is set to $10 \mathrm{pcm}$.

The azimuthal and polar angles fully define the $S_{n}$ ordinate of the problem. The inner iterations use the scalar flux to calculate the group scattering sources. The outer iterations update the fission source to start the inner iterations over and so too the calculation of the scattering sources.

The simulations have been performed only on Exercise $2 a$ or $2 b$ at HFP. The multiplication factor is summarized in Table B-1. The normalized neutron flux per unit lethargy for different polar and azimuthal discretization of Exercises I-2a and I-2b is presented in Figure B-1.

Table B-1. Evaluation of effects the azimuthal angles on the multiplication factor in Exercises I-2a and $\mathrm{I}-2 \mathrm{~b}$.

\begin{tabular}{|c|c|c|c|c|c|}
\hline Exercise & $\begin{array}{c}\mathbf{3} \times \mathbf{3} \\
(\text { reference) }\end{array}$ & $\mathbf{6} \times \mathbf{6}$ & $\begin{array}{c}\text { Absolute } \\
\text { Difference } \\
\mathbf{( p c m )}\end{array}$ & $\mathbf{1 2 \times 1 2}$ & $\begin{array}{c}\text { Absolute } \\
\text { Difference } \\
\text { (pcm) }\end{array}$ \\
\hline I-2a & 1.03680 & 1.03819 & 139 & 1.03847 & 167 \\
\hline I-2b & 0.96421 & 0.96629 & 208 & 0.96656 & 234 \\
\hline
\end{tabular}




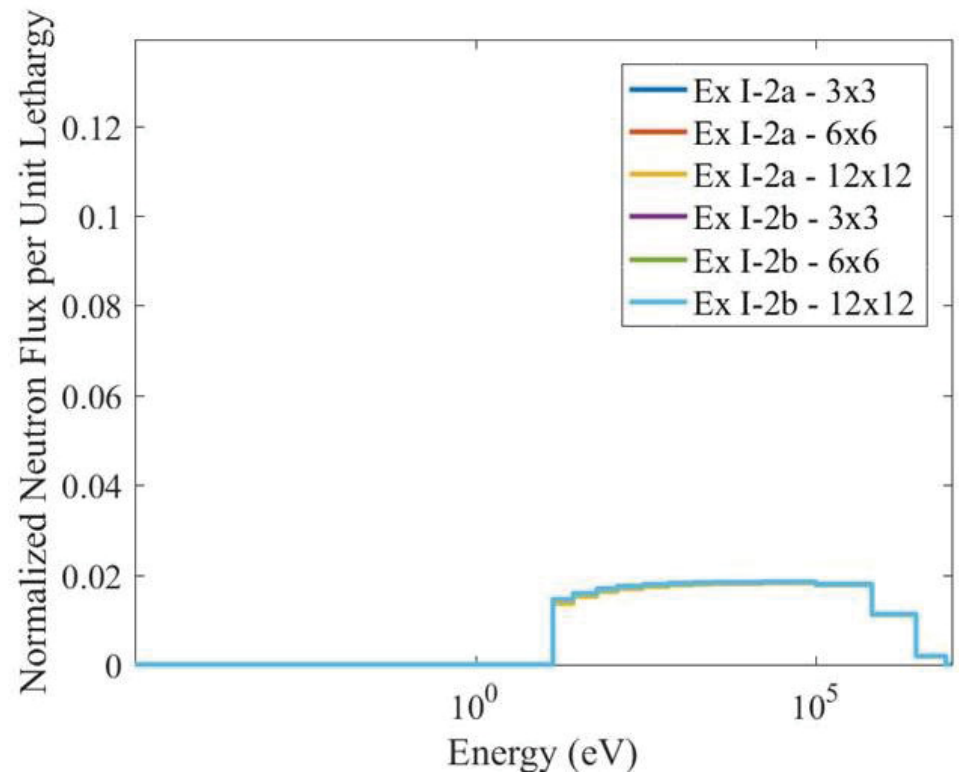

Figure B-1. Normalized neutron per unit lethargy for different azimuthal and polar angle discretization in Exercises I-2a and I-2b

The $\mathrm{P}_{\mathrm{n}}$ order for the scattering in the different mixtures has been increased from $\mathrm{P}_{\mathrm{n}}=1$ for all materials to $P_{n}=5$ for the BPs, north and south homogenized regions and reflector, $P_{n}=3$ for the fuel and the fuel matrix. $P_{n}$ is left to its initial value for the helium. The variation in the multiplication factor is only $2 \mathrm{pcm}$ in super-cell $a$.

Table B-2. Evaluation of effects the $\mathrm{P}_{\mathrm{n}}$ order on the multiplication factor in Exercises I-2a, I-2b, and I-2c.

\begin{tabular}{|c|c|c|c|}
\hline Exercise & $\begin{array}{c}\mathbf{P}_{\mathbf{n}}=\mathbf{1} \\
\text { (reference) }\end{array}$ & $\mathbf{P}_{\mathbf{n}}=\mathbf{5}$ & $\begin{array}{c}\text { Absolute difference } \\
\text { (pcm) }\end{array}$ \\
\hline I-2a & 1.03680 & 1.03681 & 1 \\
\hline I-2b & 0.96421 & 0.96427 & 6 \\
\hline I-2c (Super-cell $a)$ & 1.08090 & 1.08087 & 3 \\
\hline
\end{tabular}

A significant refinement of the geometrical parameters improves the multiplication factor by about $200 \mathrm{pcm}$, but it does not completely explain the significant discrepancies between NEWT and KENO-VI. It can therefore be concluded that the discrepancies between NEWT and KENO-VI are not due to the discretization parameters. 